
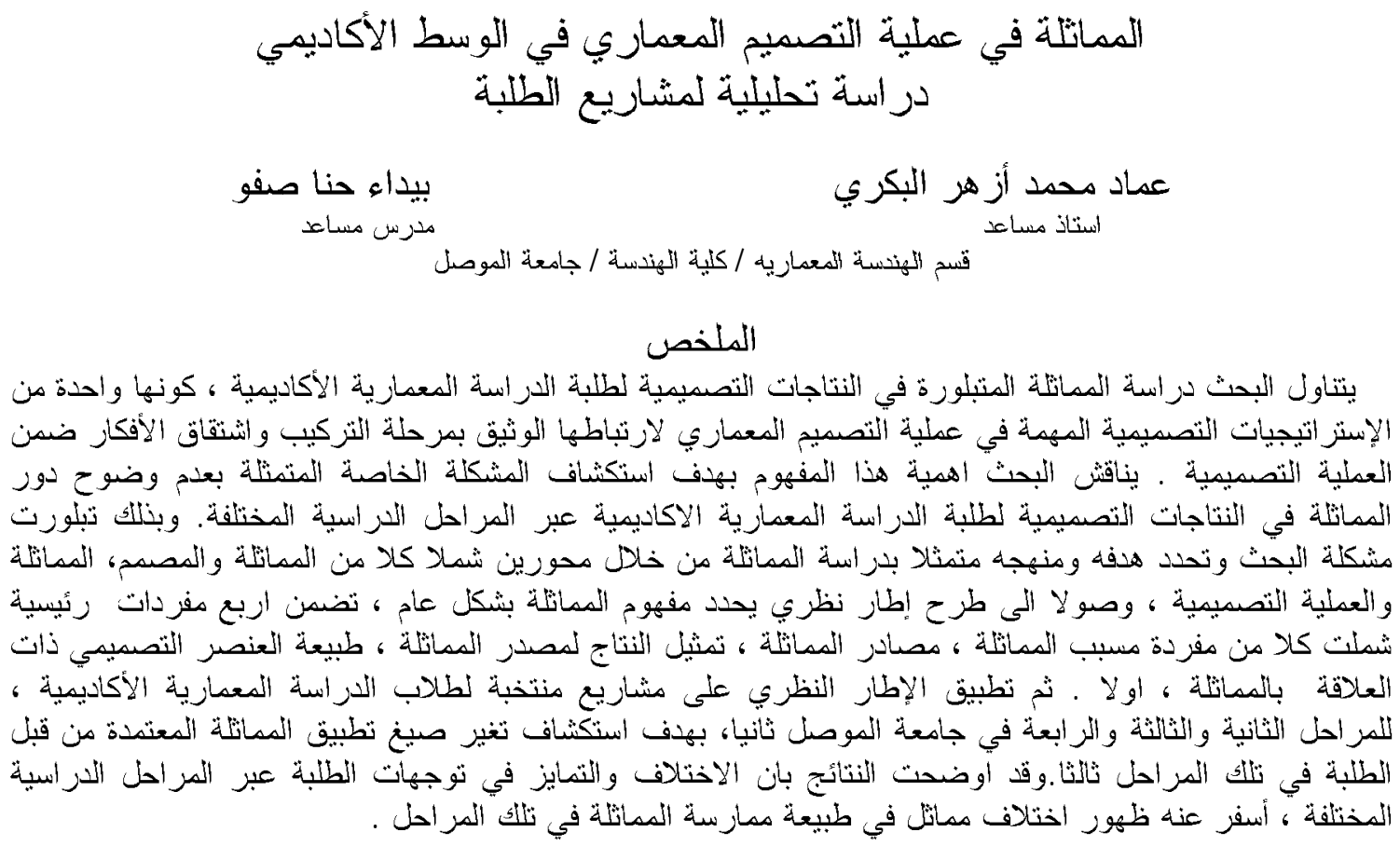

\title{
Analogy in the architectural design process in the academic medium Analytical study of students' projects
}

\author{
Imad. M. ALBakri \\ Assistant Professor
}

\section{Bayda Hanna Saffo Assistant Lecturer}

\section{Abstract}

The current research tackles the study of analogy depended on in designing products of students of academic architectural study as it is one of the important designing strategies in the process of architectural designing because it is closely related with the stage of synthesis and the derivations of architectural concepts within the designing process. The research discusses the importance of this concept in order to explore the particular problem represented by the unclarity of analogy role in the designing products of students of academic architectural study over their different grades. Therefore the problem of the research was crystallized and its objective and methodology were identified by studying analogy by two axes, included the analogy and the designer, the analogy and designing process, reaching the determination the theoretical framework, that involved four main items, which are; the item of analogy cause, analogy sources, the paradigm of dealing with the analogy source and the nature of the designing element relevant to analogy, firstly. And then applying the theoretical framework on selected projects of students of academic architectural study in the second, third and fourth grades in Mosul University, secondly, in order to explore the change of analogy application paradigms adopted by the students in those grades, thirdly. The results showed that the differences in students' trends throughout different academic grades led to the emergence of similar differences in the nature of practicing analogy in those grades.

Keywords: Analogy, Architectural design process, academic medium. 
1

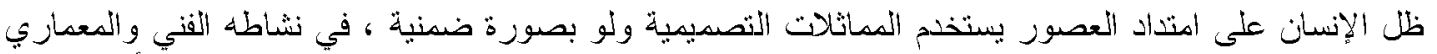

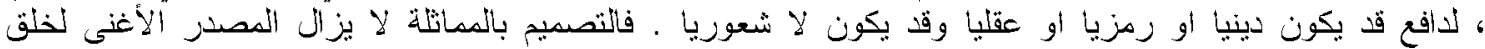

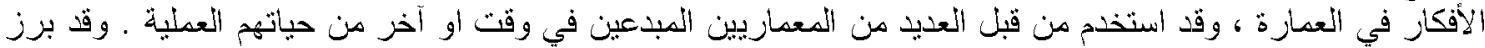

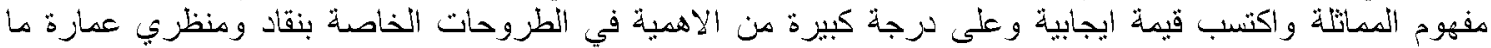

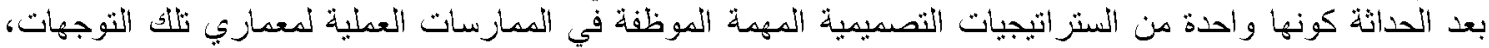

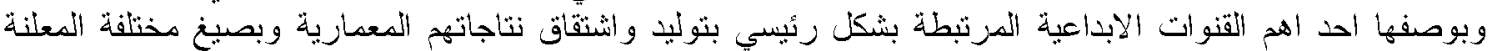

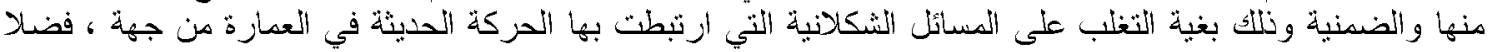

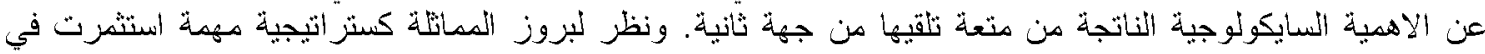

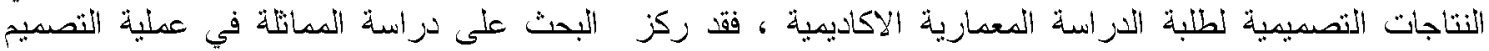

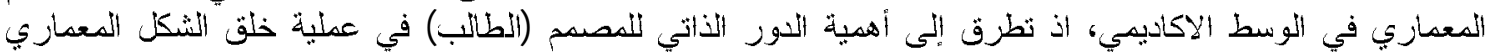

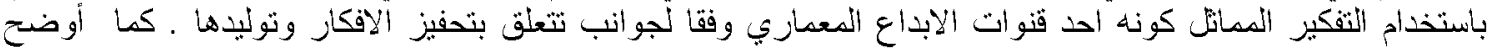

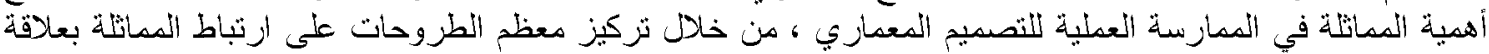

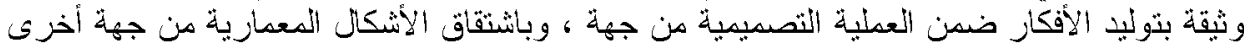

2 - أهمية البحث

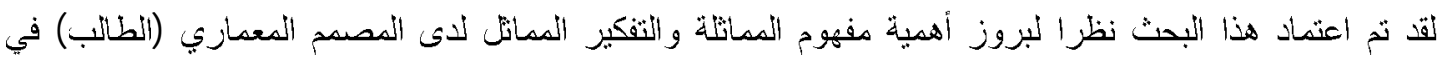

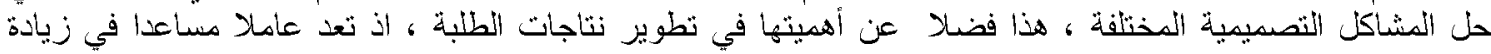

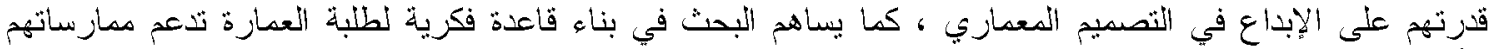

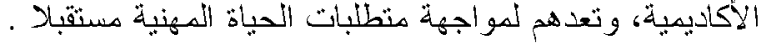

3 - مشكلة البحث وهدفه

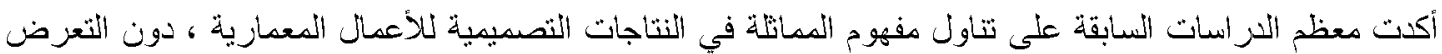

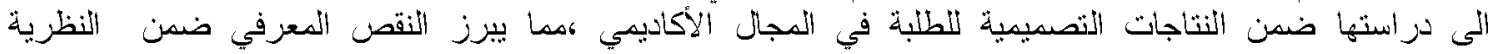

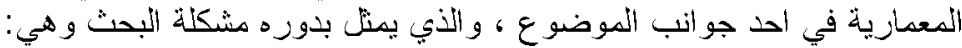

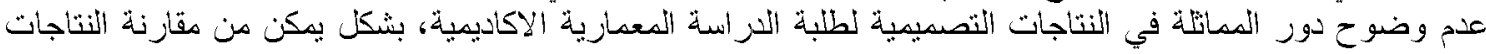
المعمازية للطلبة عبر المز احل الدر اسية المختلفة فيما يتعلق بها.

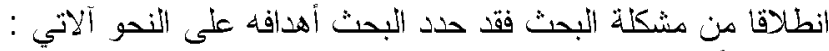

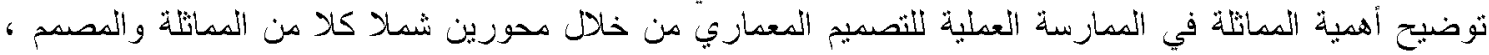
المماتلة و العملية التصميمية.

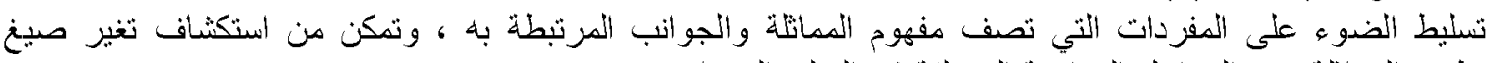
تطبيق المماتكة عبر المز احل الثرانسية المختلفة في التعليم المعماري .

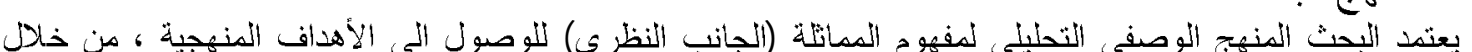

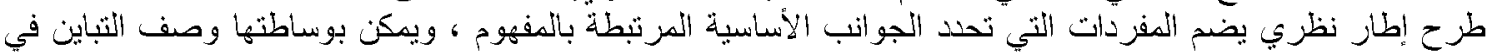

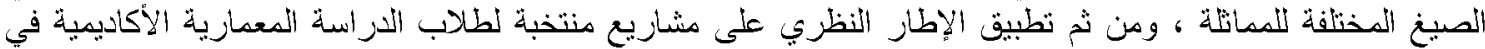

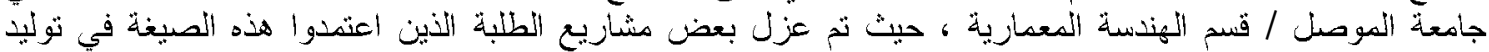

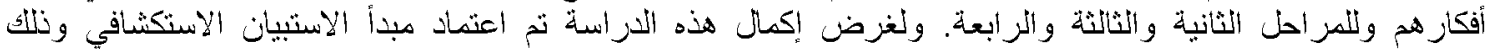

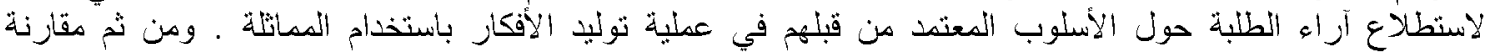

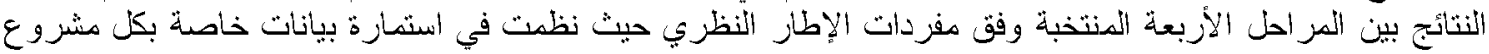

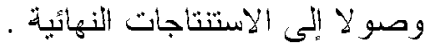


5 -الار اسة النظرية لمفهوم المماتلة

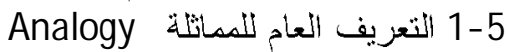

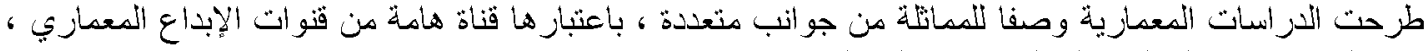

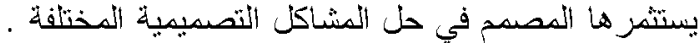

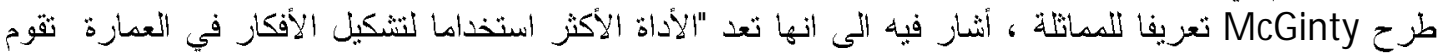

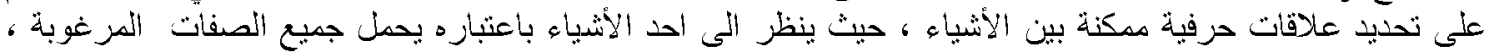

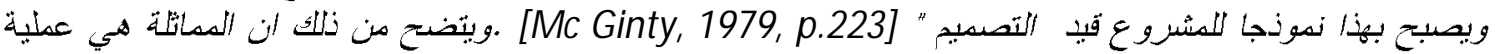

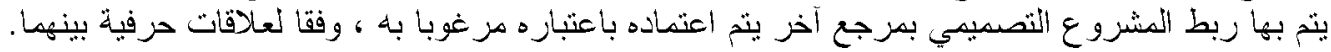

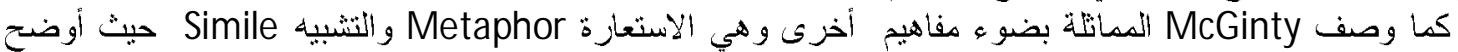

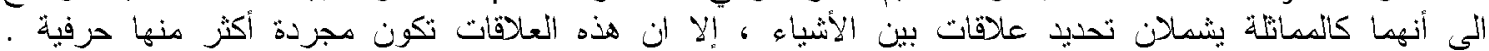
. [M cGinty, 1979, p.228]

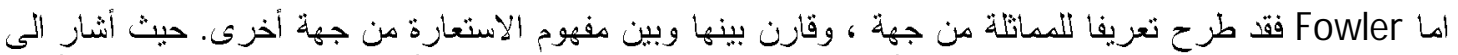

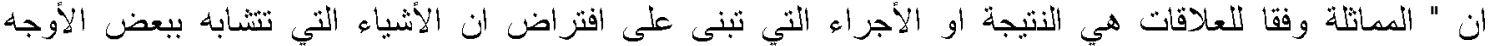

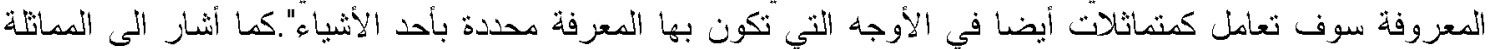

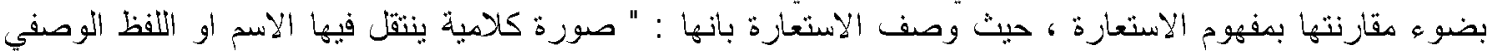

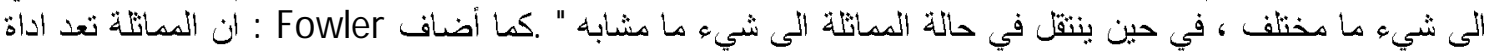

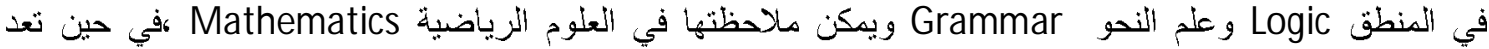

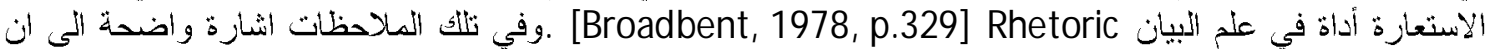

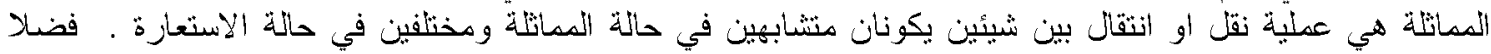
عن الأثازة الى وضوحية الممانلة ، وضمنية الاستعارة .

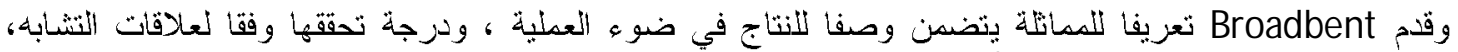

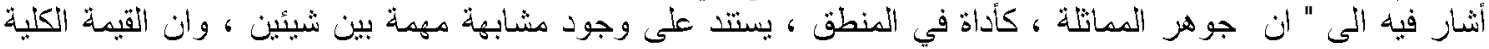

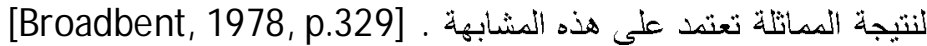

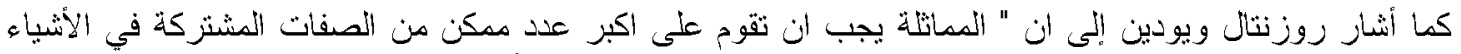

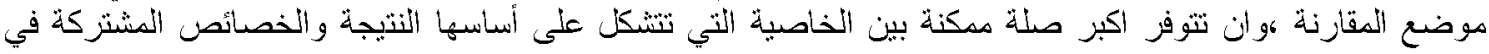

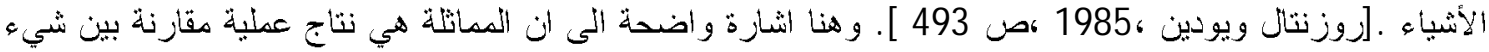

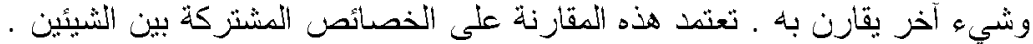

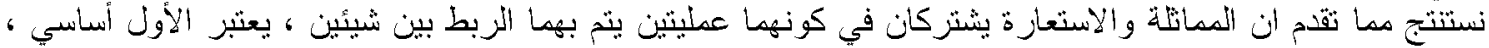

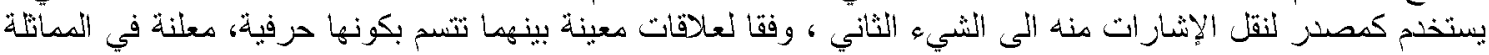

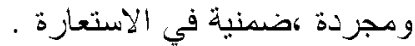

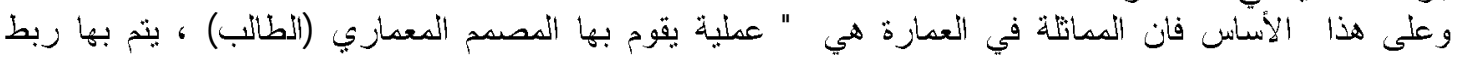

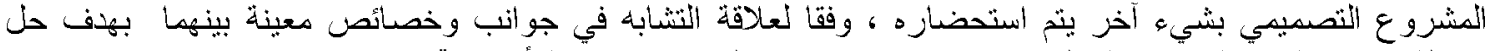

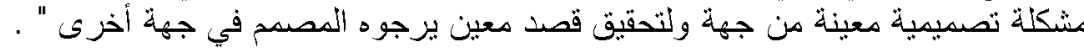

2-5 محأوز عطلية المماثلة

لقد ابرزت الثراسات المعمارية السابقة، ان عملية المماثلة في العمارة تتحور حول محورين ، يتعلق الإول منهما

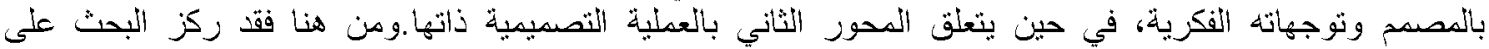

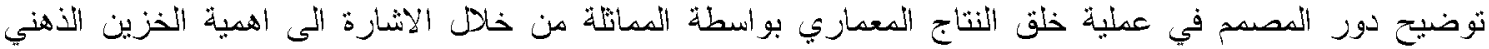

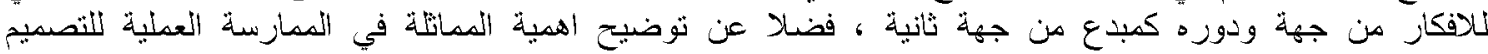

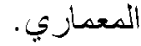

$$
\text { 1-2-5 المحوز الأول : الممانلة والمصم }
$$

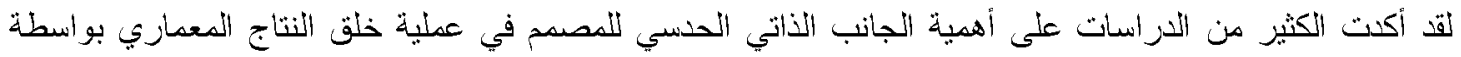

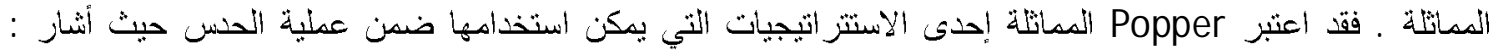

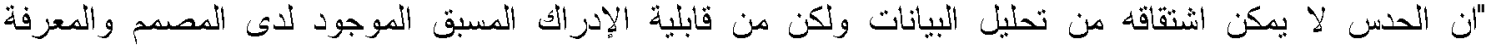




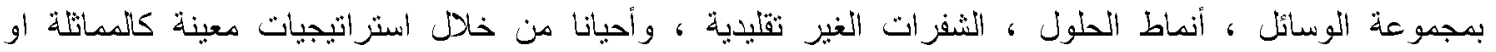

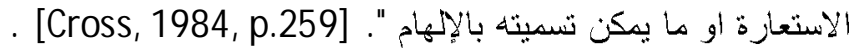

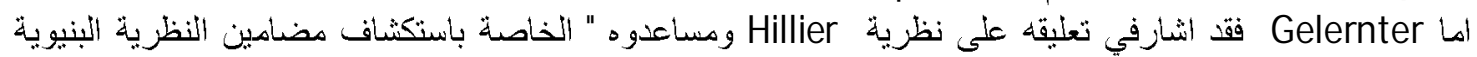

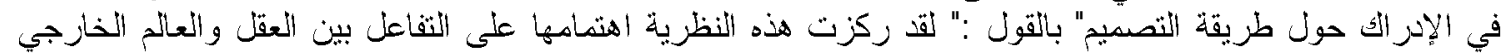

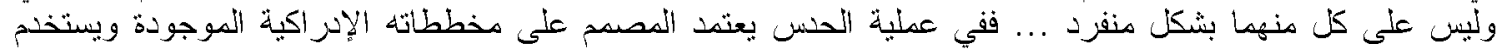

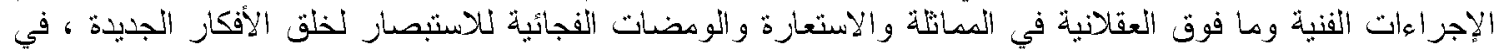

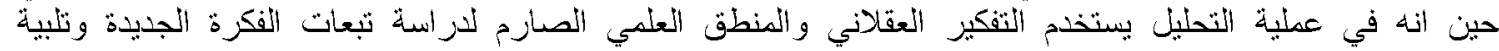

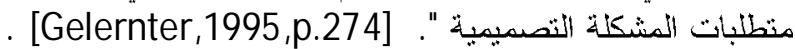

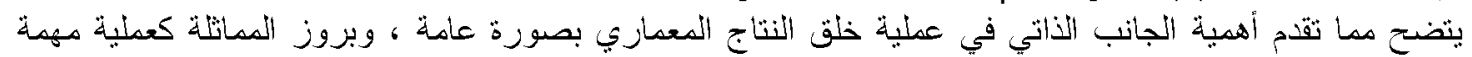

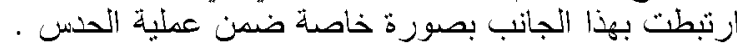

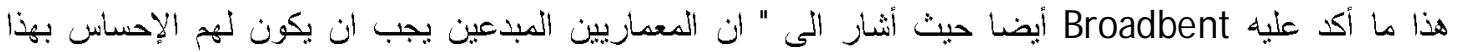

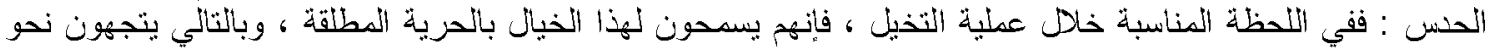

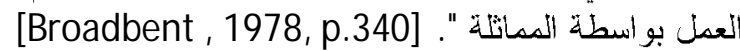

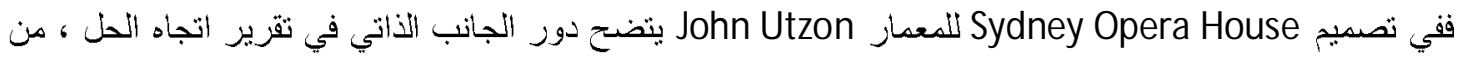

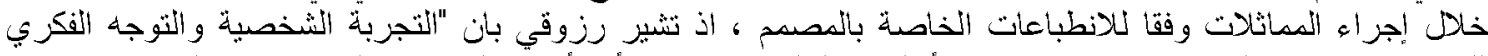

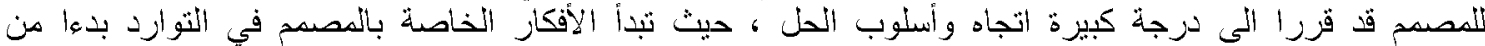

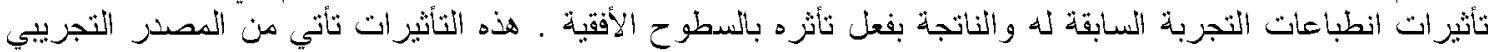

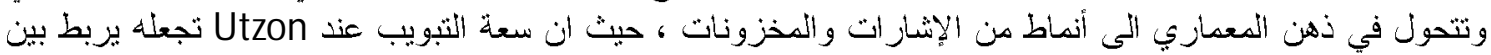

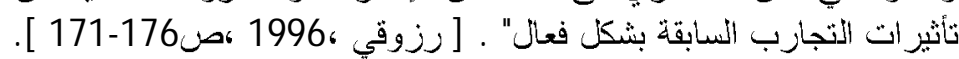

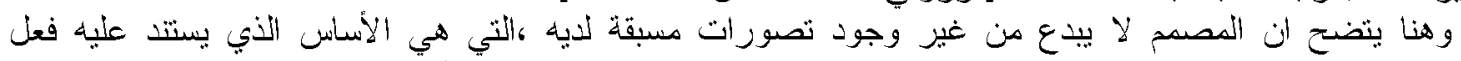

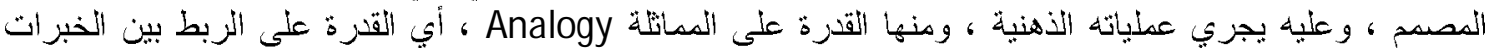

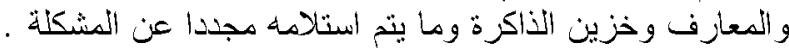

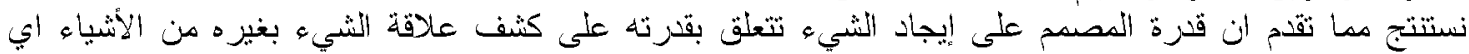

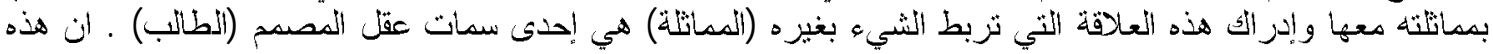

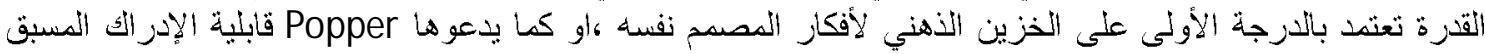

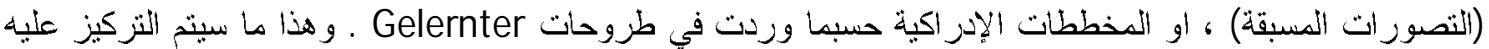

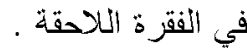
أ -الخزين الذهني للأفكاز أنشارت العديد من الطروحات المعمارية النى أهمية الخزين التهني للأفكاز داخل عقل المصمح في عملية خلق النتاج

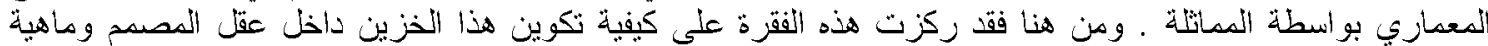
فعل الإدر أك في تكوينه.

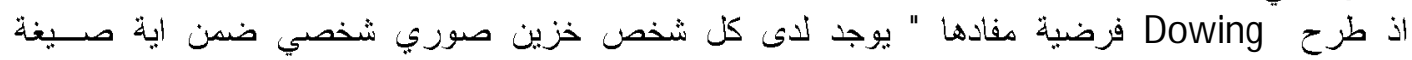

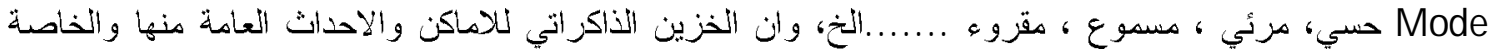

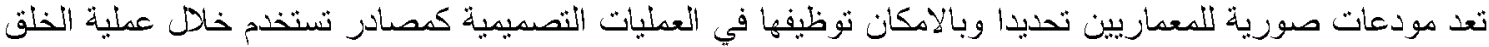

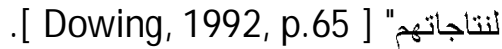

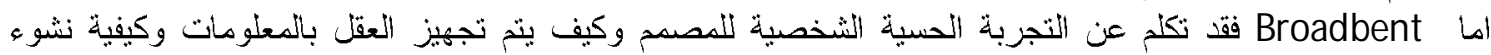

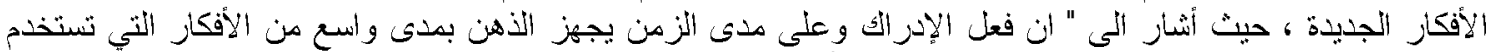

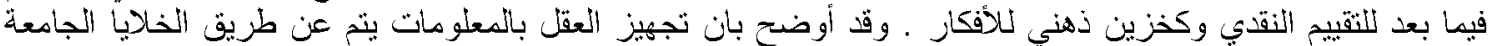

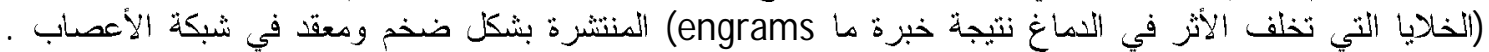

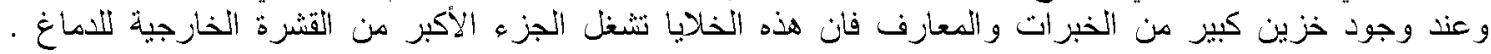

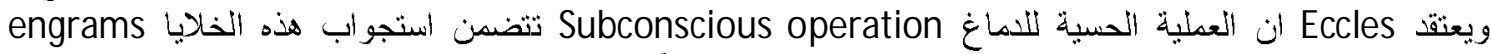

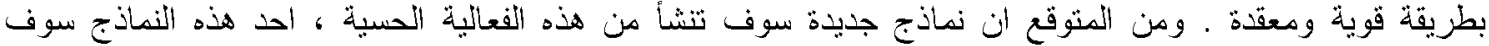

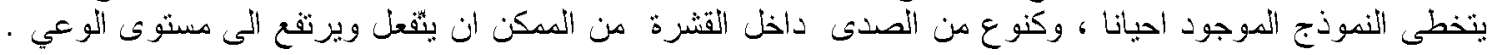
في هذه اللحظة يظهر كفكرة جديذة نخضع مباشزة لعملية النق و التقييم" . [Broadbent, 1978,p.341] 


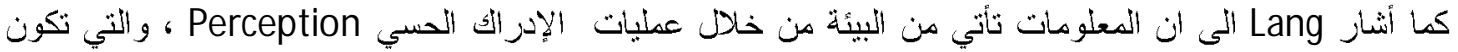

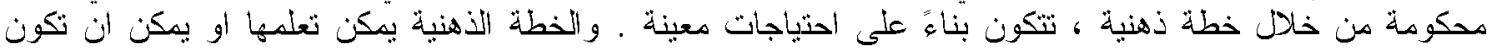

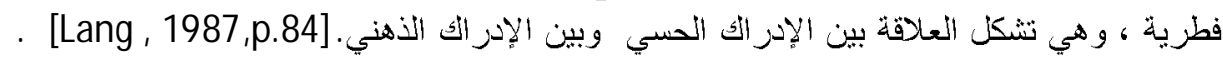

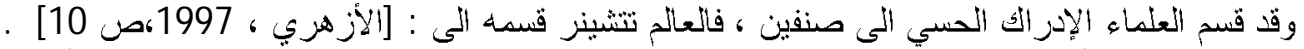

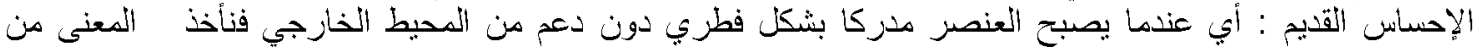
خواصه مباشرة ، فالمعنى يكون موجودا بشكل غبر واعي Unconscious في العقل. وقد اطلق عليه العالم تزيزاثان

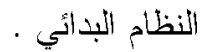

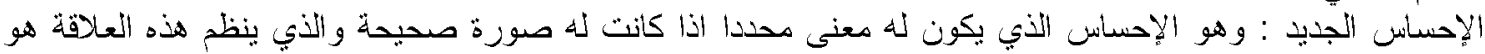

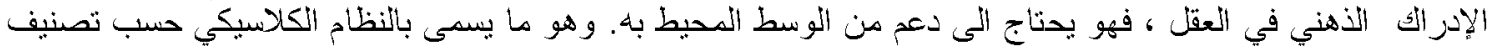
تزيراثان . الأن يدعم ذلك العالم نوزمان ديكسون الذي أكت أيضا بان هنالك نظامين عصبيين في النماغ الأول يمنح المعلومات

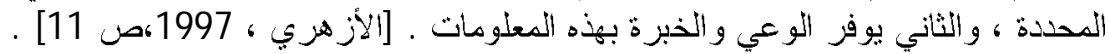

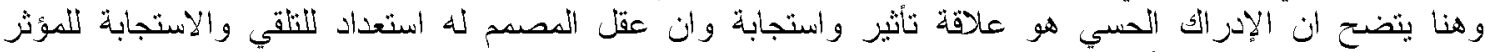

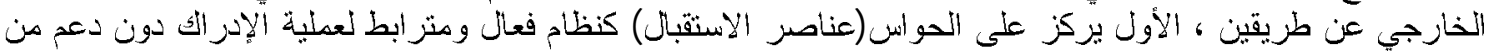

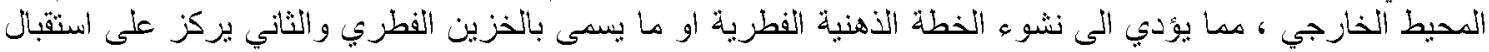

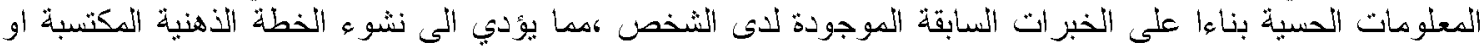

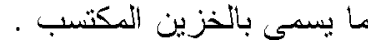

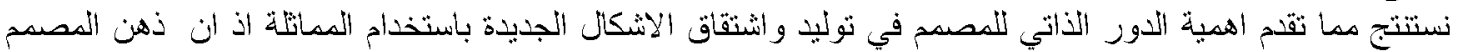

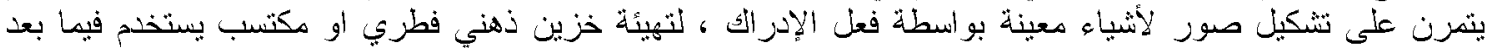

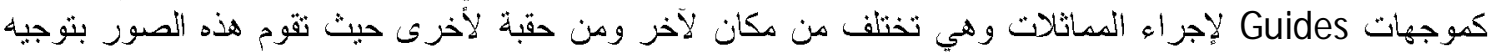

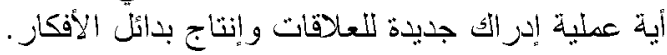

$$
\text { ب -المماتظة والإبداع }
$$

تحتل المماثتلة موقعا مهما في الأساليب الإبذاعية Creative Techniques في العملية التصميمية ـ. اذ تعد التقنية

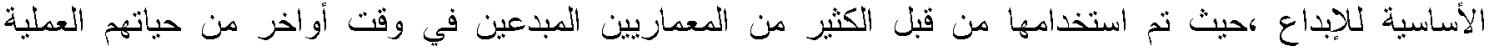

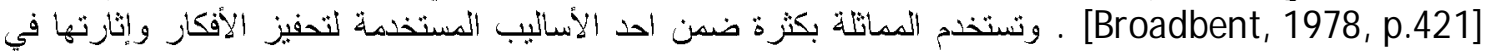
هرحلة التركيب ضمن العطلية التصديمية وهو أنسلوب الــ SynecticS ، وهي فعالية مجمو عة من الاشخاص تركز

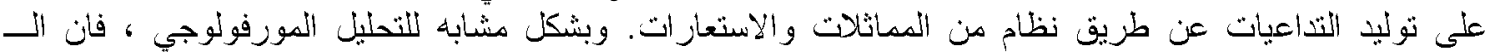
SynecticS

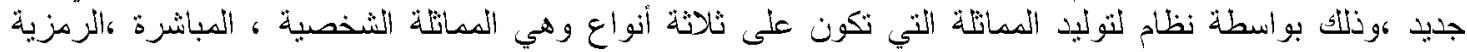
[Broadbent , 1978, p.349- 353]

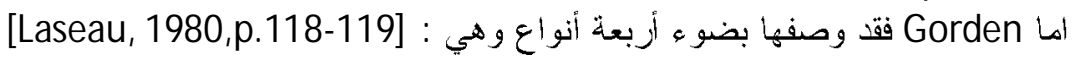
- الممانتة الزمزية او العلاماتية Symbolic Analogy : وهي تمثل مقارنة بين صفات عامة لنشيئين ، ومثالها المقارنة

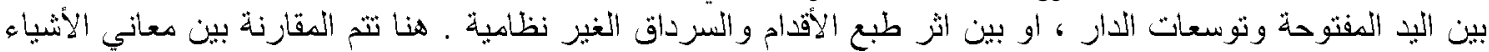

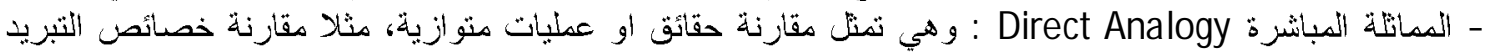

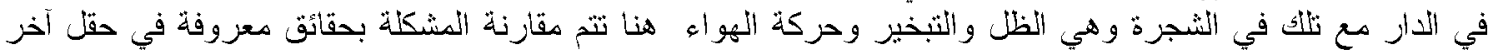
هن حقول النطبيعة او الفن او النتكنولئوجيا.

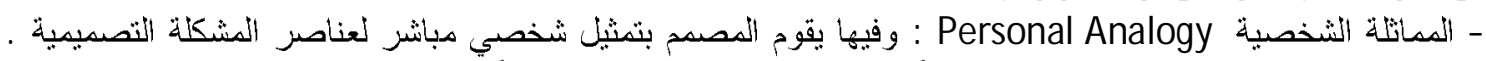

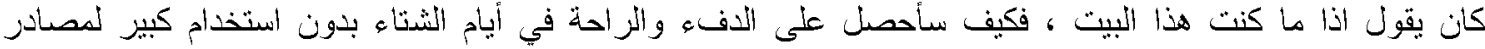
الطاقة .

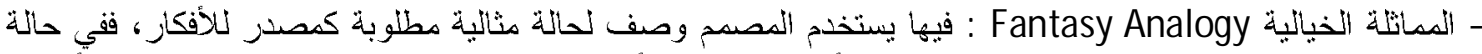

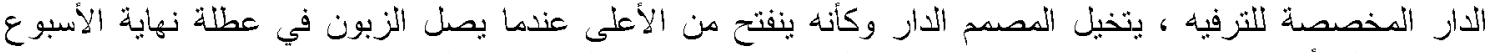

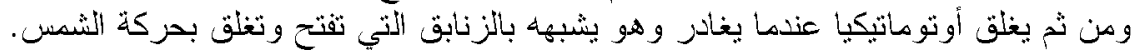

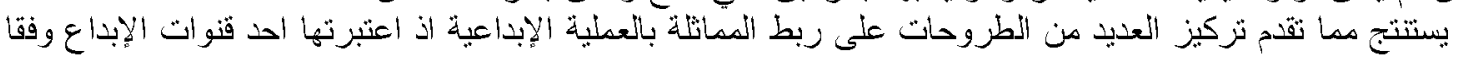
لجو انب تتعلق بتحفيز الأفكاز وتوليدها كالأسانيب الإبداعية. 


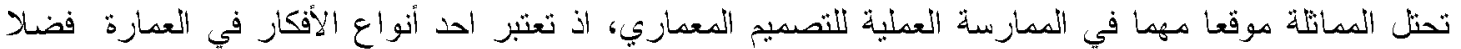

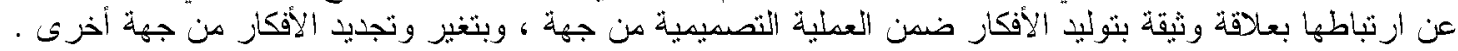

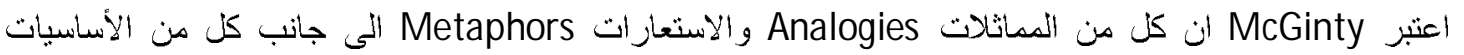

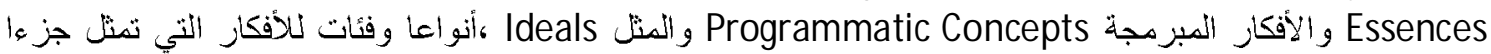

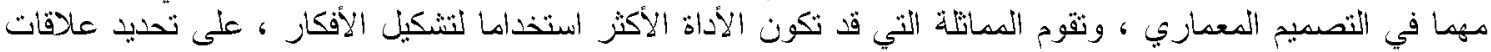

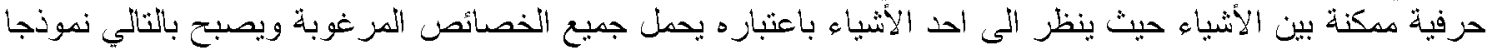

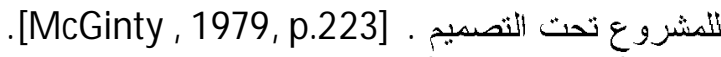
وقد أنشاز Jencks أبضا التى دور المماتلة في الحصول على الأفكار التصميمية ، حيث أوضح ان نماذج المساتنة Analogical Models

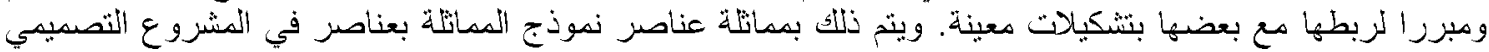

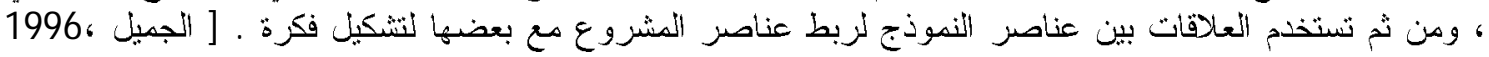

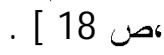

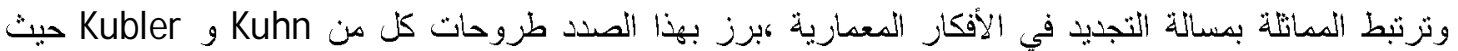

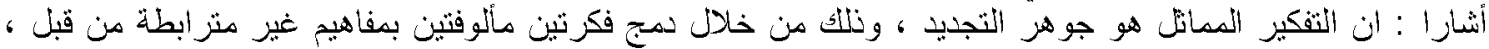

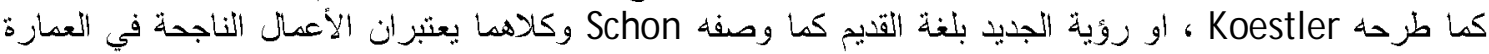

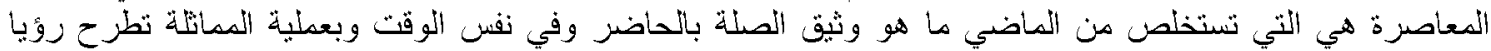

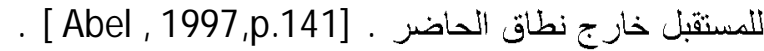

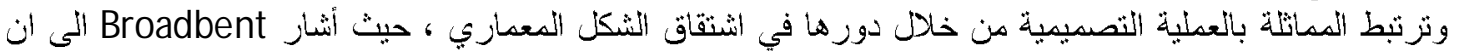

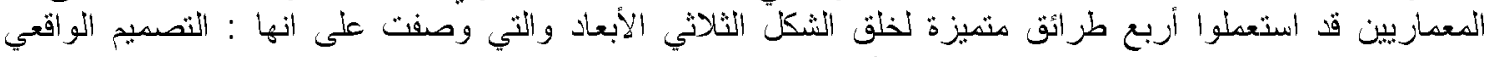

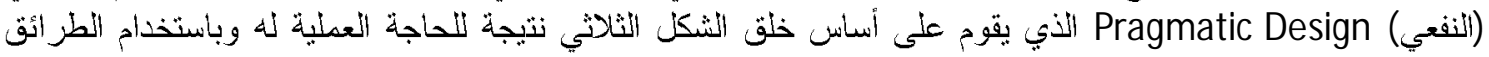

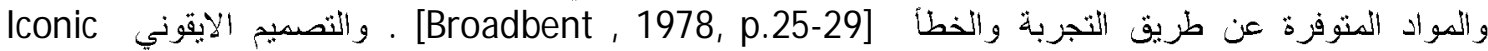

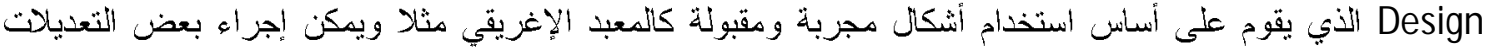

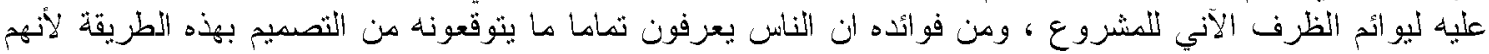

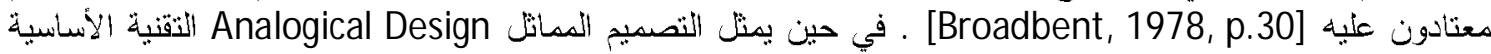

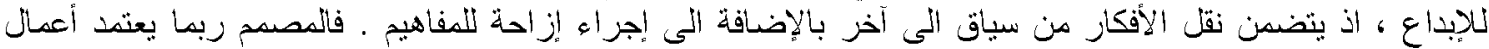

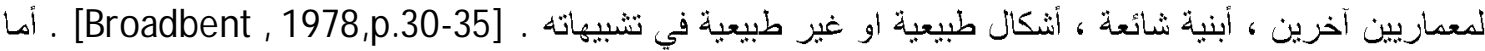

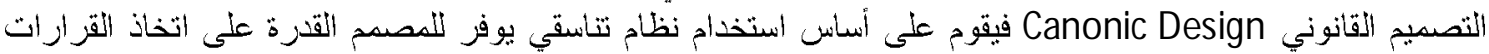

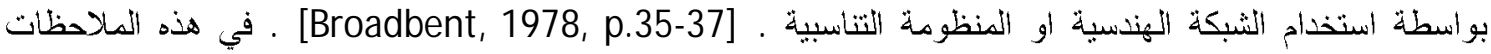

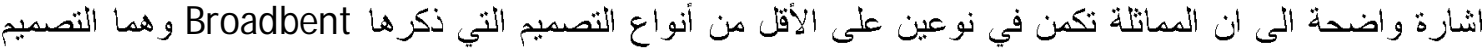

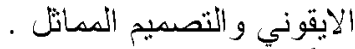

أما طروحات النجيدي فنتيز بهئا المعنى الىى وجود نمطين أساسين من الأنماط المستخدمة في توليد النشكل: يركز

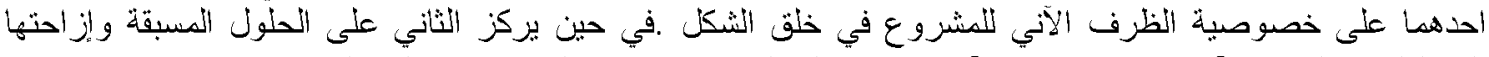

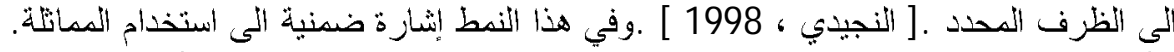

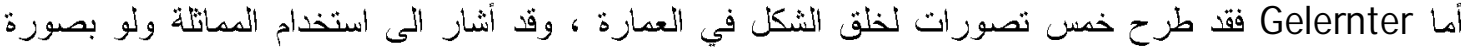

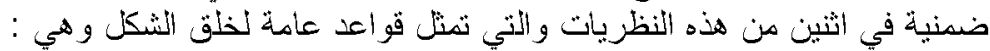
وضع أفكار قديمة معا بطريقة جديدة ، وفقا للنظرية التي تفسز اشتنقاق الشكل من خلال عطية تخيل إبداعية . [Gelernter, 1995,p.7]

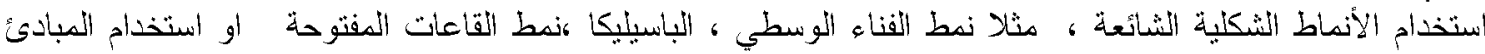

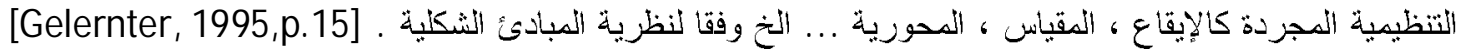

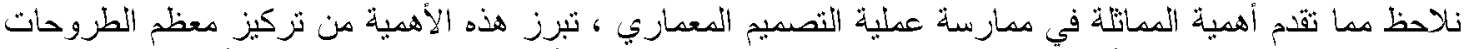

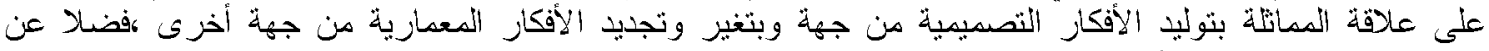
حوز ها المهي في اشتقاق الأشكال المعمارية . 
6 - مؤشرات الاطار النظري

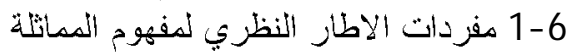

لقت ثركز مفهوم المماثلة بشكل عام حون جو انب مختلفة تبلورت في اربع مفردات اساسية شملت كلا من :

- 1 - 1-1 المفردة الاولى: مسبب المماتلة

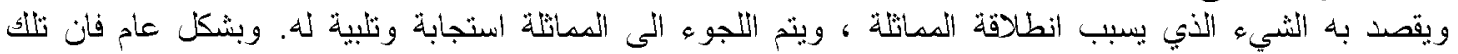

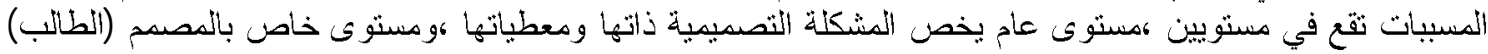

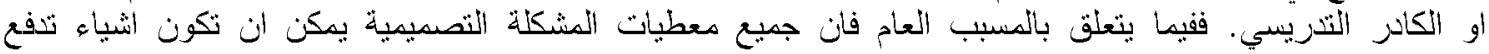

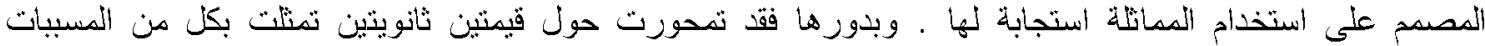

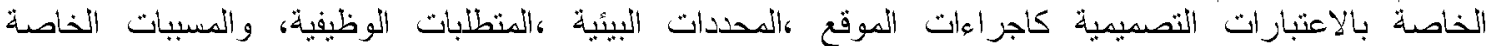

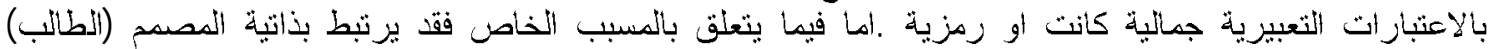
وتوجها الفكري باو بتو جهات الكادز التنزيسي (الاستاذ المسؤول).

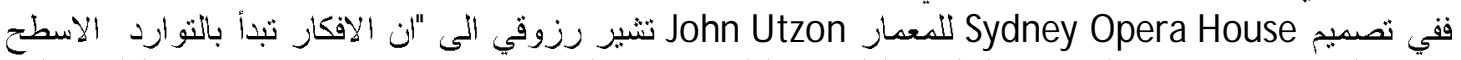

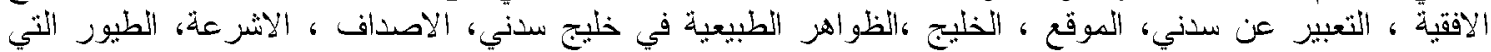

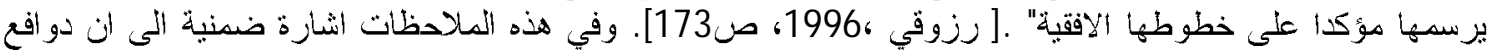

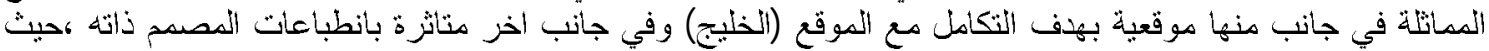

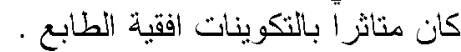

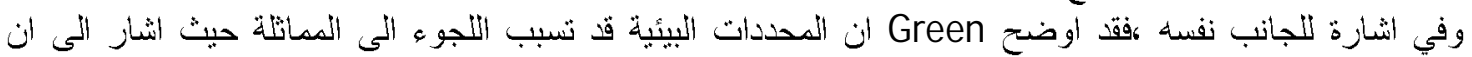

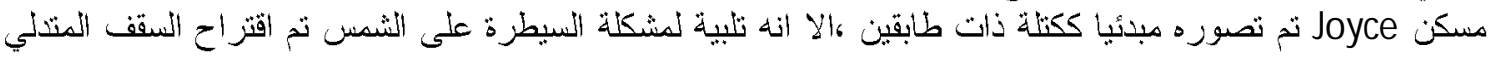

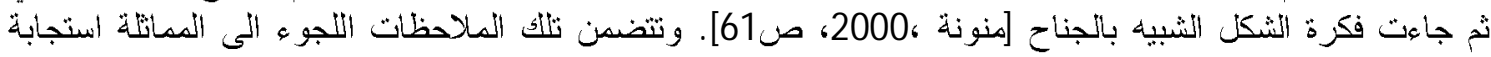
اللمحدات البيئية.

- 6 - 2- المفردة الثانية : مصادز المماتلة

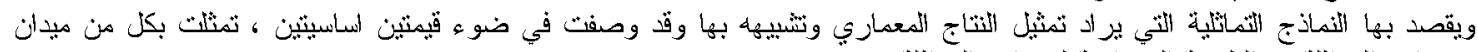

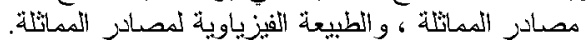

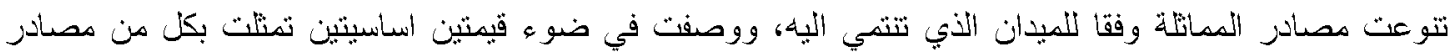

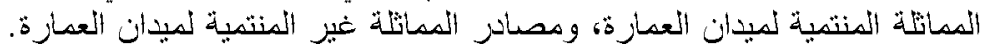

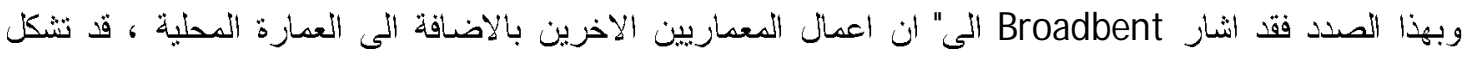

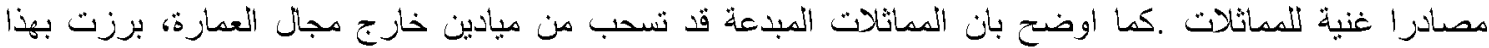

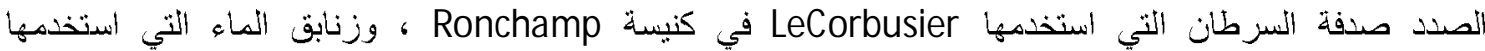

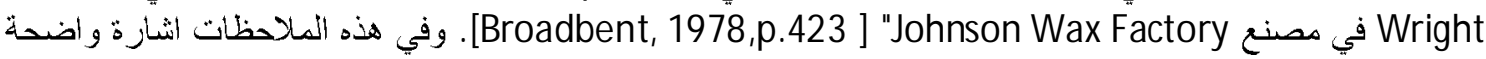

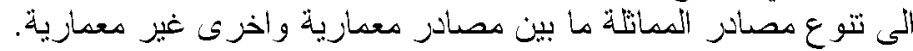

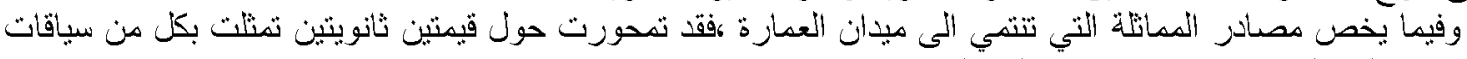
مصادز الممائلة ومرجعيات مصائر الممأثلة.

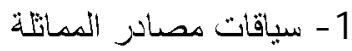

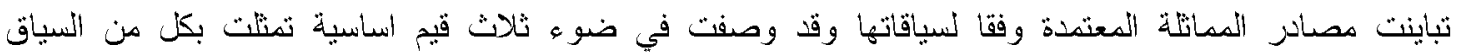

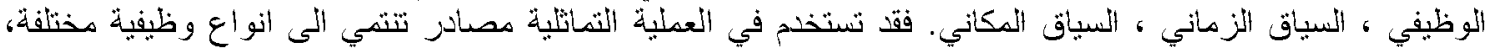

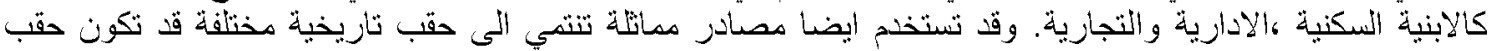

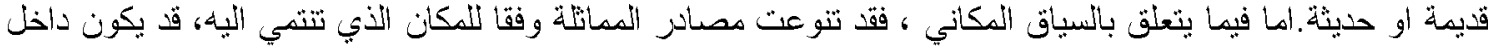

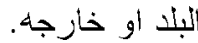

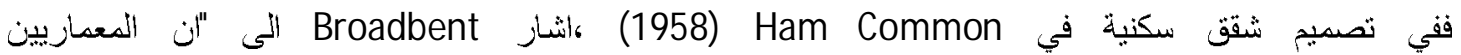
Jaoul اعتمدوا نفس المفردات التي استخذمها LeCorbusier Stirling and Gown Houses

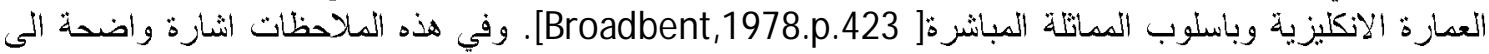


ان مصادر الممأتلة من داخل ميدان العمارة ، وتتنمي للابنية السكنية من حيث سياقها الوظيفي وللحقب الحديثة من حيث

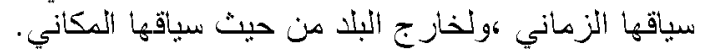

$$
2 \text { - 2 - مزجعيات مصاندر الممانة }
$$

تتوعت مصادر المماثلة المعتمدة وفقا لمرجعياتها .وقد عبر عنها بثلات قيم ثانوية نمثلت بكل من مصادر مرتبطة

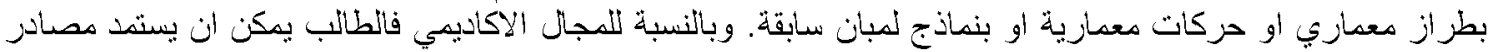

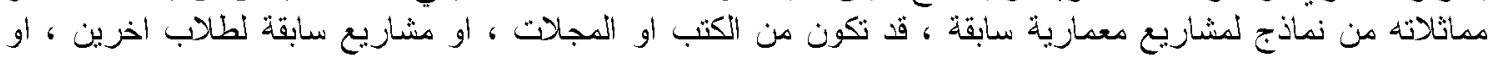
ابنية محلية او عالمية.

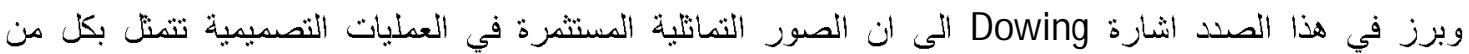

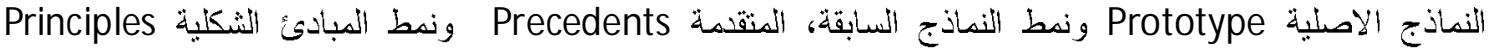
.[Downing, 1992,p.67 ] Formal

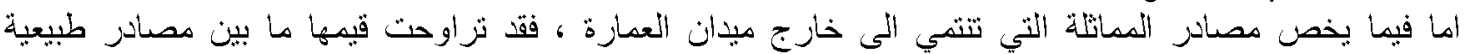

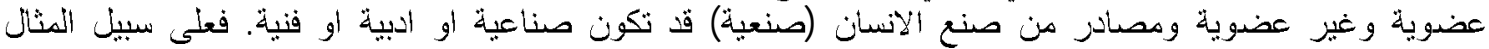

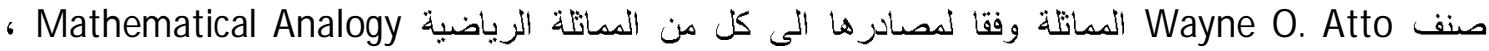
الممانٔة البايولوجية Biological Analogy والتي يمكن ان تتخذ شكلين هما ، العضوية Organic و الحيوية Biomorphic

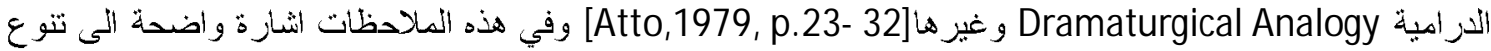

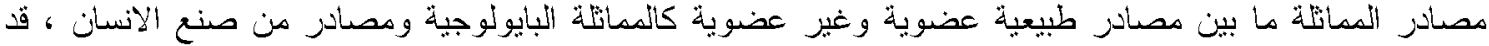

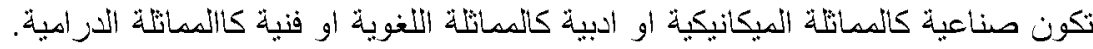

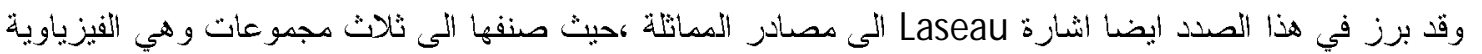

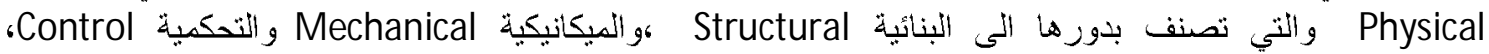

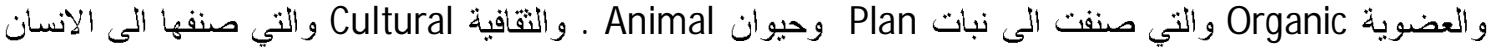

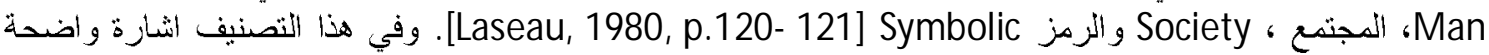

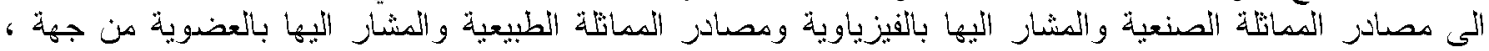

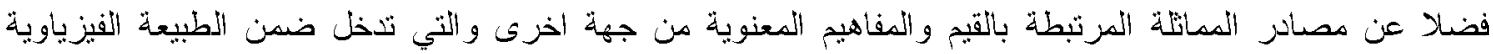
المصنر الممانظة.

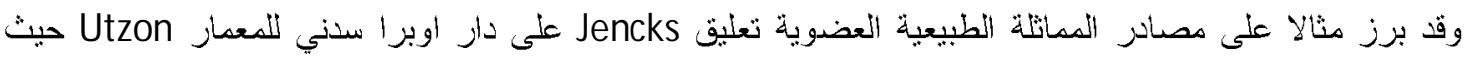

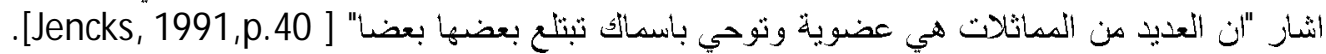

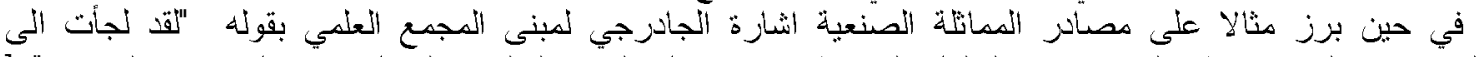

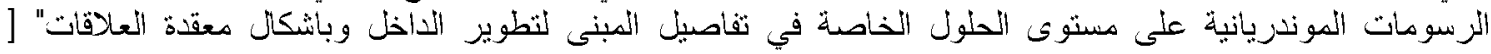

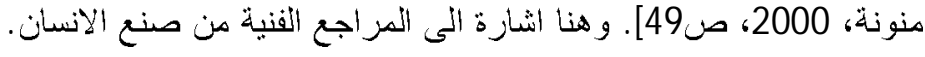

ب - الطبيعة الفيزياوية لمصادز المماتلة

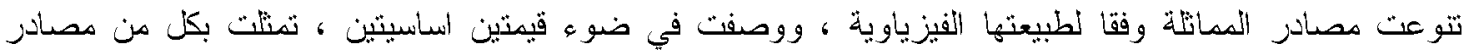

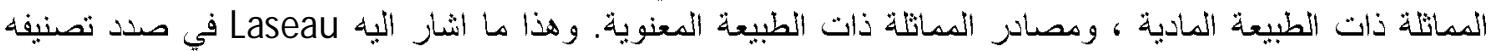

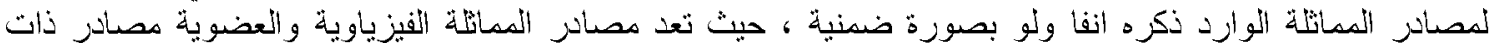
طبيعة مادية ، في حين تعد مصادز المماتلة الثقافية مصادر ذات ذبن طبيعة معنوية.

- 6 -3 المفردة الثالثة: صيغة النعامل مع مصنز المماتلة

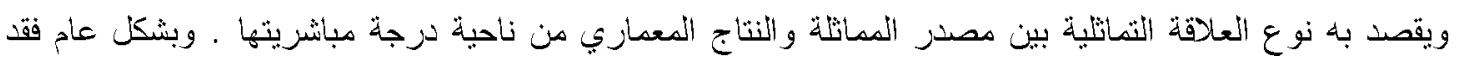

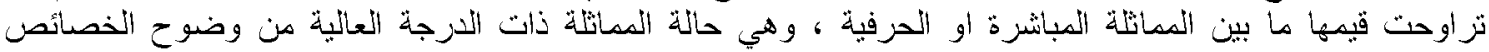

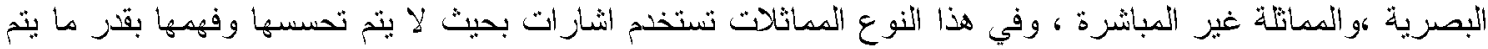
الإيحاء بها.

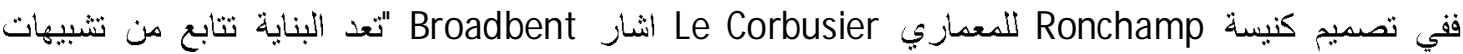
مباشرة Sequence of direct Analogies ان صدفة السرطن الموضوعة على لوحة رسم Le Corbusier 
تصبح سقف المبنى وجسم المبنى على شكل جرس ، العديد من التشبيهات مأخوذة من تاثيرات قيبمة لسفراته

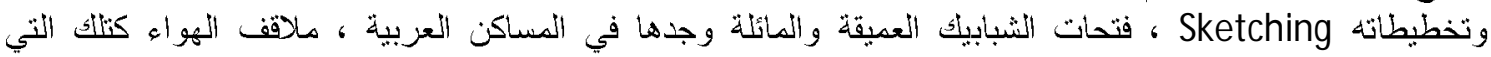

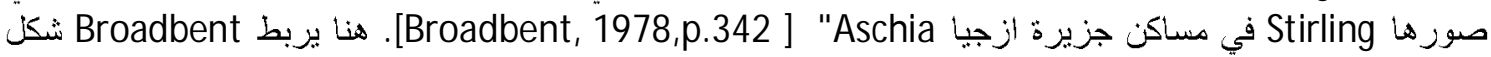

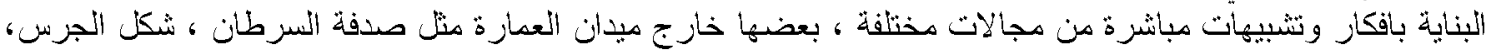

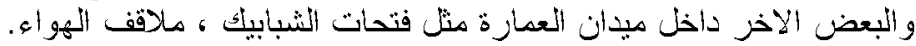

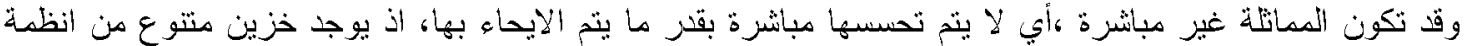

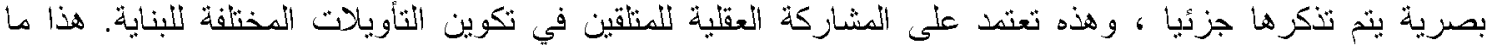

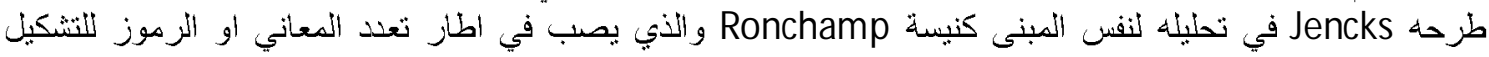

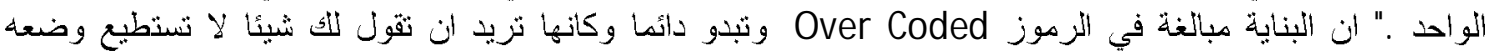

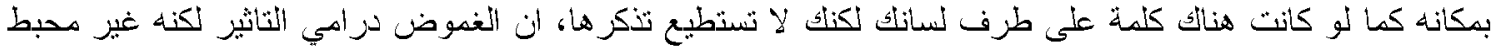

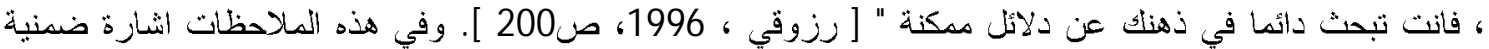

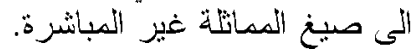

6 - 6 -4 المفردة الز ابعة : العنصر التصميمي ذاث العلاقة بالمماثلة

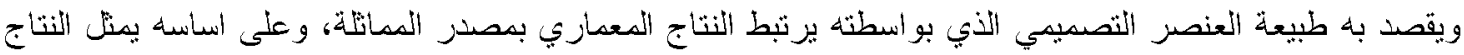

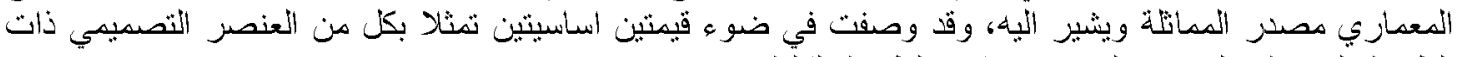

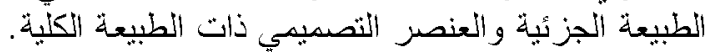

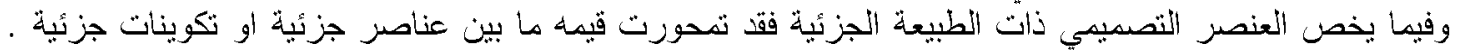

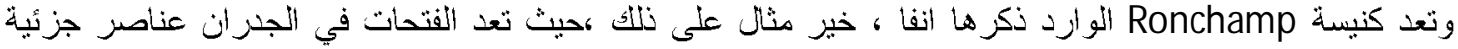
في حين تعد ملاقف الهواء تكوينات جزئية. اما فيما يخص العنصز التصميمي ذات الطبيعة الكلية فقد تمحورت قيمه ما بين ثنائي الآبعاد وثلاثي الإبعاد برز مثالا

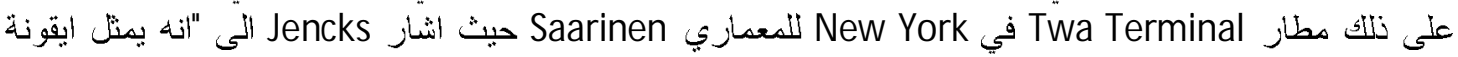

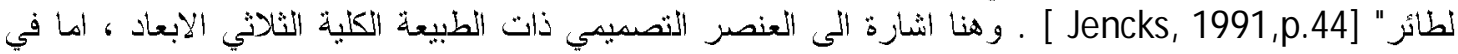

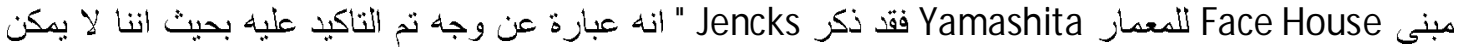

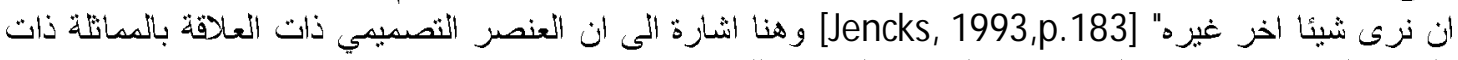

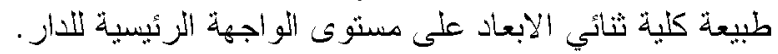

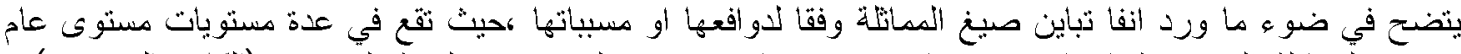

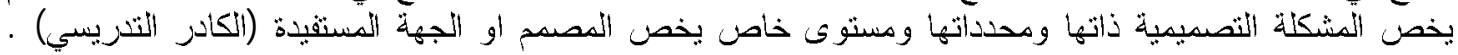

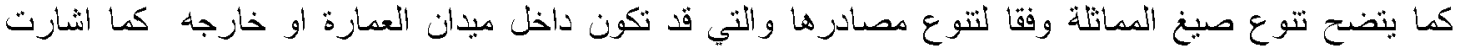

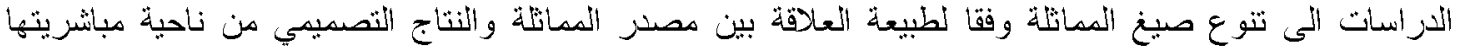

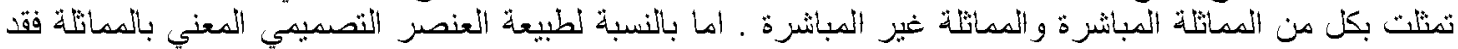

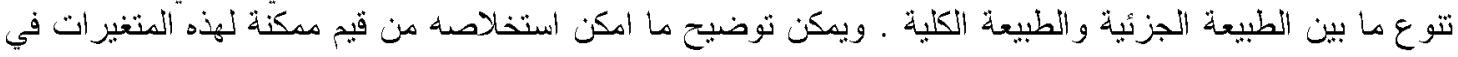

تحقيقا لهوف البحث المتمثل باستكثاف وجود انماط معينة للمماتلة ، توضح تباين صيغها ان وجد في توجهات الطلبة

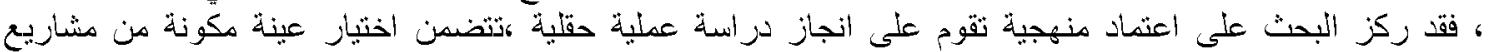

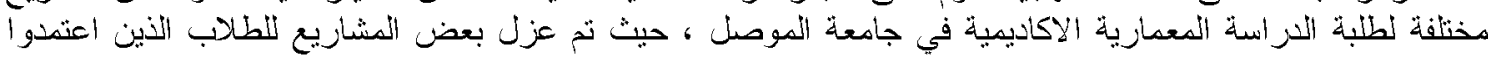

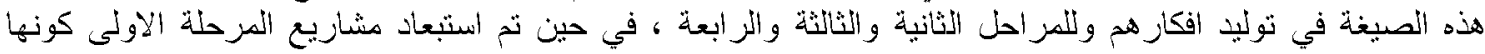

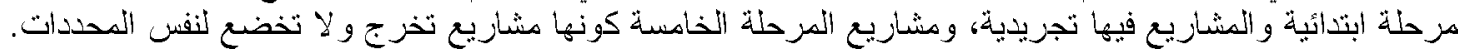

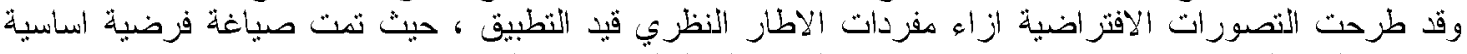

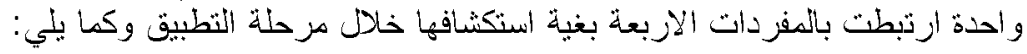

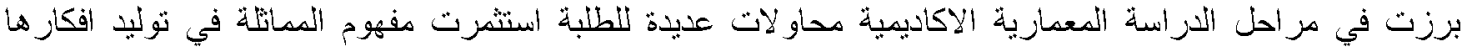

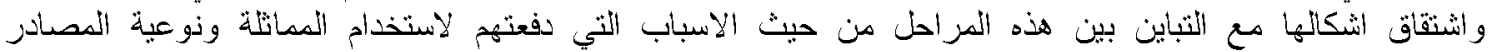

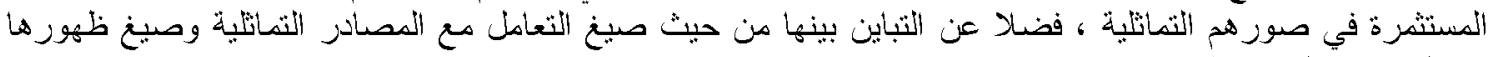
في المشاريع المعمارية. 


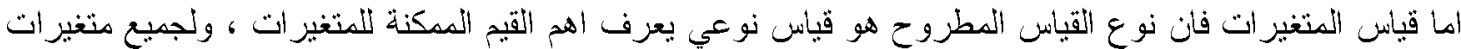

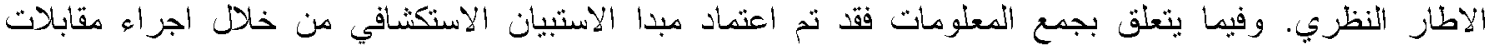

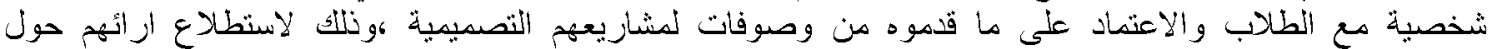

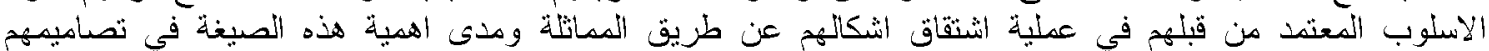

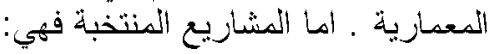

جدول [1-6] القيم المدكنة لمفردات الاطار النظري

\begin{tabular}{|c|c|c|c|c|c|c|}
\hline \multicolumn{3}{|c|}{ القيب الممكنة } & \multicolumn{2}{|c|}{ المتنير ات الفرعية } & المتنغير ات الرئبسية & ت \\
\hline \multicolumn{2}{|l|}{ اجز اءتات الموقع } & \multirow{4}{*}{ تصميمي } & \multirow{7}{*}{\multicolumn{2}{|c|}{ مسبب عام }} & \multirow{10}{*}{ مسبب المماثلة } & \multirow[t]{10}{*}{$\bar{~} 1$} \\
\hline \multicolumn{2}{|l|}{ محندلت يئية } & & & & & \\
\hline \multicolumn{2}{|l|}{ متطلبات وظبفية } & & & & & \\
\hline \multicolumn{2}{|l|}{ جو أنب اخرى } & & & & & \\
\hline \multicolumn{2}{|l|}{ رمزبي } & \multirow{3}{*}{ تعييزثي } & & & & \\
\hline \multicolumn{2}{|l|}{ جمالي } & & & & & \\
\hline \multicolumn{2}{|l|}{ جو أب اخرى } & & & & & \\
\hline \multirow{2}{*}{\multicolumn{3}{|c|}{ ذذاتبة المعماري (الطالب)وتوجهيه الفكري }} & \multirow{3}{*}{\multicolumn{2}{|c|}{ مسبب خاص }} & & \\
\hline \multirow{2}{*}{\multicolumn{3}{|c|}{ توجهات الكادر التّريس }} & & & & \\
\hline & & & & & & \\
\hline سكني & \multirow{5}{*}{ سياق زماني } & \multirow{7}{*}{ سياقات مصادادر } & \multirow{12}{*}{ داخل ميحان } & \multirow{20}{*}{ مثيدان } & \multirow{22}{*}{ هصـادر المماتلةلة } & \multirow[t]{22}{*}{2} \\
\hline إدارب & & & & & & \\
\hline اخرث & & & & & & \\
\hline حقب قديمة & & & & & & \\
\hline حقب حيثة & & & & & & \\
\hline يداخل البلا & \multirow{2}{*}{ سياق مكاني } & & & & & \\
\hline خازج البلك & & & & & & \\
\hline \multicolumn{2}{|c|}{ طرز وحركات معمارية } & \multirow{5}{*}{ مرجياتر } & & & & \\
\hline كتب ومجلاتت & نماذج معمارية & & & & & \\
\hline مشاريح سابقة للطلاب & سابقة & & & & & \\
\hline ابنية محلية، ابنية عالمبة & & & & & & \\
\hline اخرى | ل اخ & & & & & & \\
\hline انسان & عضون ــة & & & & & \\
\hline نبات & 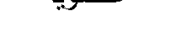 & طسعبة & & & & \\
\hline حيولن & & & خا - & & & \\
\hline نوبة (تكو ينات ظبيعية) & 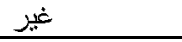 & & مثناً. & & & \\
\hline مية (تقنية ، ميكانيكية) & & & القعار : & & & \\
\hline أديية & & هن صنع من & & & & \\
\hline فنية & & الإلنسان & & & & \\
\hline 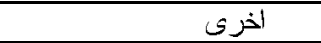 & & & & & & \\
\hline & & & أل القيزياوية & الظبيع - الظيع & & \\
\hline & & & بار الدماتثلة & & & \\
\hline 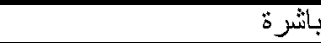 & مهاثلة & & نذه التحكامل مع & نوع صبي & صيغة التعامل مع & 3 \\
\hline مباتشرة & ممـثلة غ & & لخز المماثلة & مص & مصنر المماثلة & \\
\hline عناصر جزئية & & طبيعة جزئة & 14 & طبي & العنصر التصديمي & 4 \\
\hline تكوينات جزئية & & & سميمي ذات & & ذات العلاقة & \\
\hline ثثائي الأبعاد & & طييعة كلية & جلقة بالمماثلة & & بالمماثلة & \\
\hline ثلاني الابعاد & & & & & & \\
\hline
\end{tabular}

- A

1 - مشروع دار سكني مع ستوديو لمصور فو تغر الفي ، ويزمز لـ بالرمز A1 ، الجدول [7 -1]. 


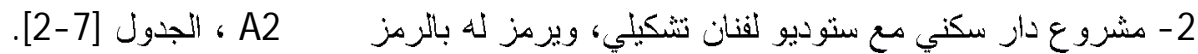

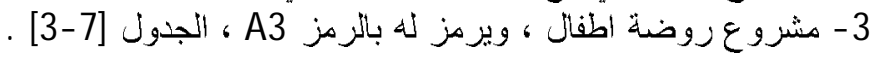

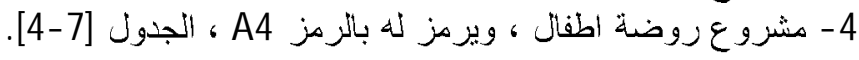

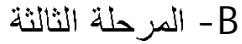

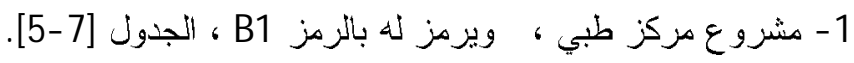

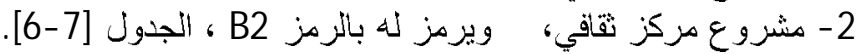

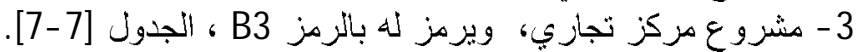

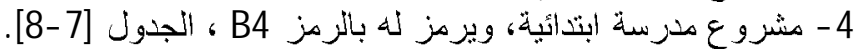

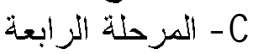

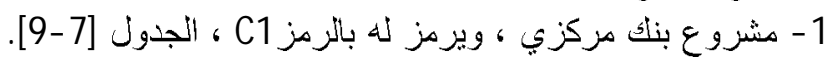

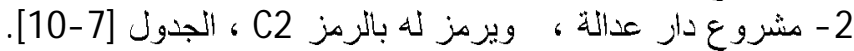

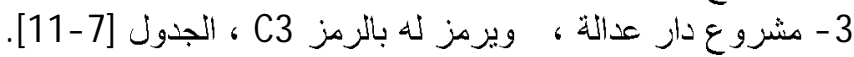

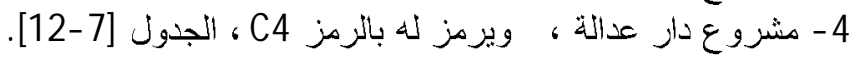

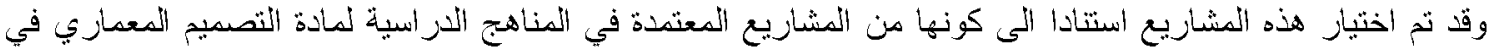

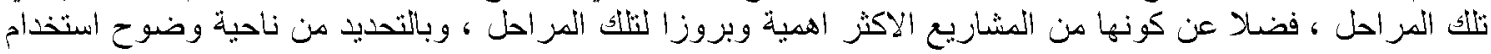

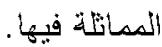

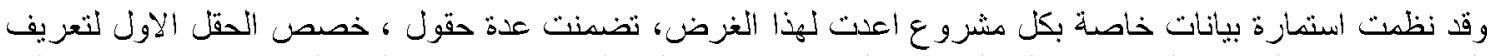

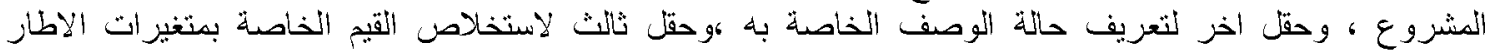

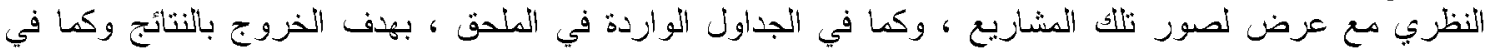
الجدون [8 -1] و الني تم على اسناسها صياغة الإستنتاجات النهائية للبحث .

8 - 8 - مناقشة النتائج و الاستتاجات

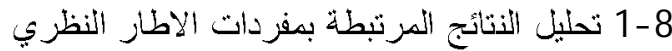
استند تحليل النتائج الى مقارنة المزاحل الثلاثة فيما يتعلق بكل مفردة من مفردات الاطار النظري .

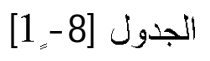

8 -1 - 1 النتائج المزتبطة بمفردة مسبب الممانثة

$$
\text { أ - مسببات عامة }
$$

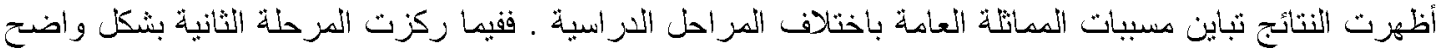

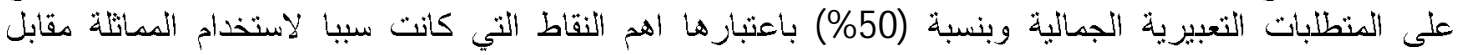

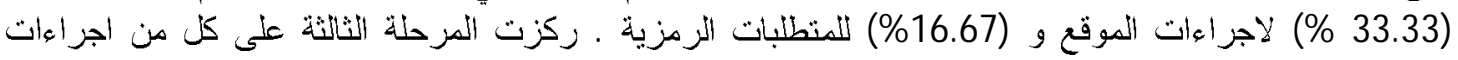

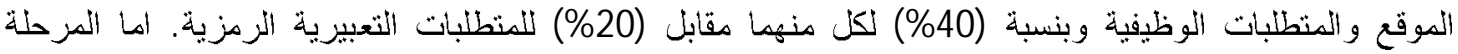

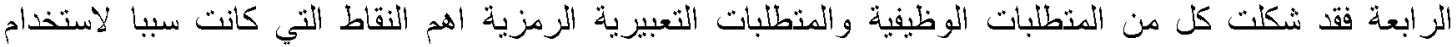

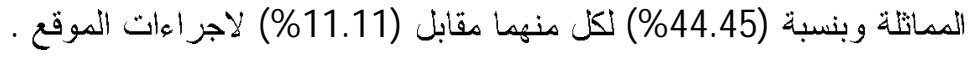

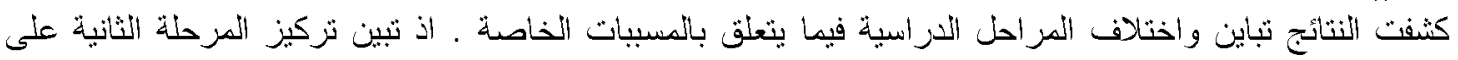

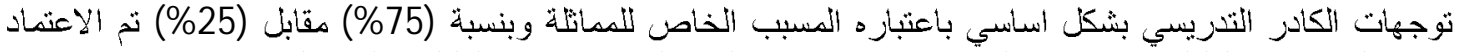

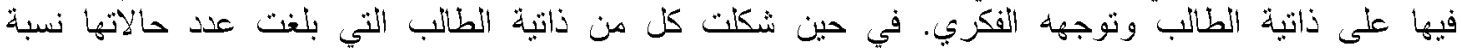

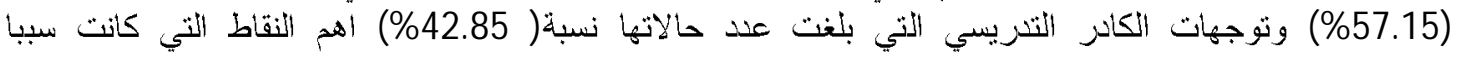

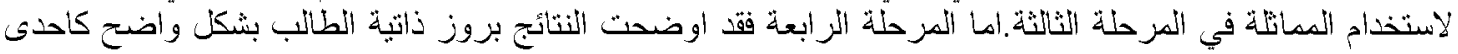
الأسباب لاستخدام المماتلكة حيث بلغت عدد حالاتها نسبة (80\%) مقابل(20\%) تم الاعنماد فيها على توجهات الكات الكادر 


$\begin{array}{llll}\text { Al-Rafidain Engineering } & \text { Vol.18 } & \text { No.3 } & \text { June } 2010\end{array}$

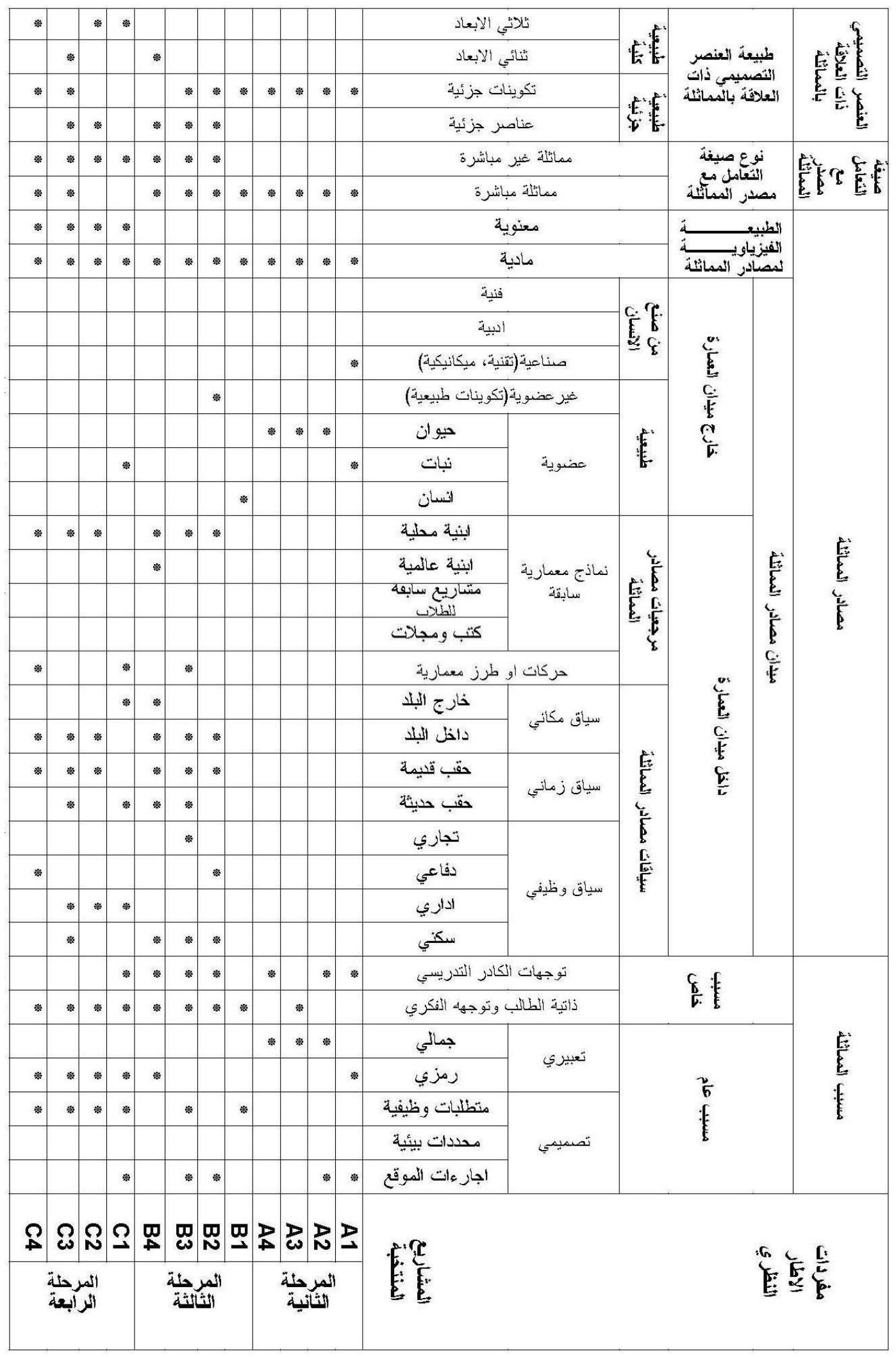




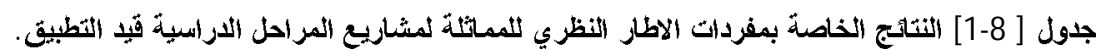

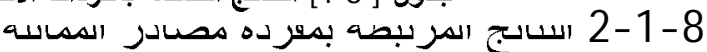

أ أ - ميذان مصادر الممانلة

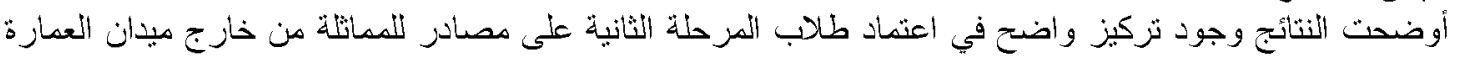

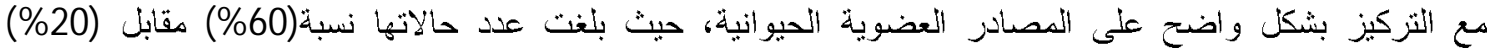

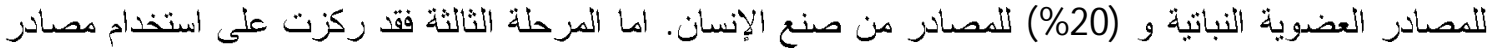

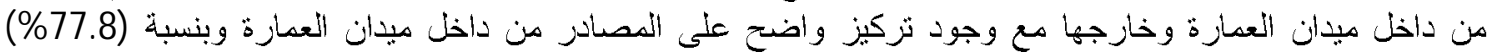

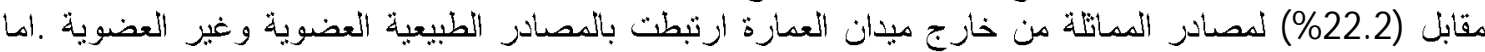

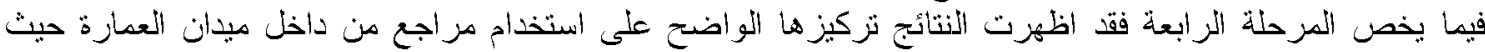

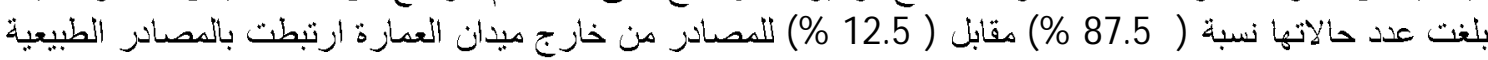

العضدوية.

1 أظهرت النتائج وفيما يخص السياق الوظيفي تركيز طلاب المرحلة الثالثة التواضح على المباني السكنية باعتبازها

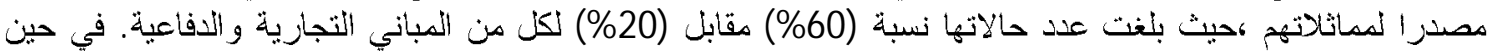

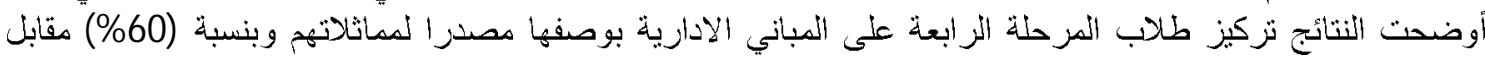

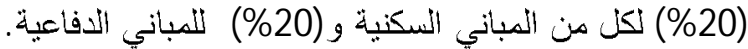

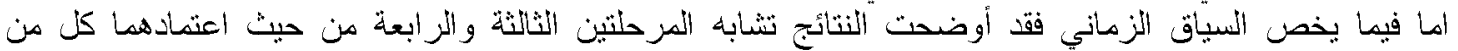

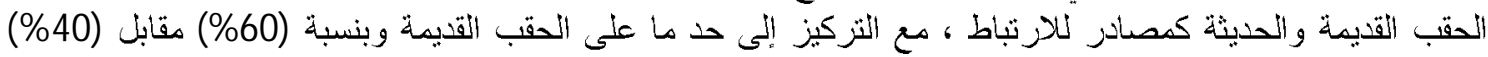

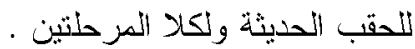

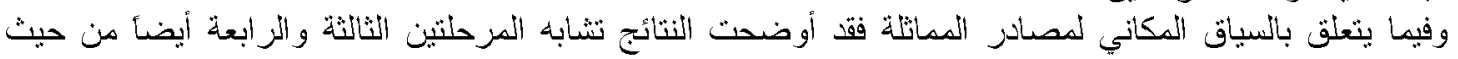

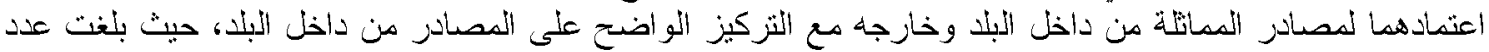

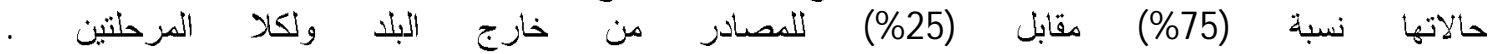

2 - مرجعيات مصنادز المماثلة

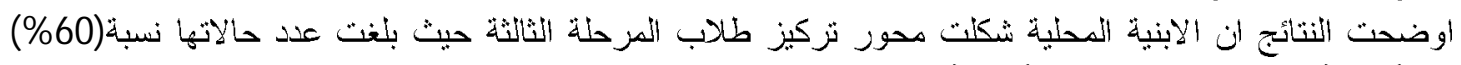

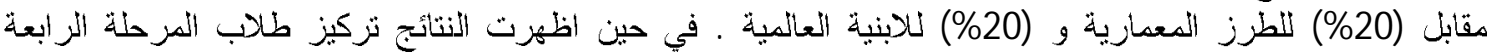

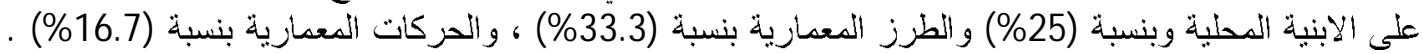

ب - الطبيعة الفيزياوية لمصادز المماثلة

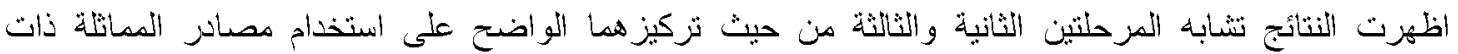
الطبيعة المادية وبنسبة (100\%) في حين اوضحت النتائج نركيز طلاب المرحلة الزرابعة على كل من مصادر المماثلة ذات الطبيعة المادية و المعنوية وبنسب منساو ية بلغ الغت (50\%) لكل منهما.

8 - 8 -3 النتائج المرتبطة بمفردة: التعامل مع مصنر المماثلة اظهزت النتائج تباين المر احل الثلاثة فيما يتعلق بصيغة التعامل مع مصدر المماتئة حيث تبين تزكيز طلاب المرحلة

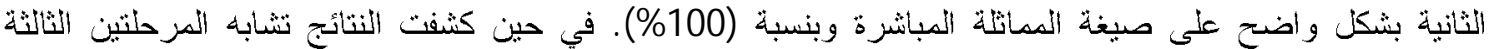

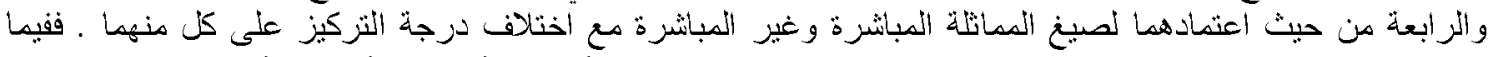

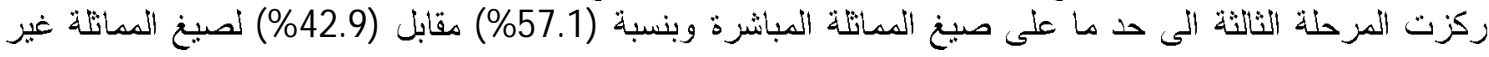
المبانشزة. ركزت المرحلة اللرابعة بشكل واضح على الستخدام صيخ المماتظة غيز المباشرة وبنسبة (66.7\%) مقابل (33.3) الصيغ الممانتة المباشرة.

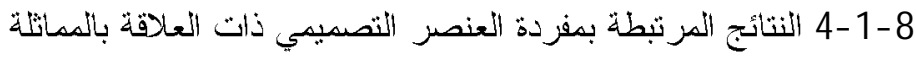

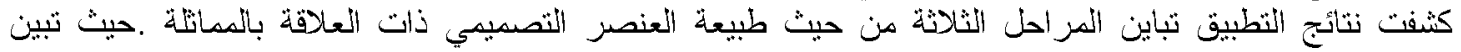

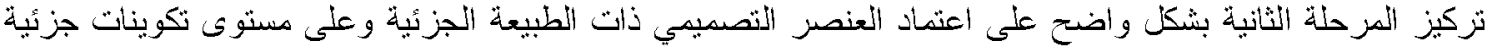

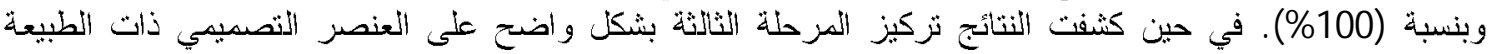




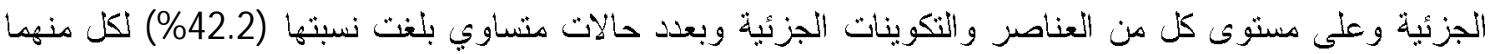

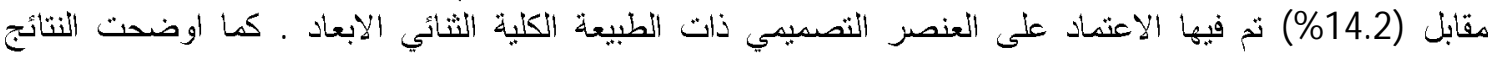

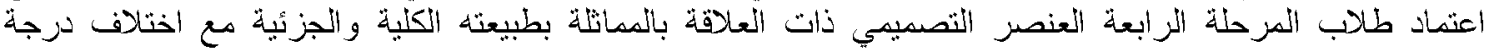

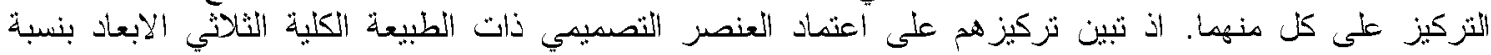
(37.5\%) مقابل (12.5\%) للطبيعة الكلية الثنائي الإبعاد و (25\%) لكن من العناصر الجزئية والتكوينات الجزئية.

2-8 20 الاستتاجات النهائية ركزت الاسنتاجات اللنهائية على محوزين اساسيين ، نعلق الاول منهما بالجانب النظري، في حين ركز المحور

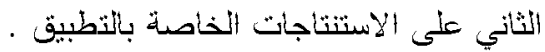

8

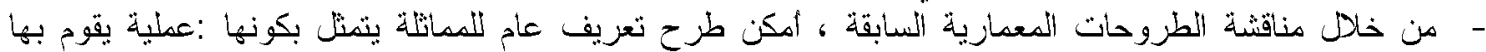

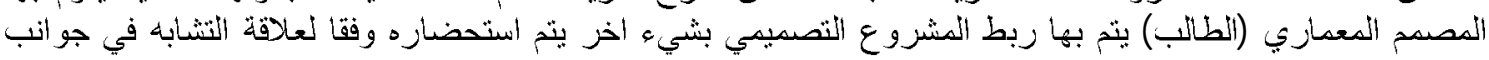

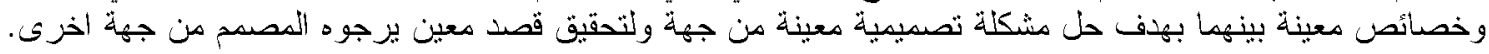

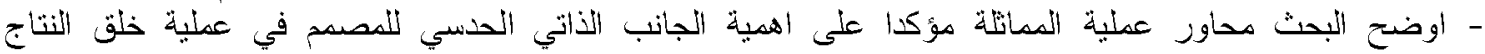

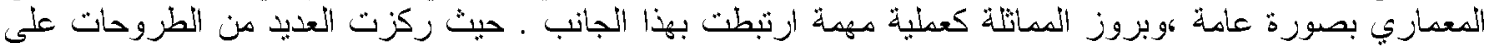

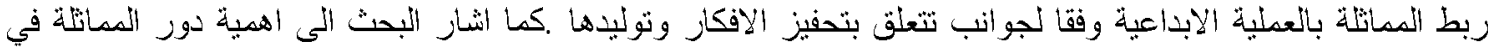

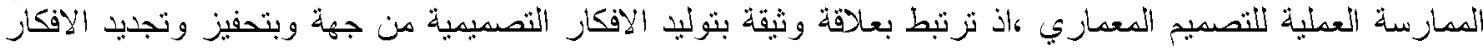

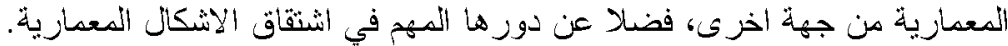

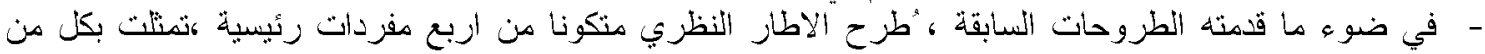

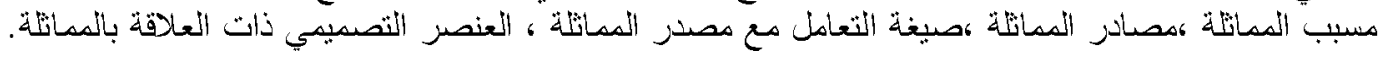

8 -2-2 2- الاستتناجات الخاصة بالتطبيق

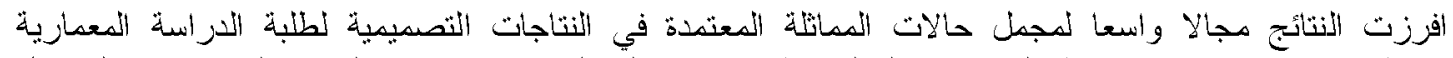

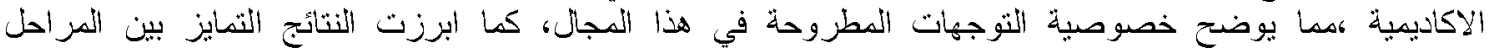

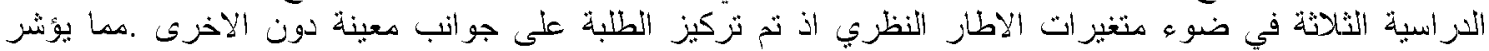

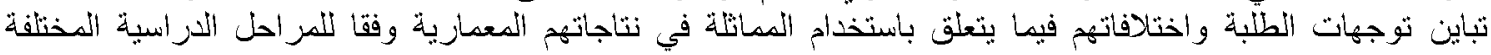

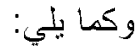
1 - برزت المنطلبات النعبيرية الجمالية واجزاءات الموقع بشكل واضح كاحثى الهم النقاط التي كانت سببا

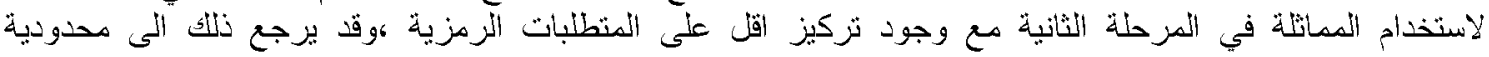

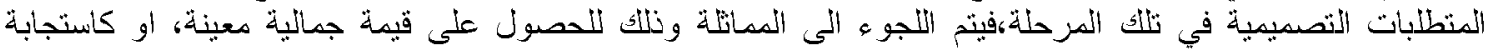

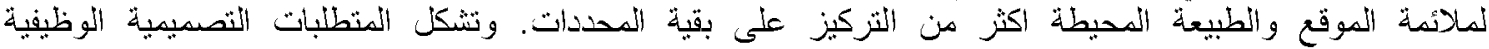

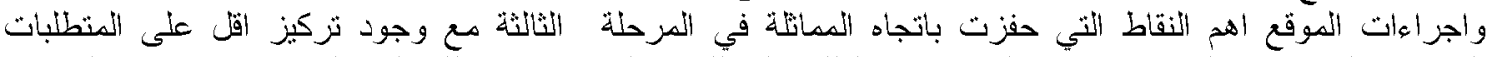

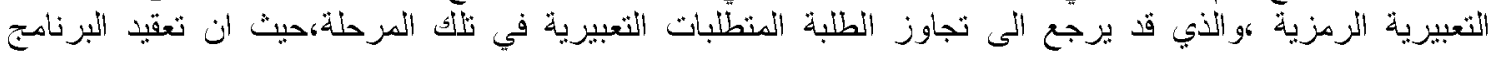

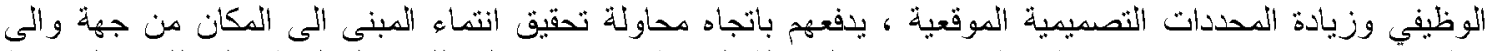

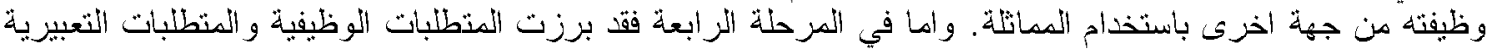

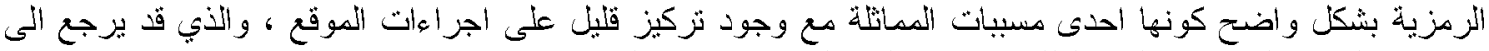

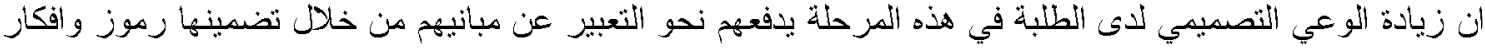

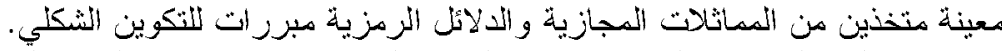

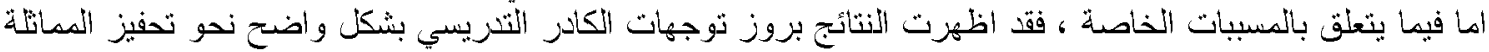

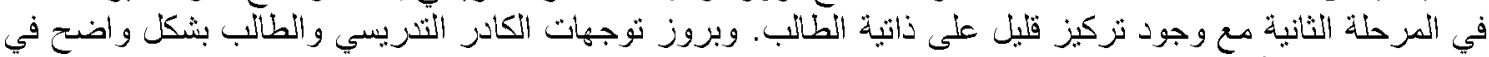

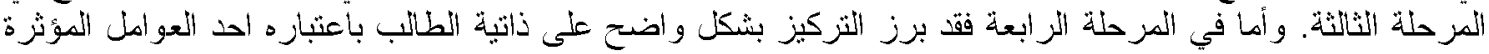

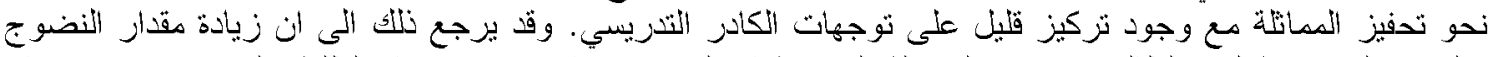

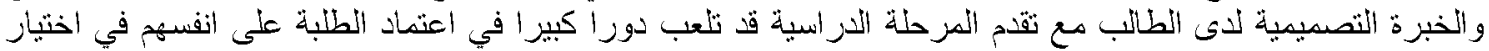
مز أجعه, والانطلاق بافكار هم التصميمية. 


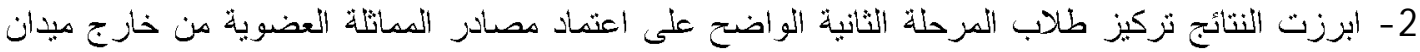

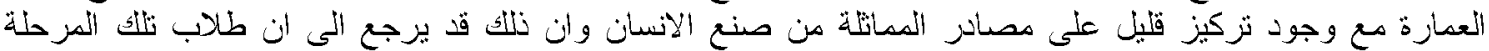

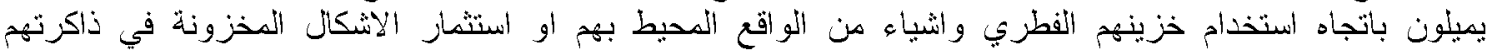

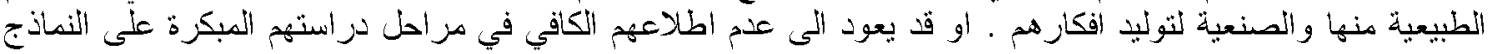

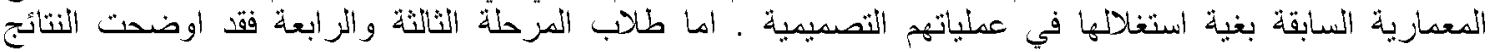

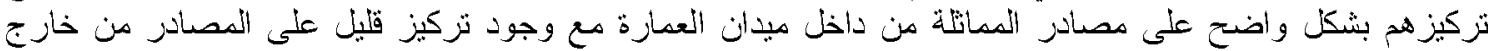

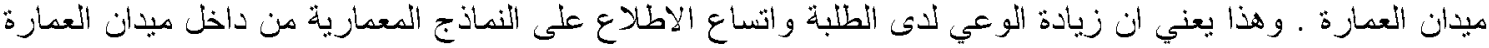

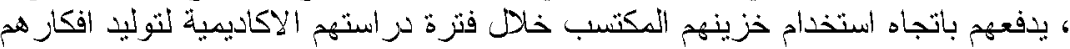

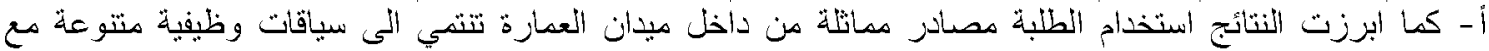

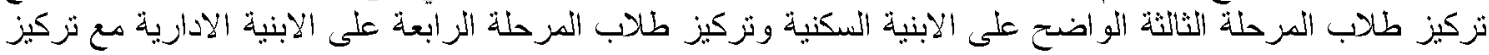

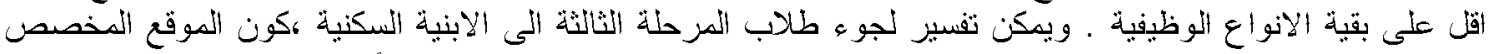

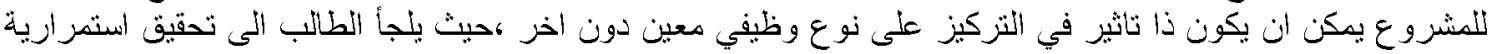

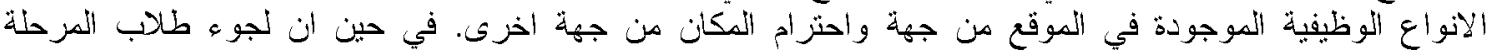

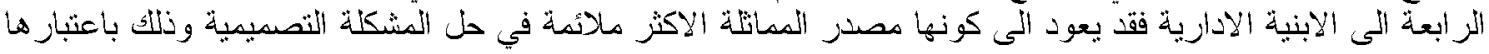

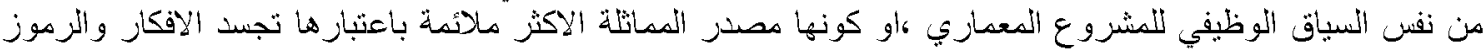

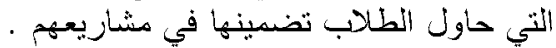

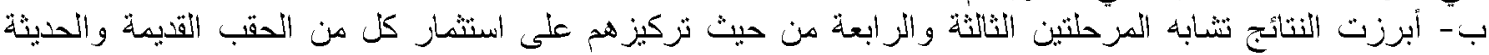

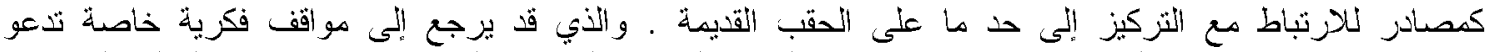

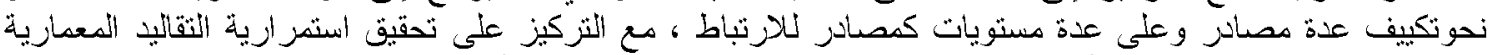

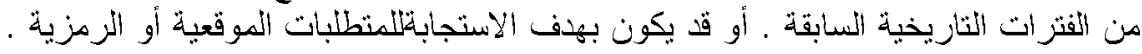

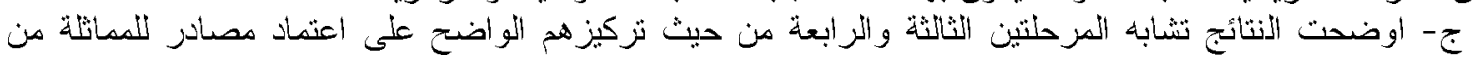

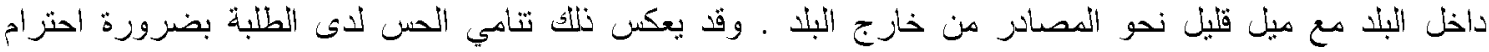

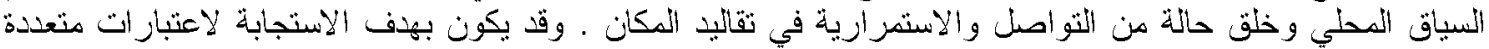

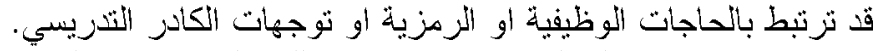

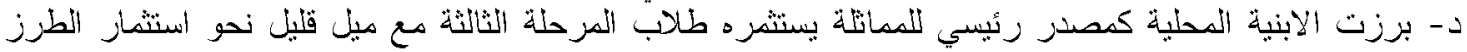

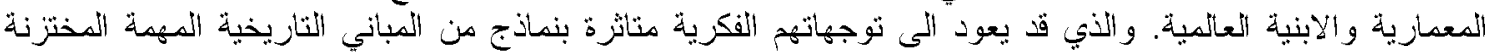

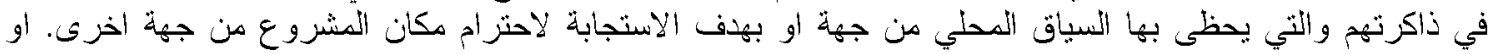

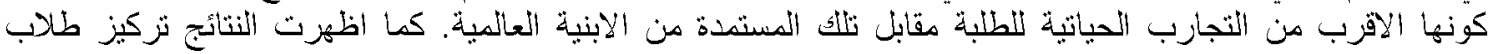

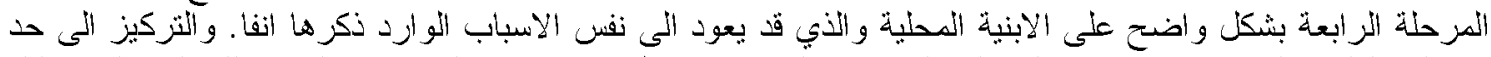

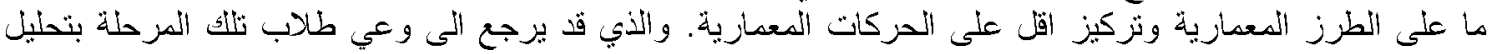
النماذج و الاعتماد على انسها الطز ازية كانماط لصوز لهم التماتلية.

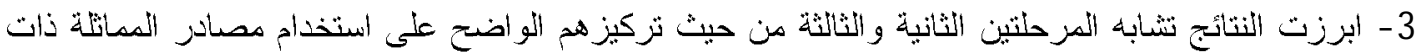

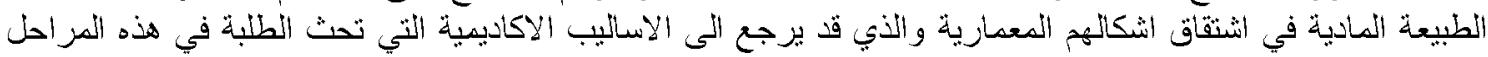

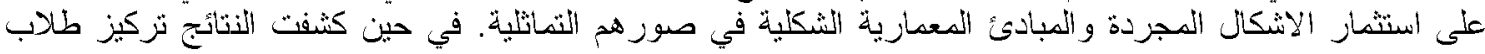

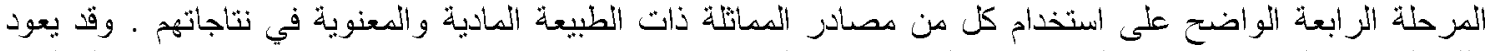

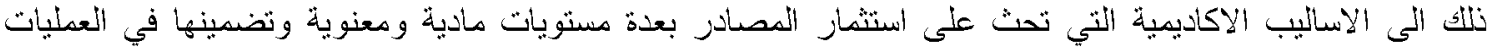

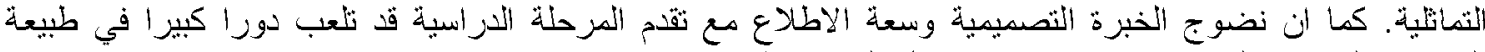

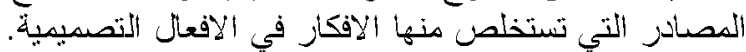

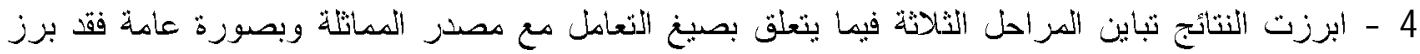

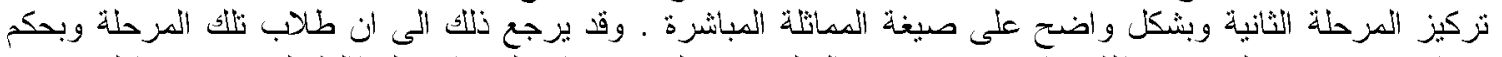

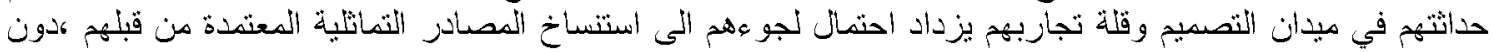

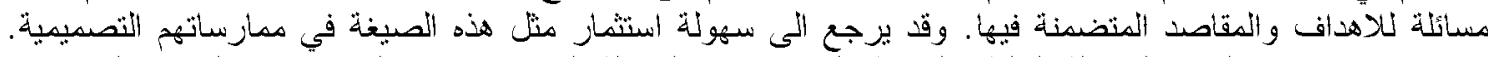

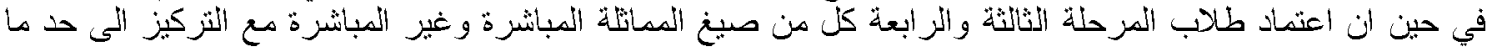

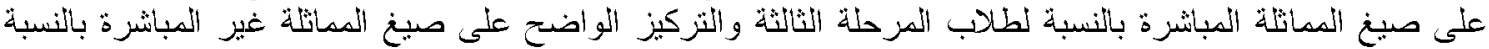

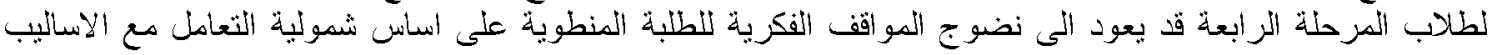

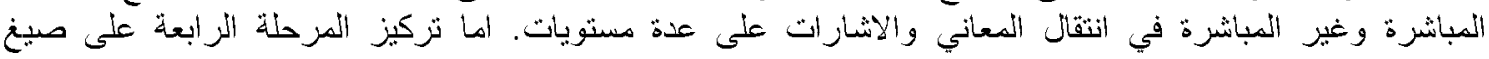




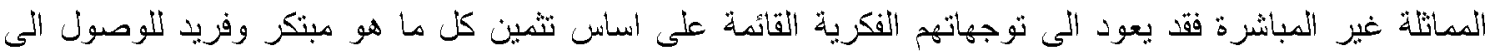

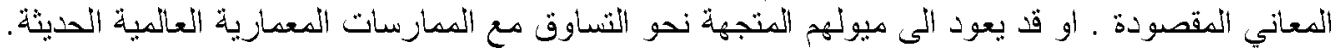

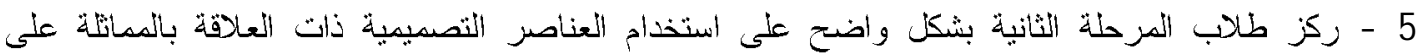

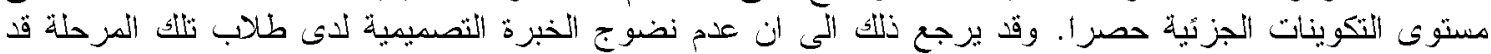

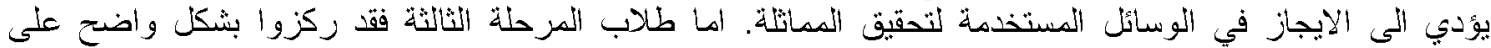

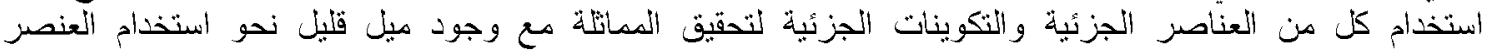

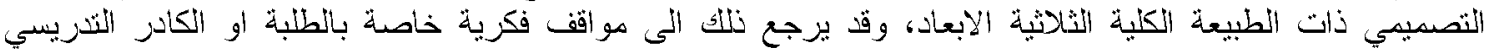

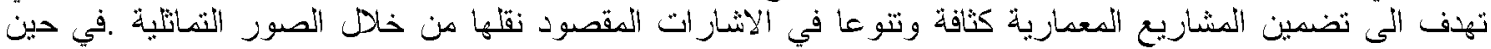

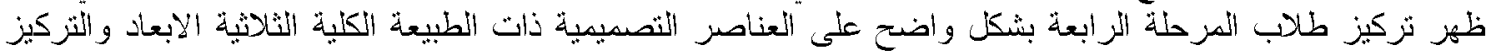

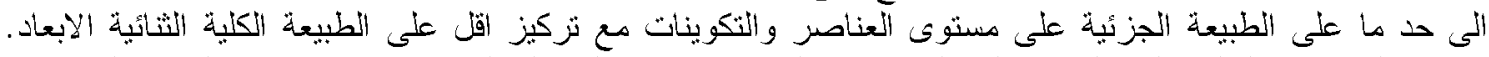

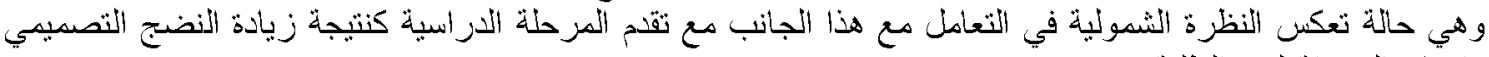
و واتساع المعزفة لدى النطبة.

9

ركز طلاب الدزاسة المعمارية الاكاديمية على استخدام المماثلة في نتاجاتهم التصميمية باسلوب تباين عبر المر أحل

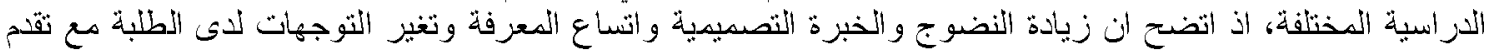

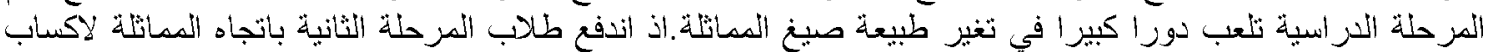

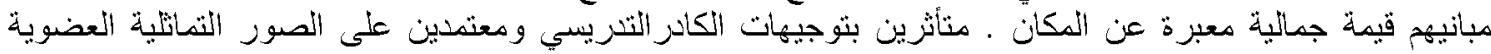

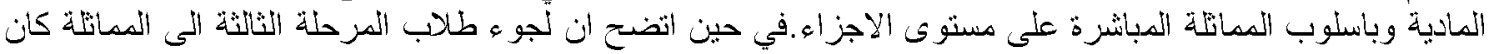

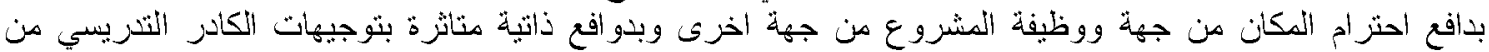

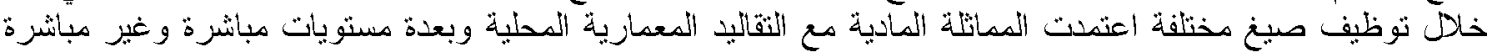

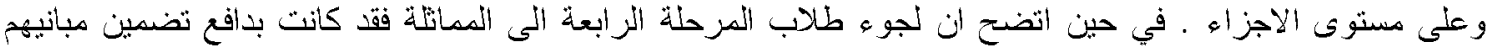

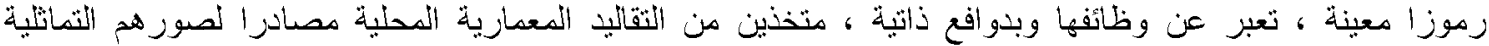

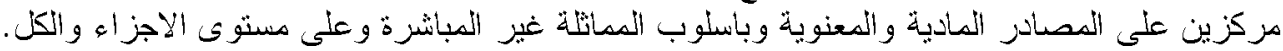

10

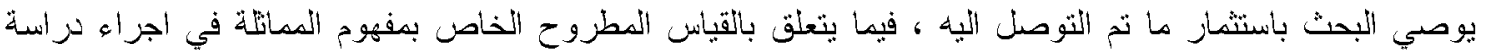

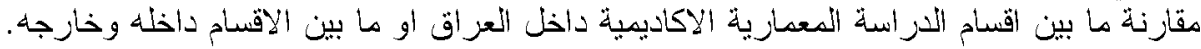

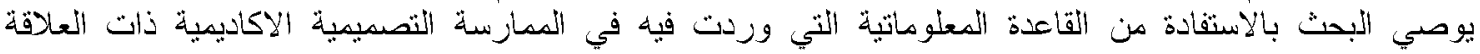
بالمفهوم وبما ينسجم معن.

ملحق البحث:

يتضمن ادراج الجداول انخاصة باسنمازات فياس متغيزات الإطل النظزي في النتاجات المعمازية للطلبة قيد التطبيق ، وكما موضح في الصفحات النلاحقة . 
البكري : المماتلة في علية التصميم المعماري في الوسط الأكاديمي دراسة تحليلية لمثاريع الطلبة

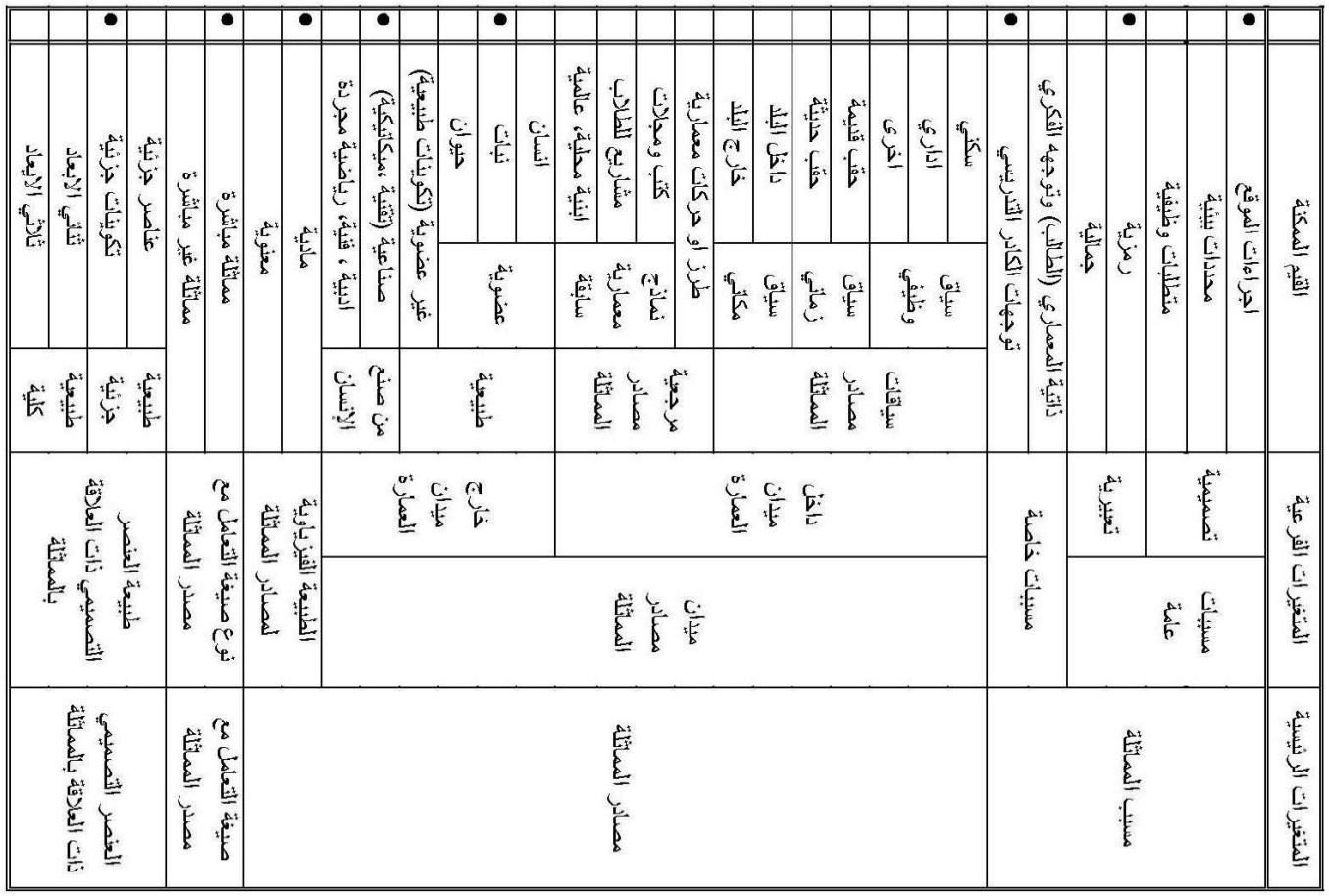

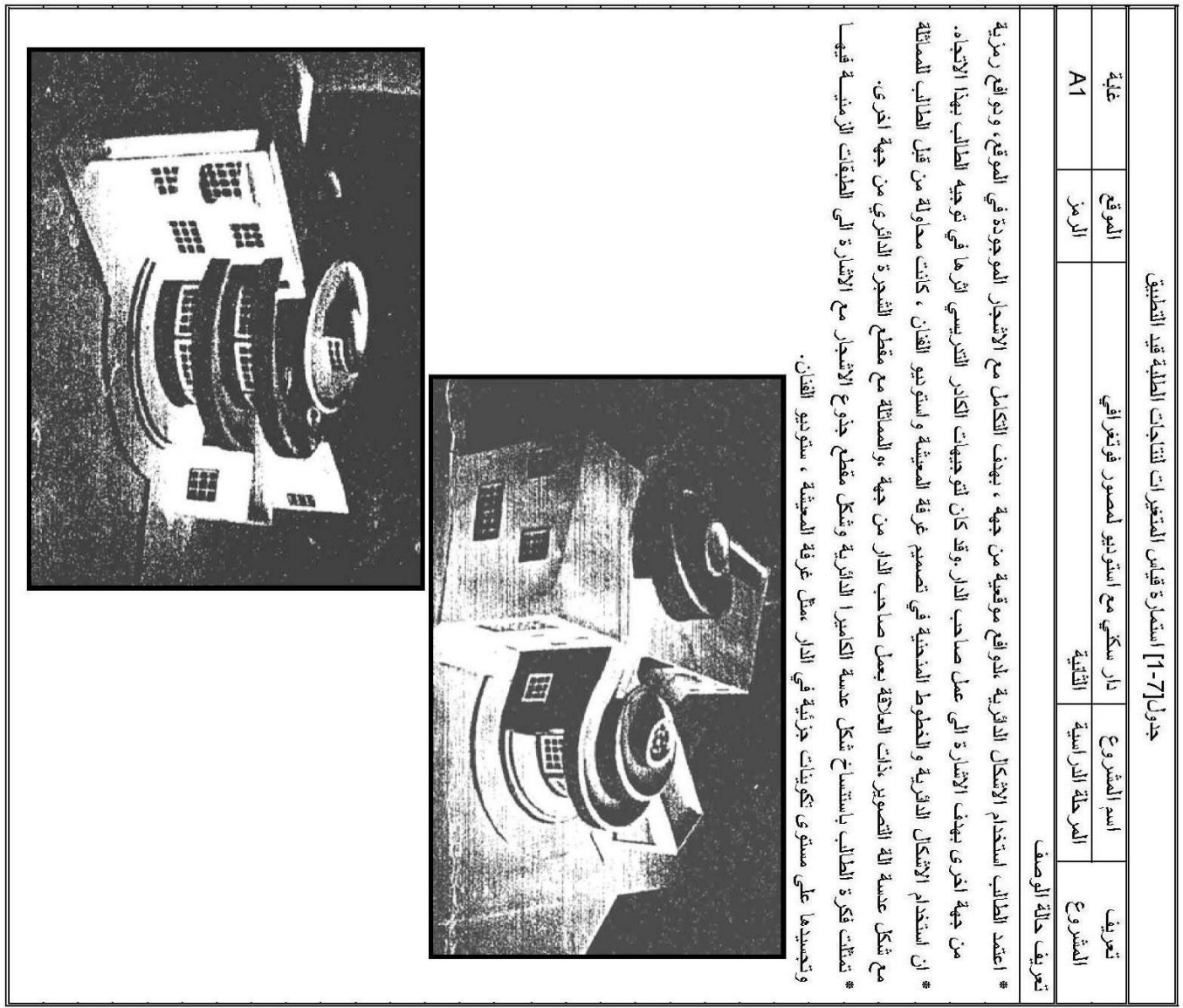




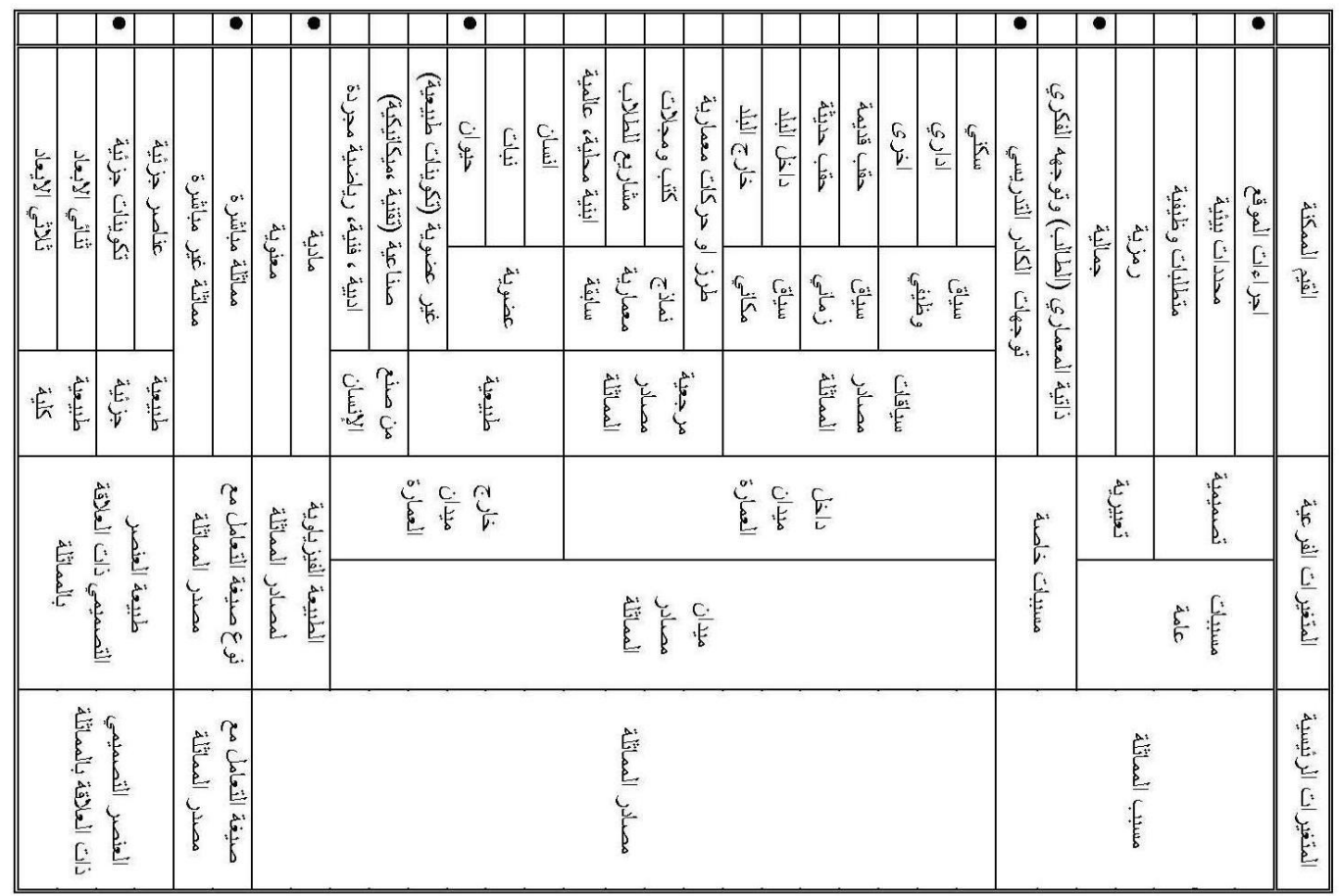

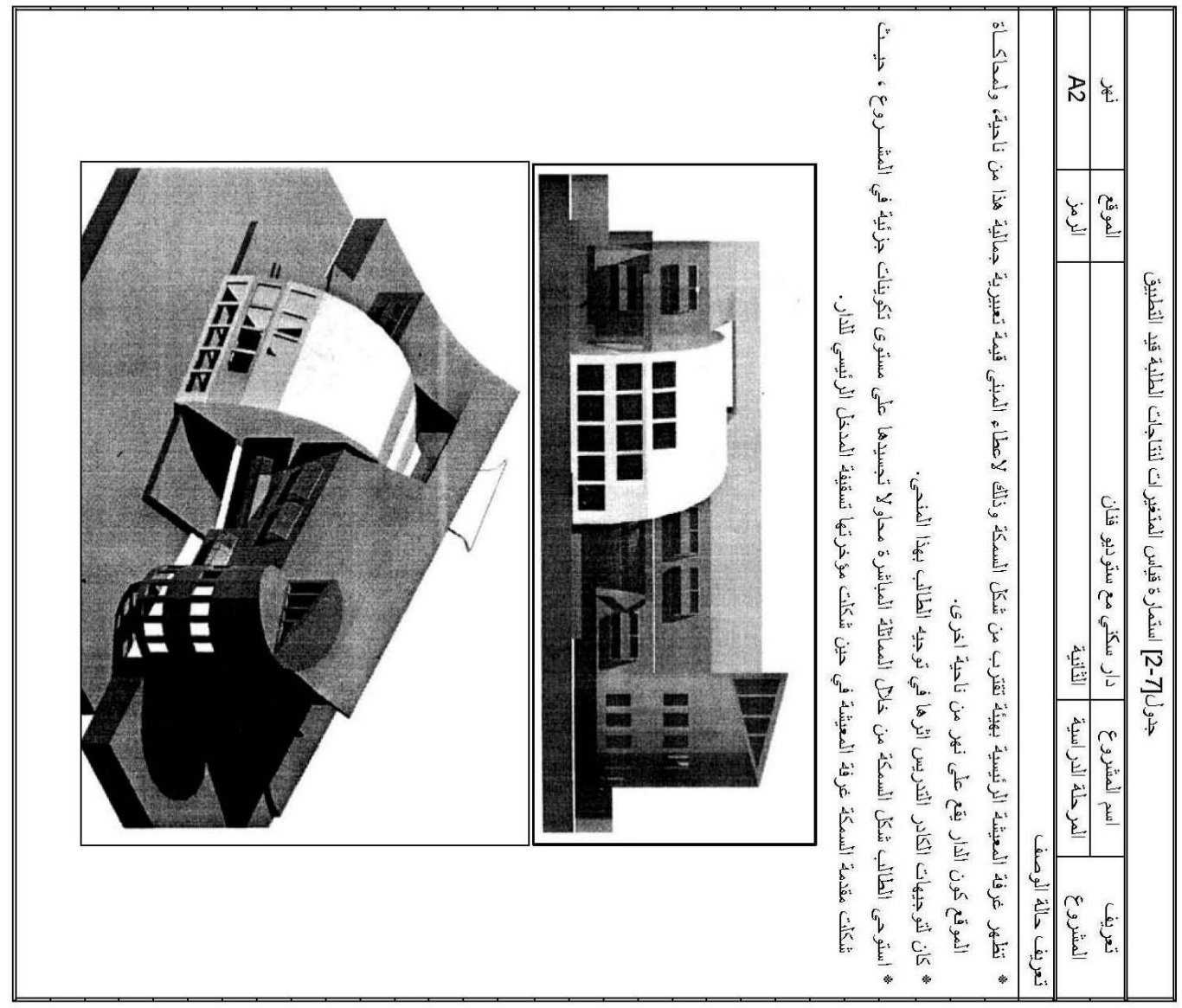


البكري : المماتلة في علية التصميم المعماري في الوسط الأكاديمي دراسة تحليلية لمثاريع الطلبة

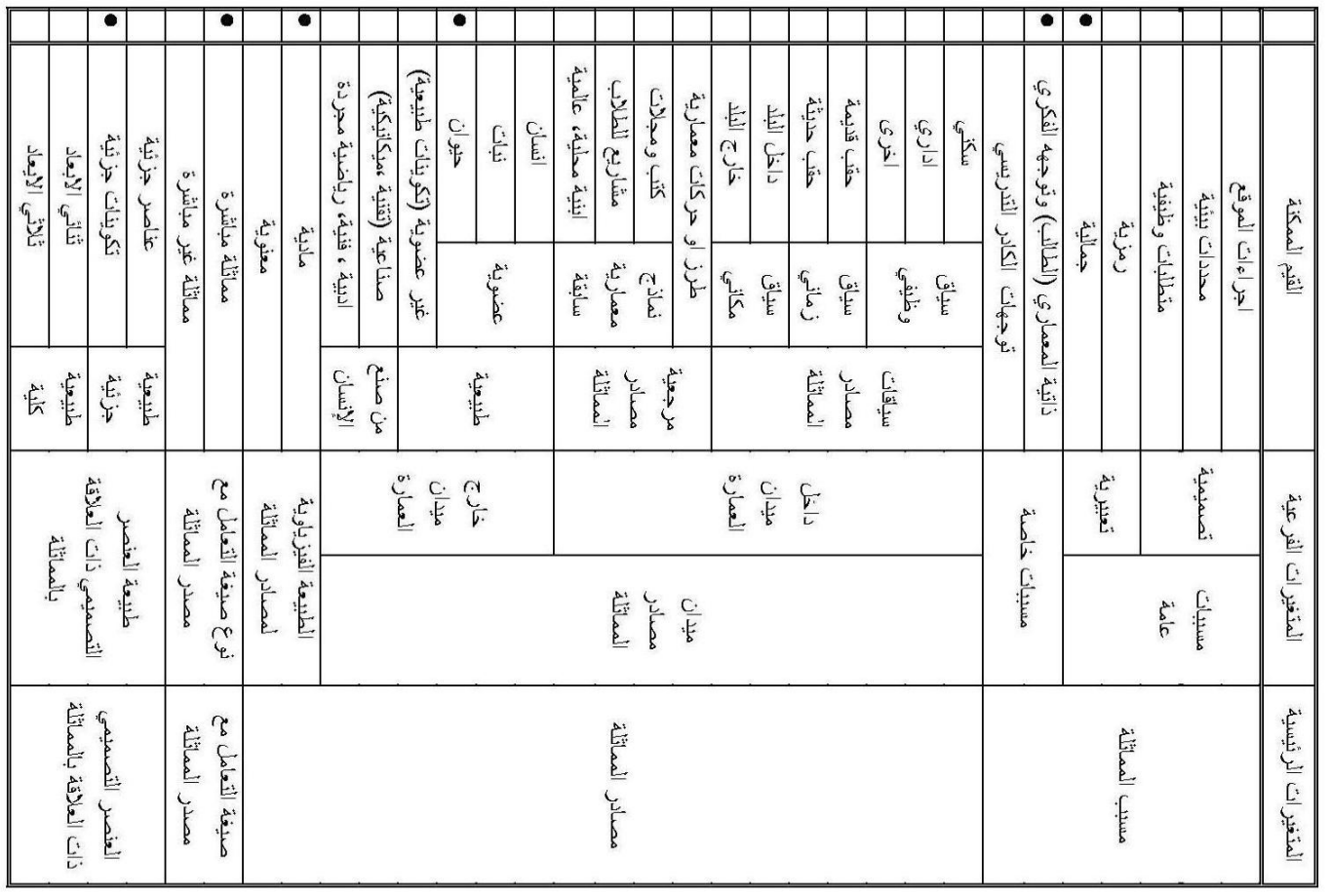

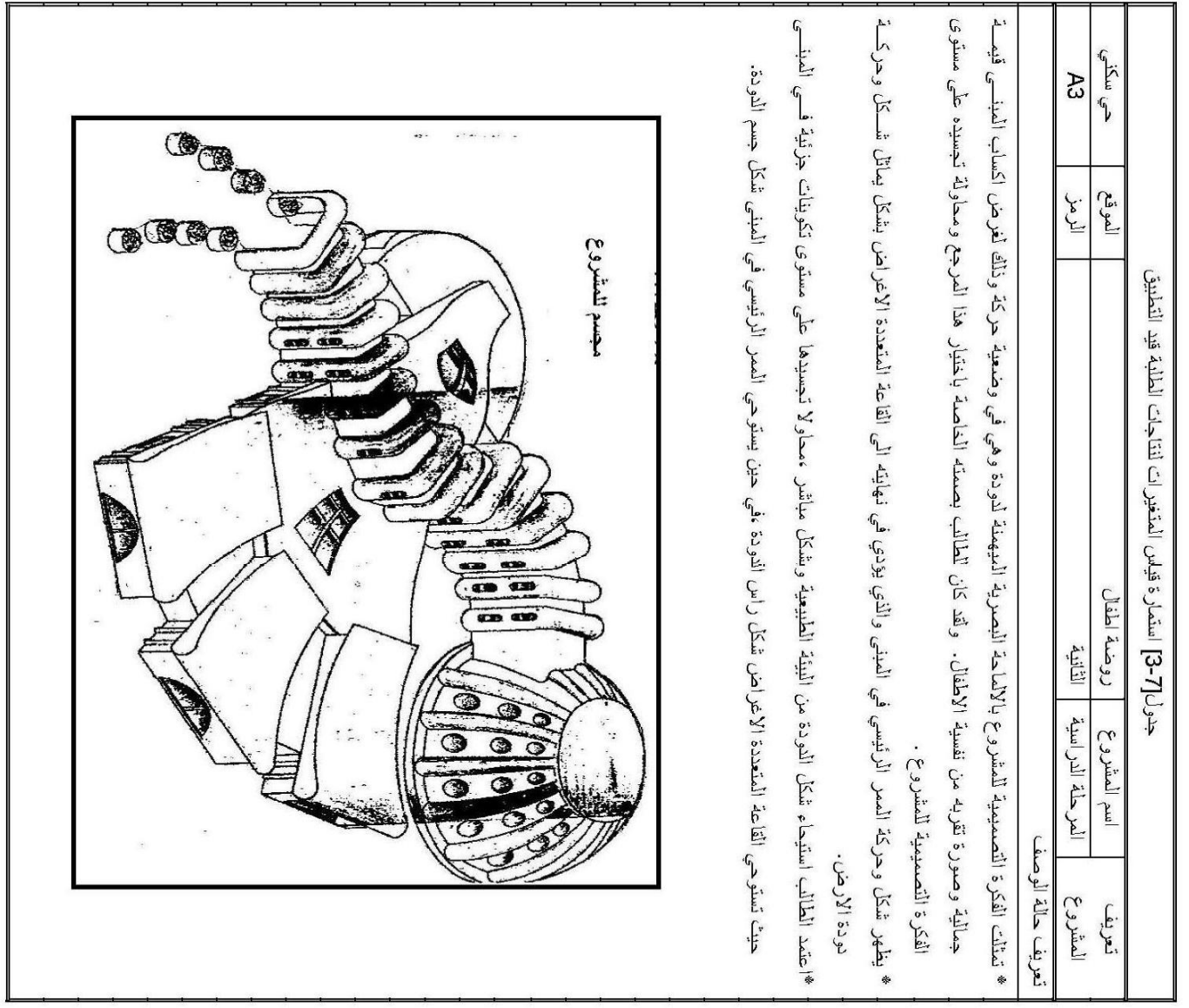




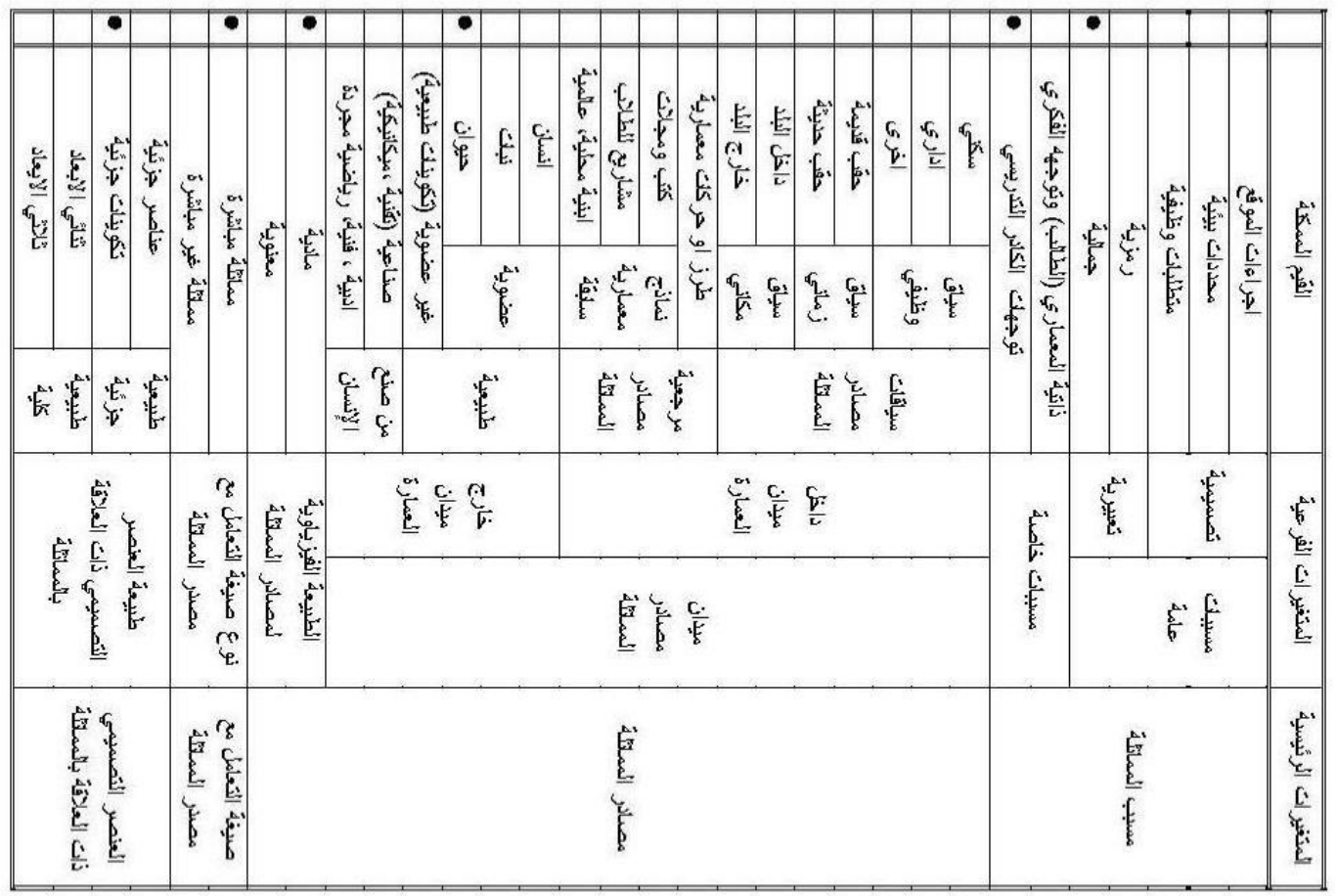

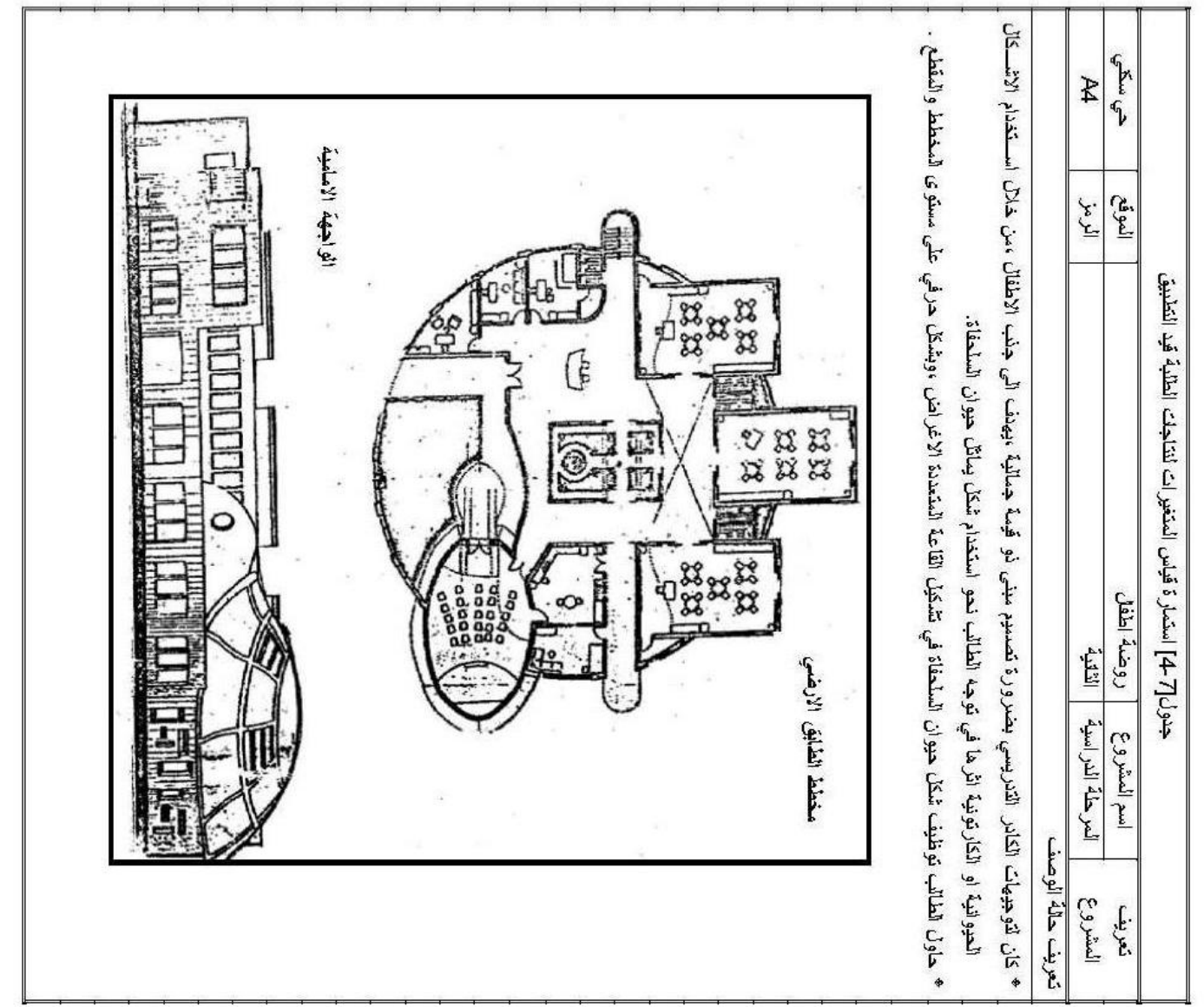


البكري : المماتلة في علية التصميم المعماري في الوسط الأكاديمي دراسة تحليلية لمثاريع الطلبة

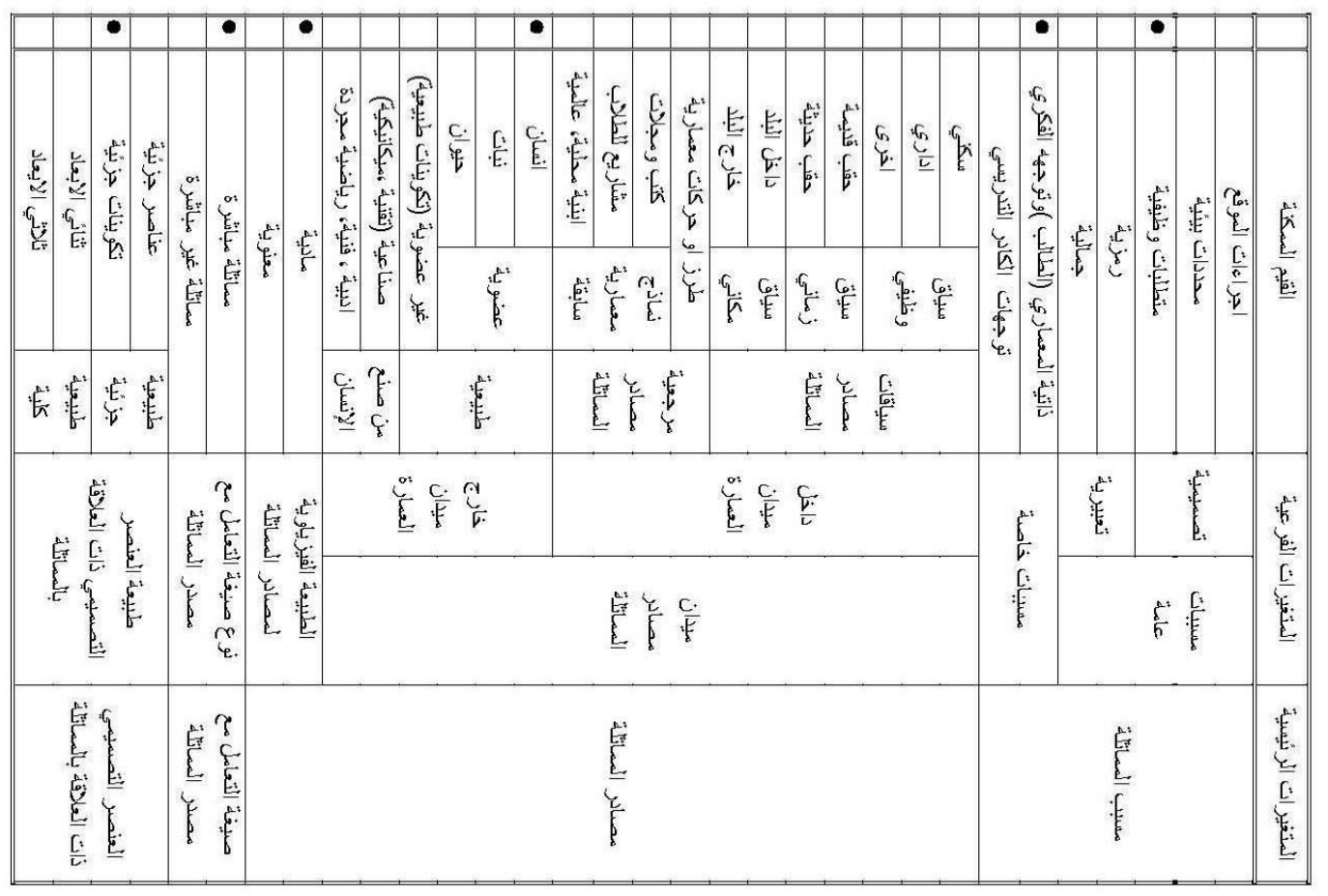

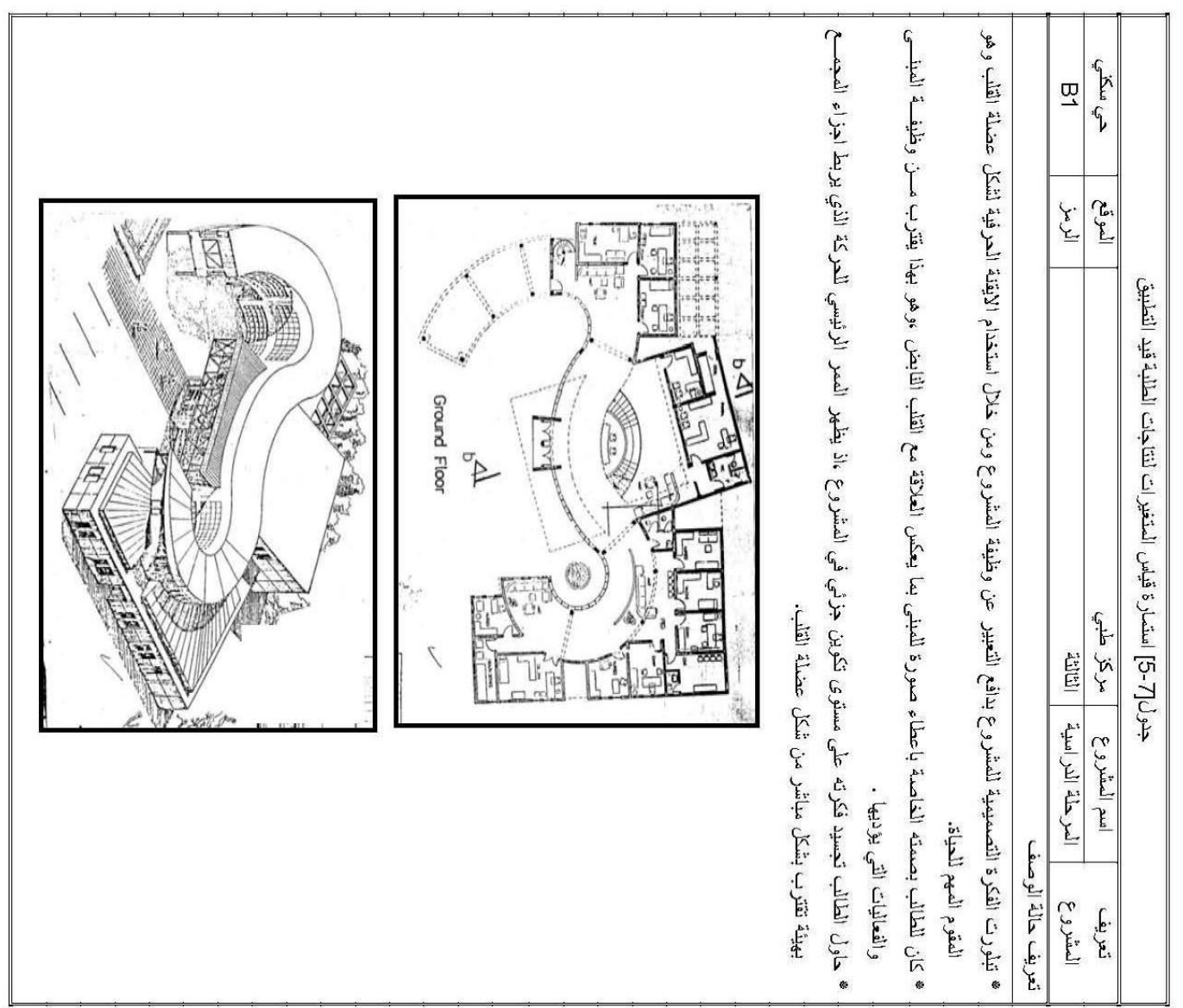




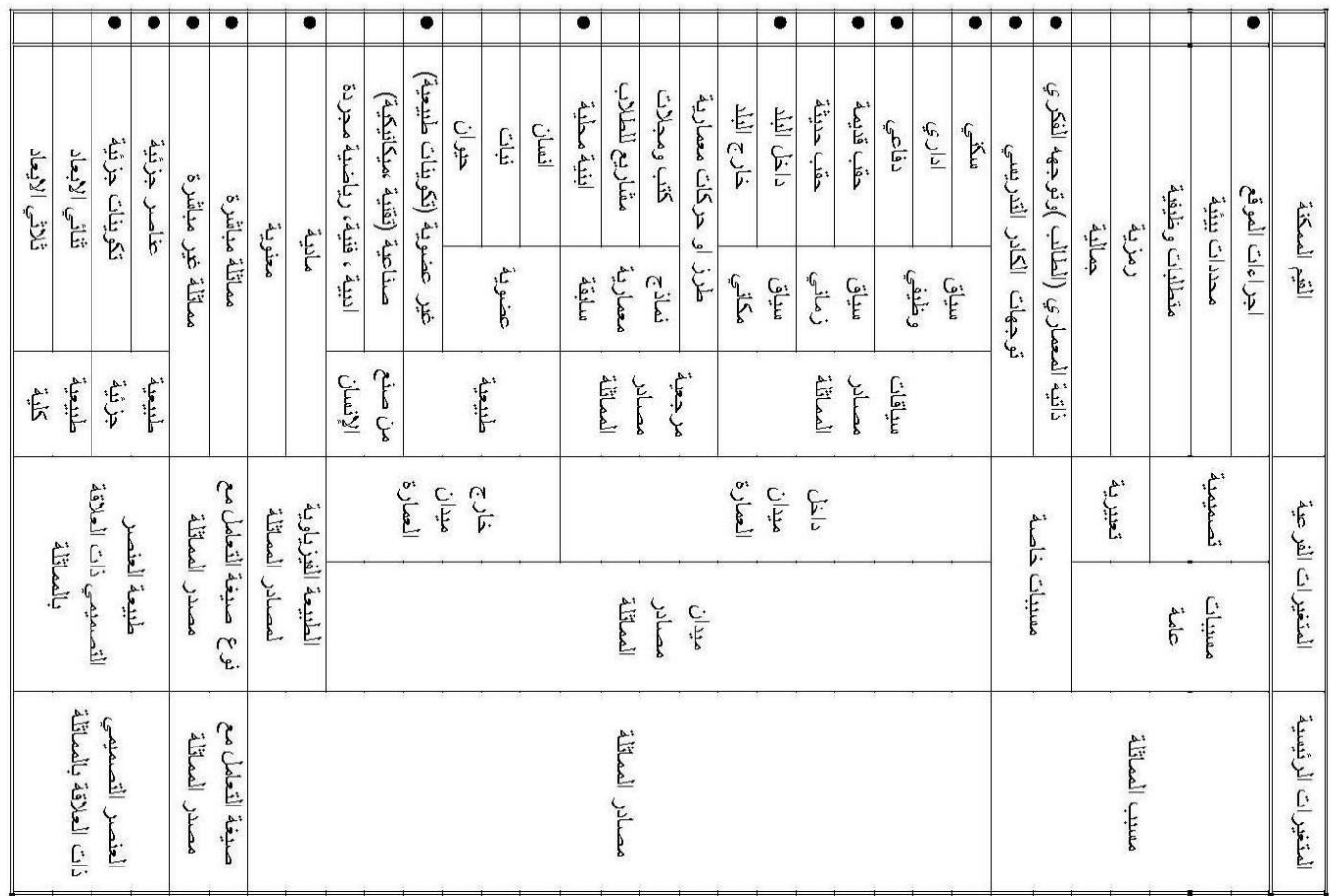

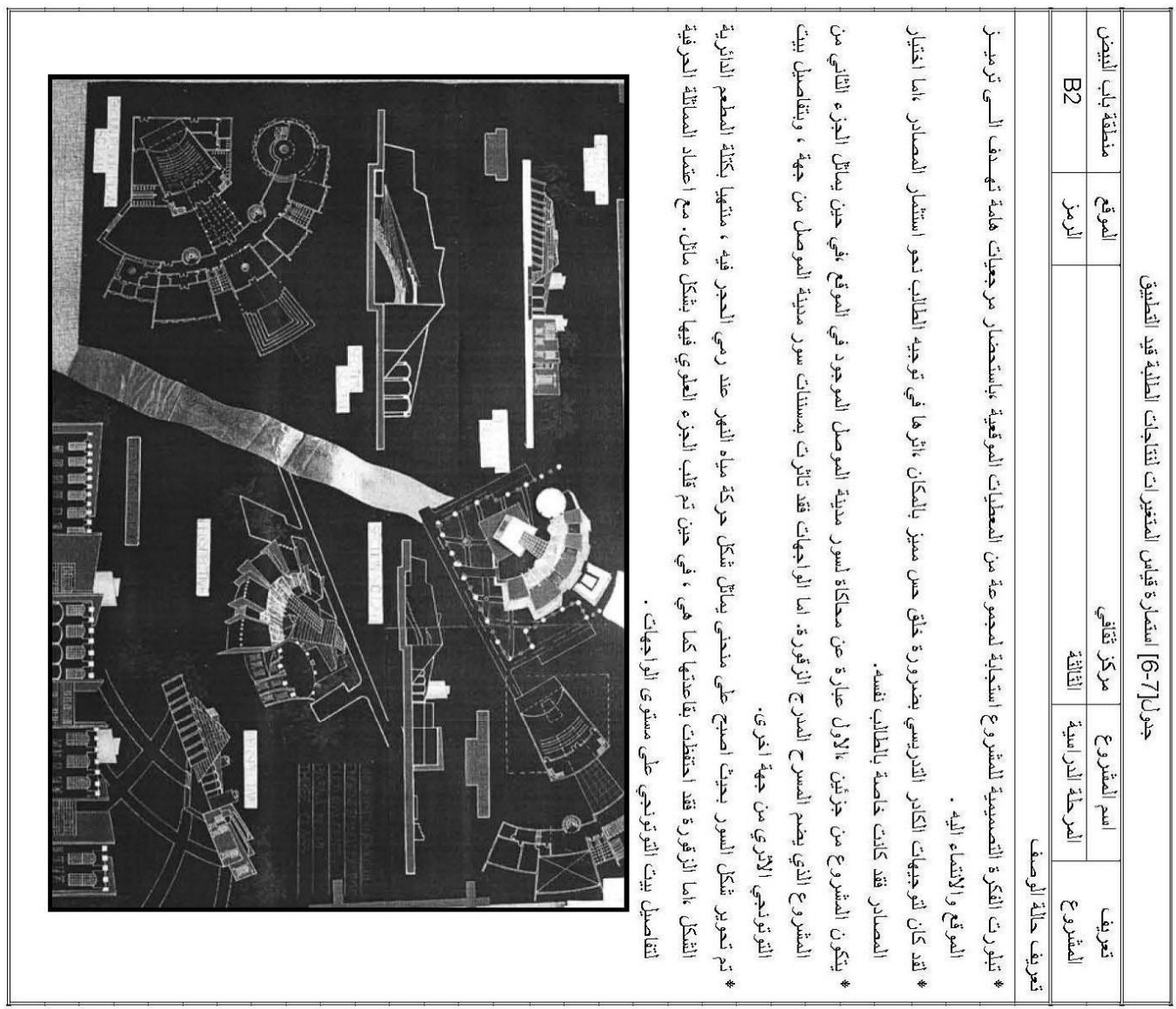


البكري : المماتلة في علية التصميم المعماري في الوسط الأكاديمي دراسة تحليلية لمثاريع الطلبة

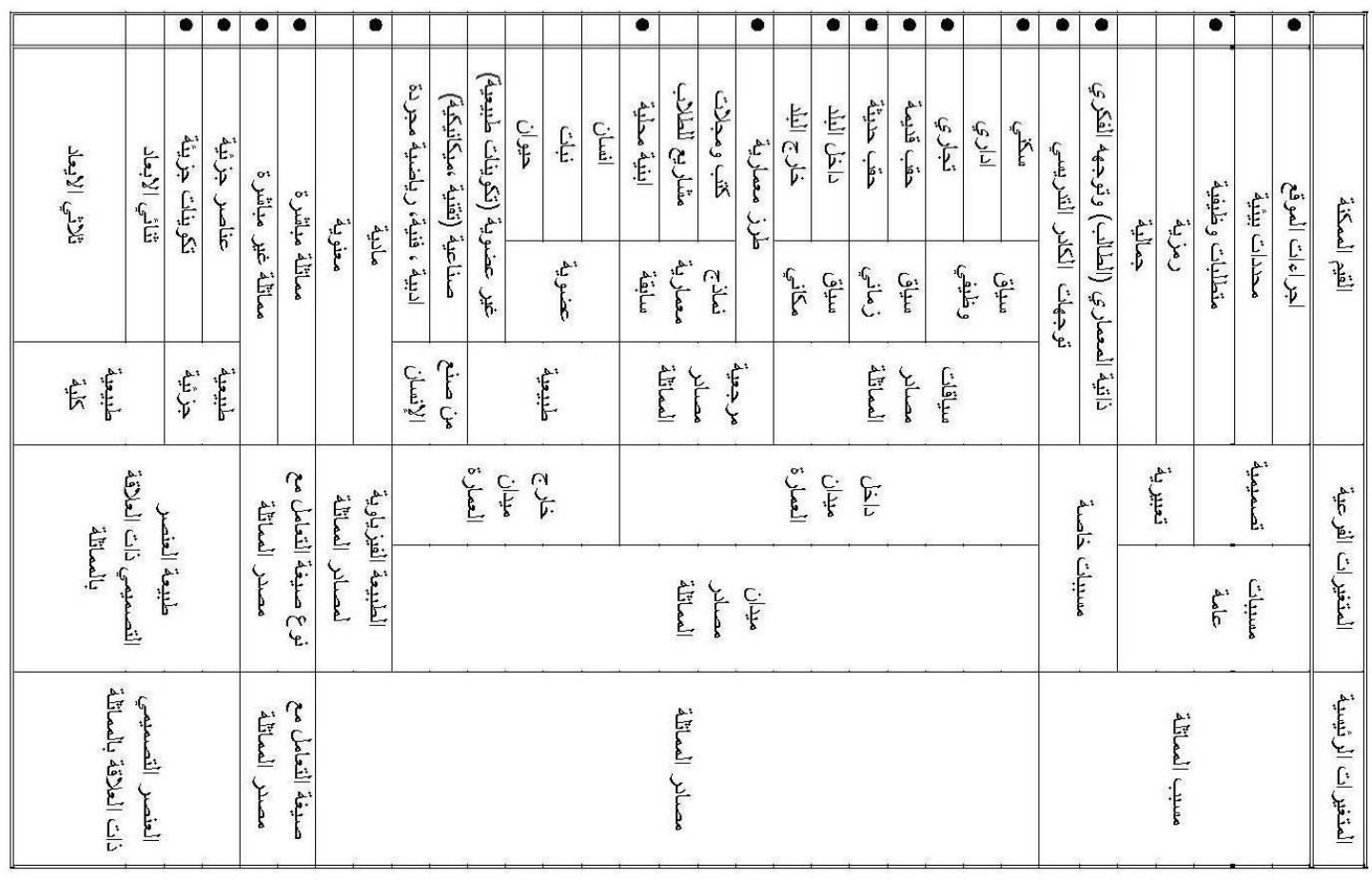
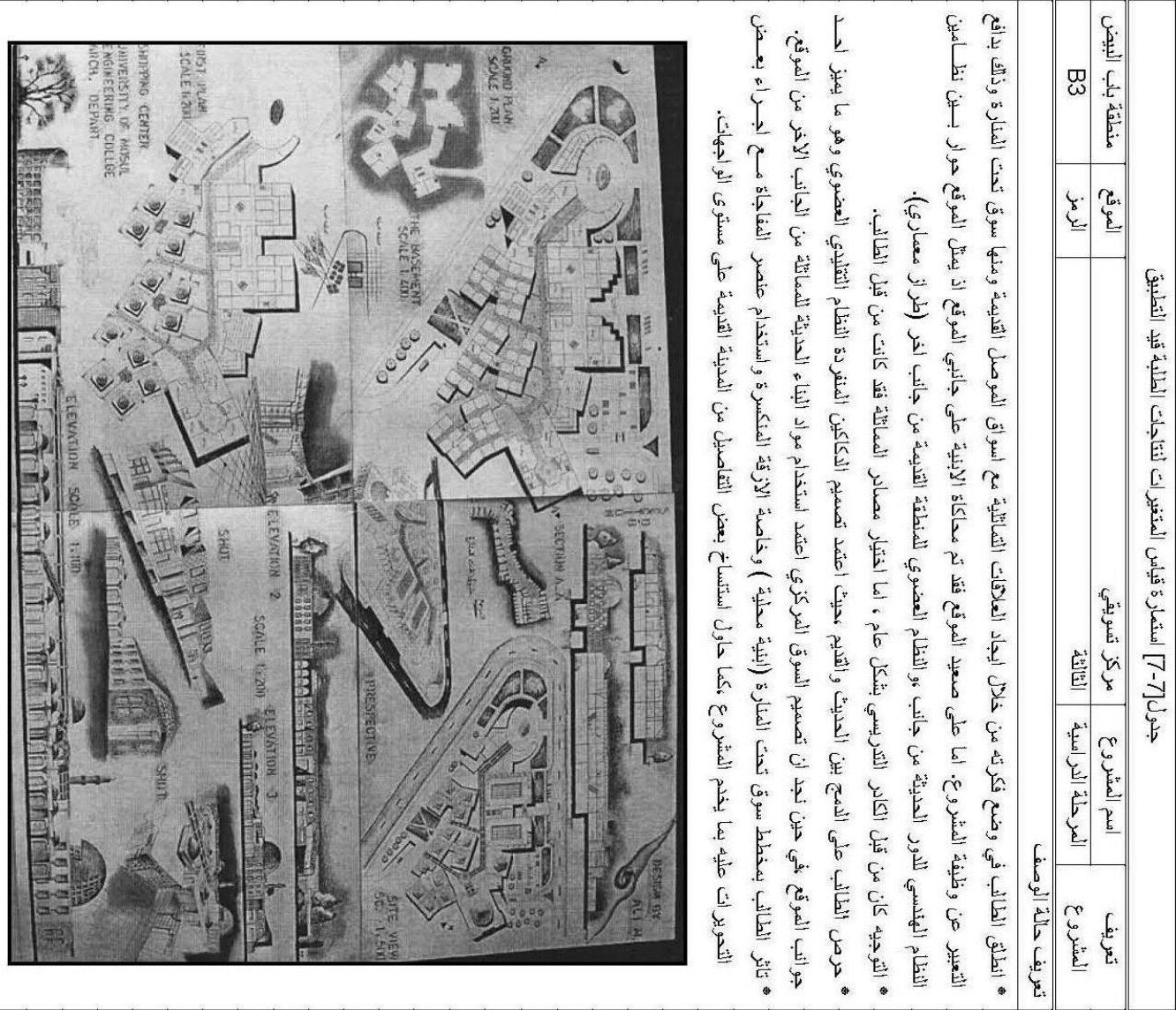


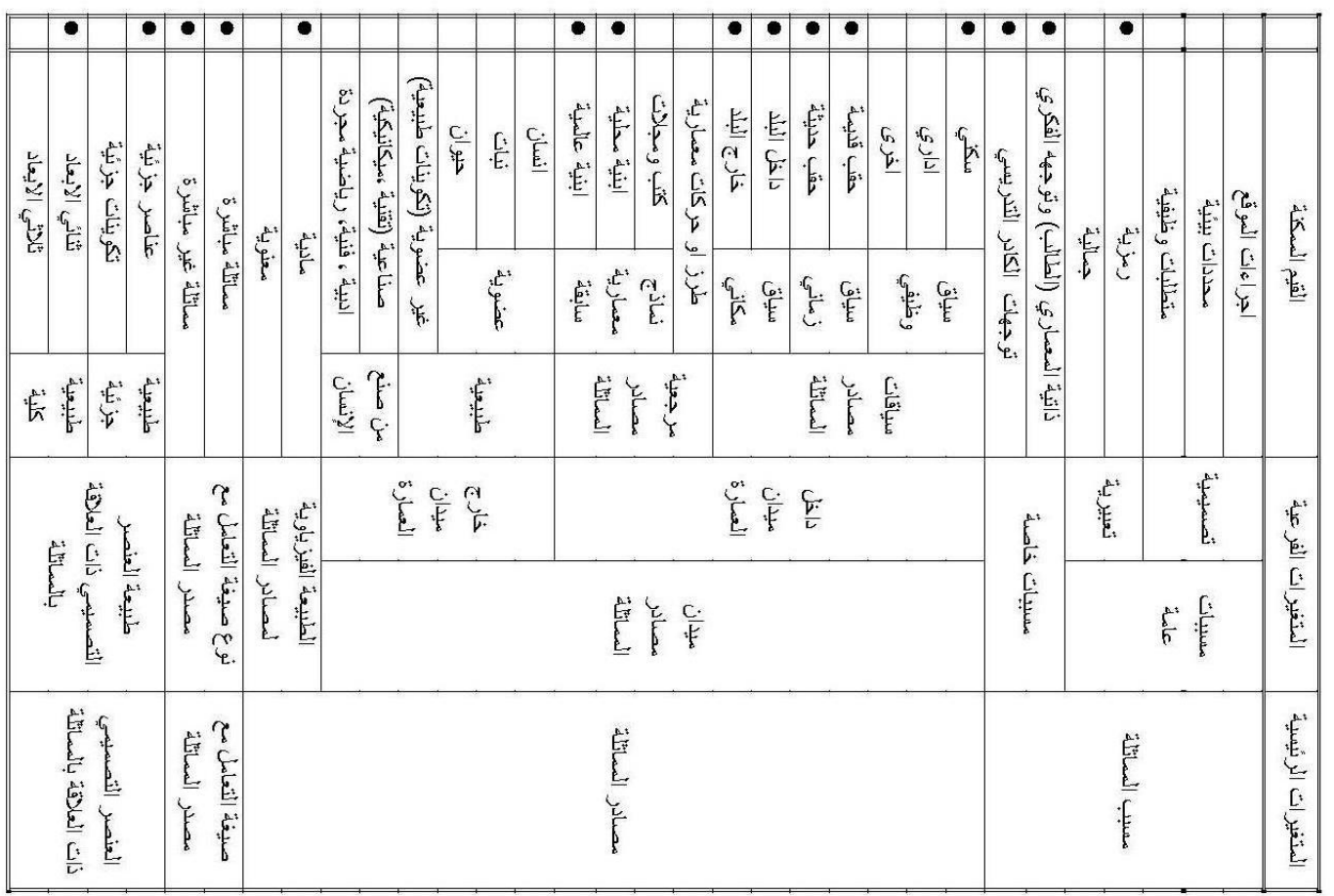

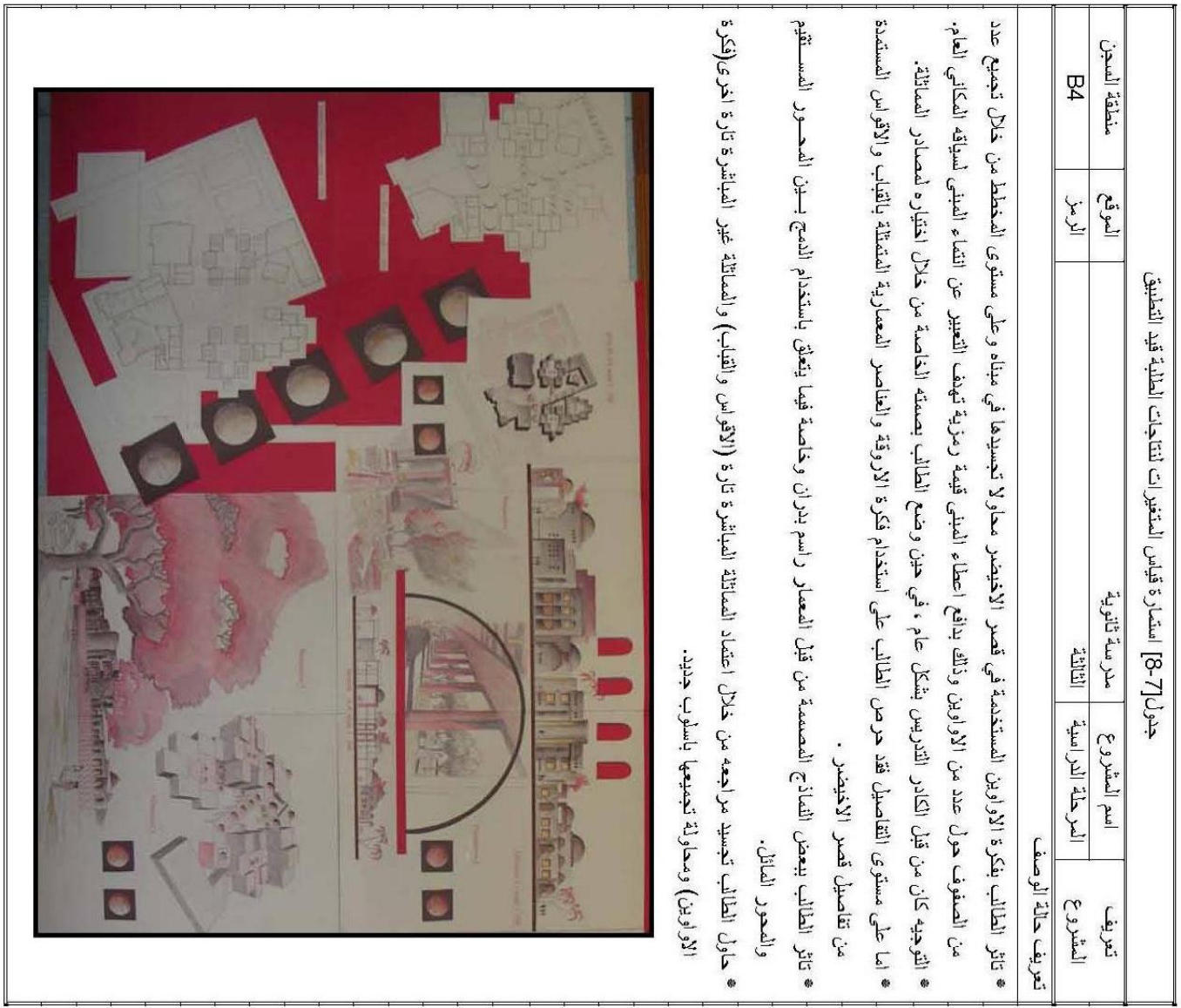




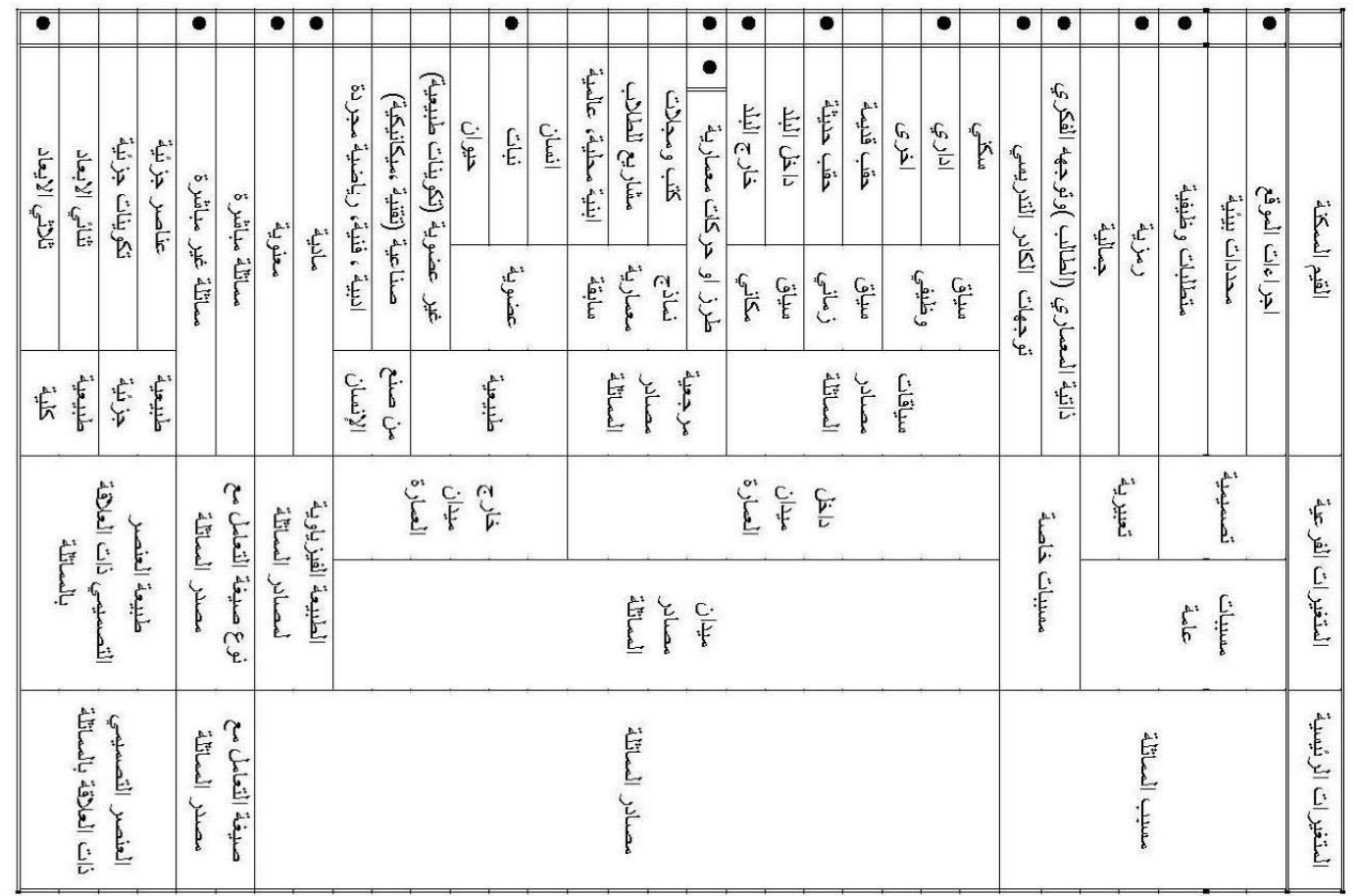
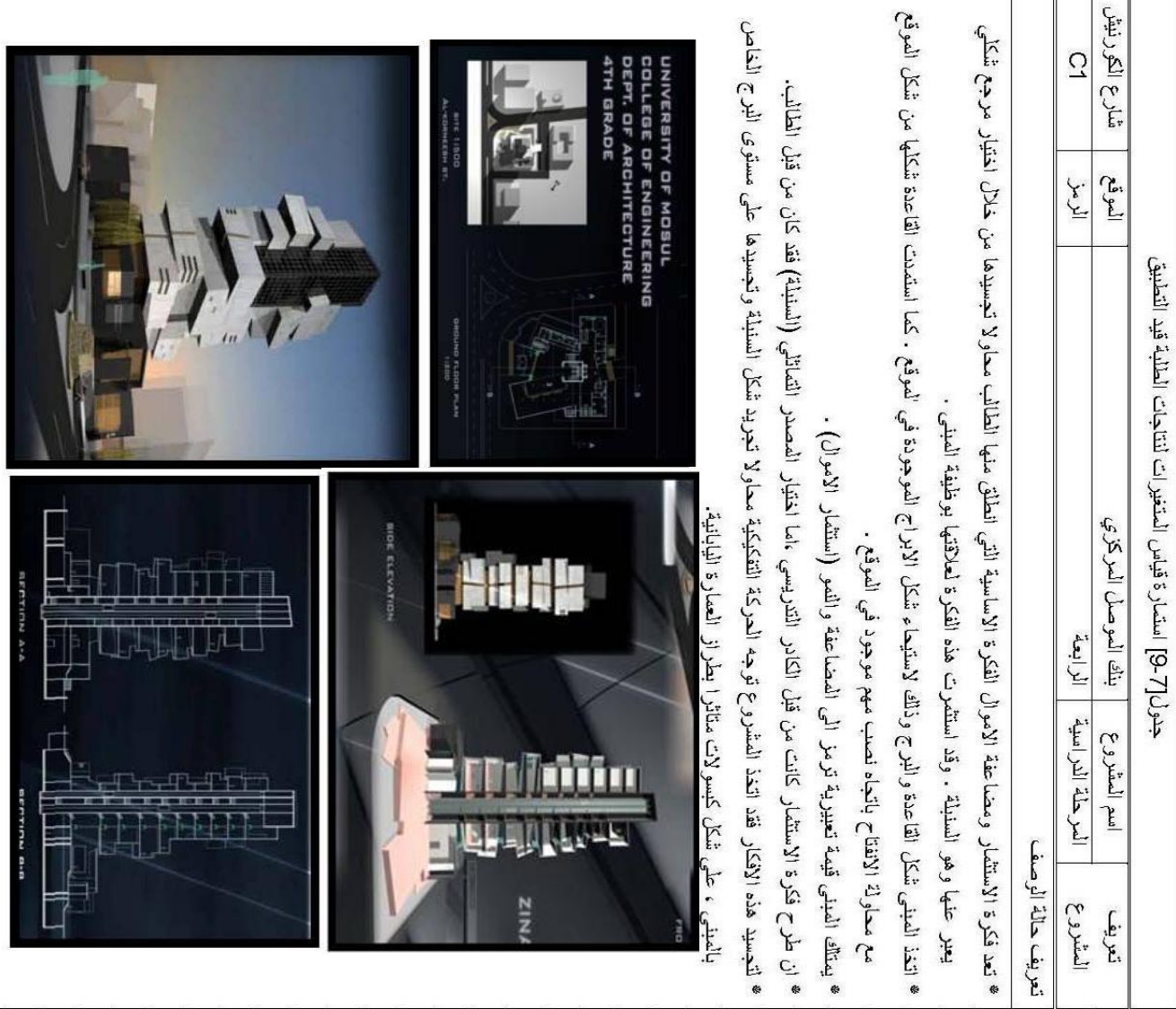


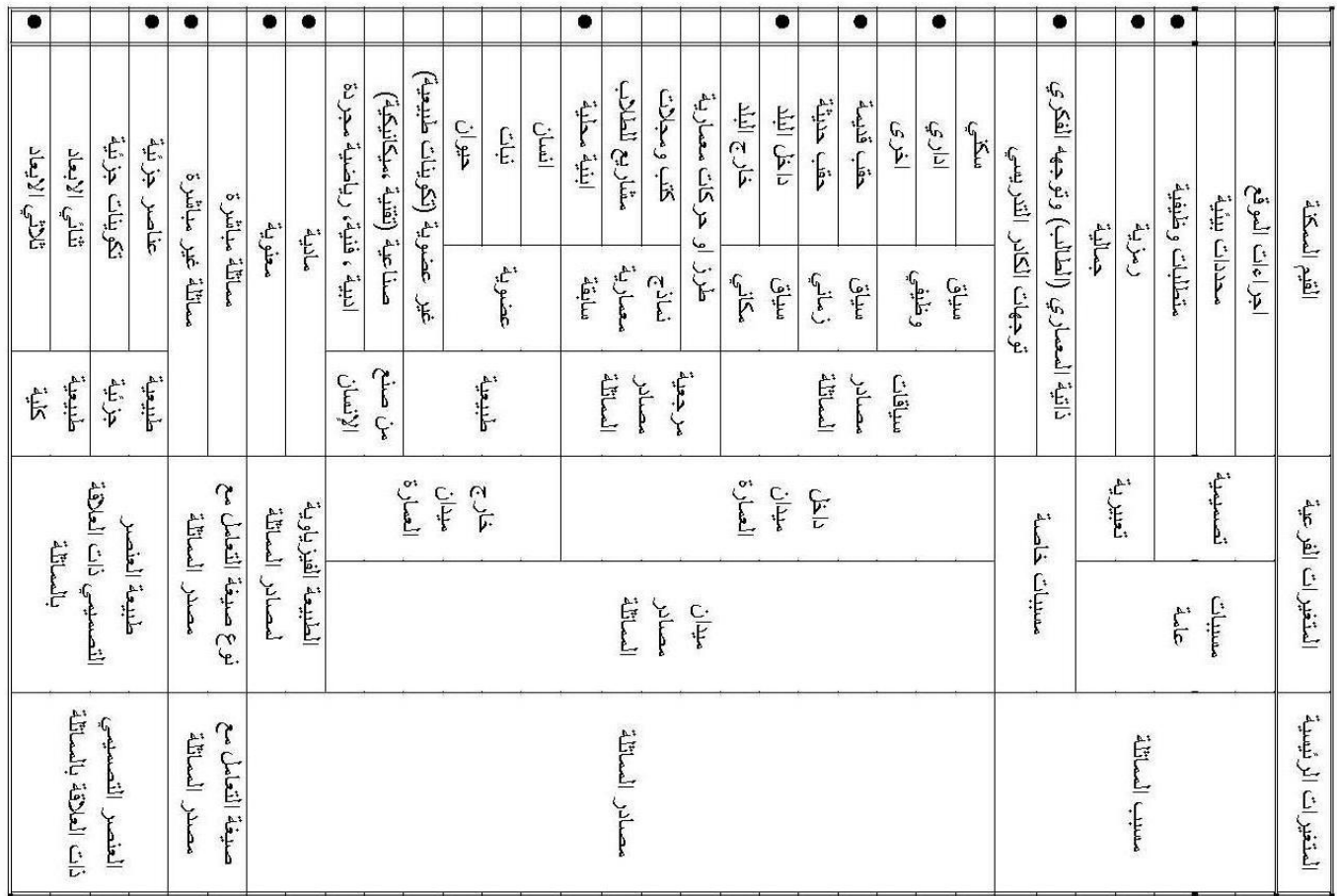

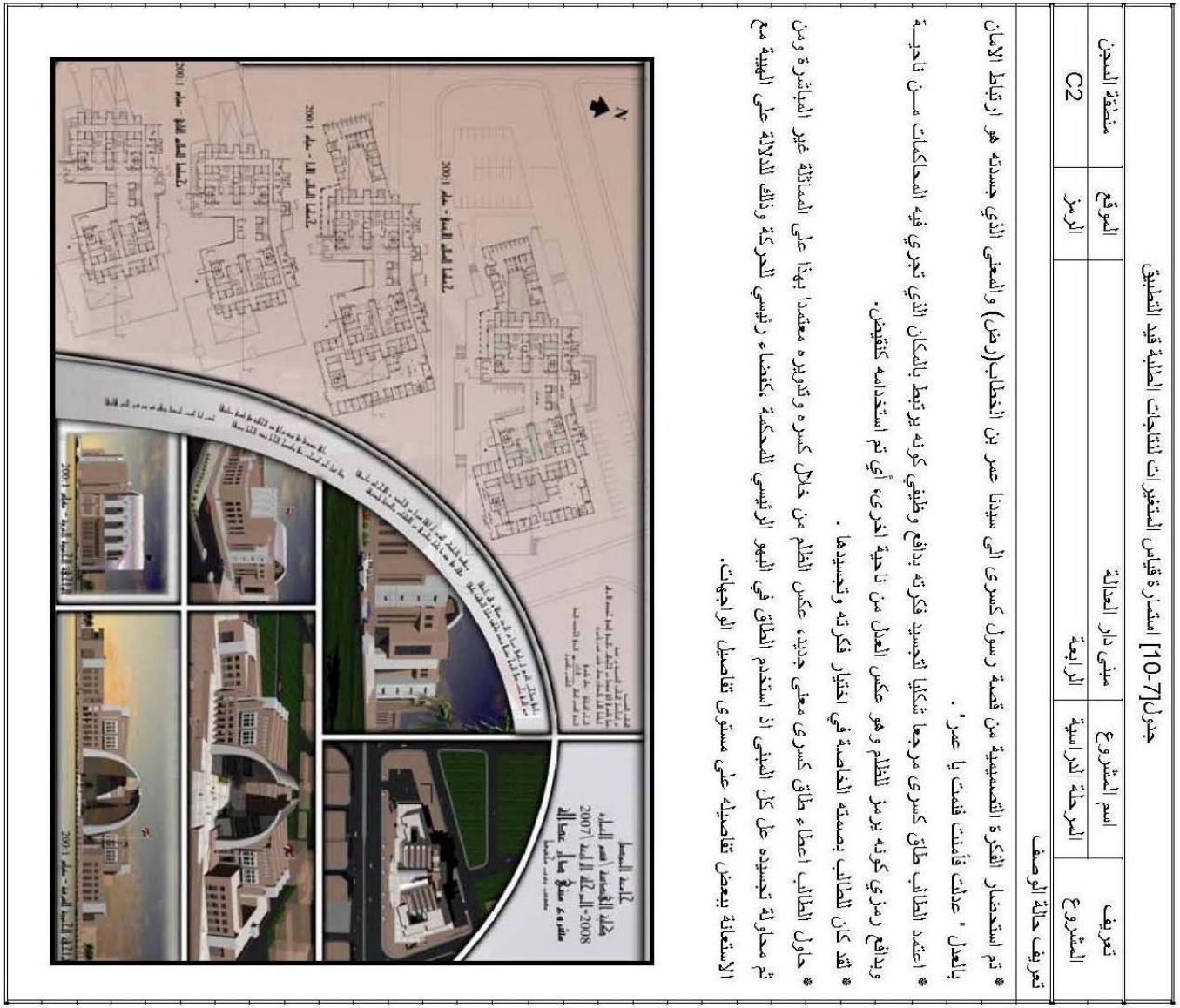


البكري : المماتلة في علية التصميم المعماري في الوسط الأكاديمي دراسة تحليلية لمثاريع الطلبة

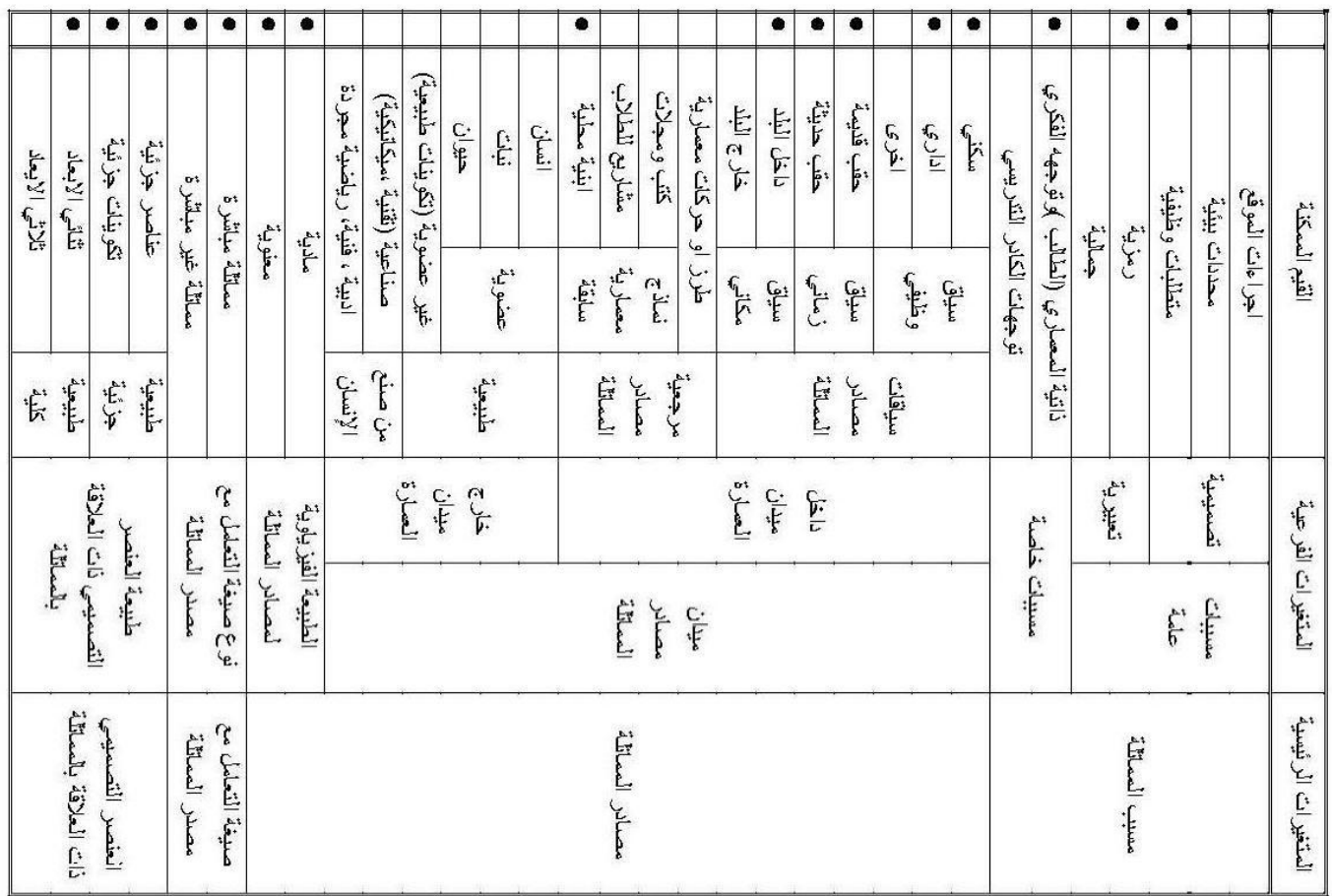
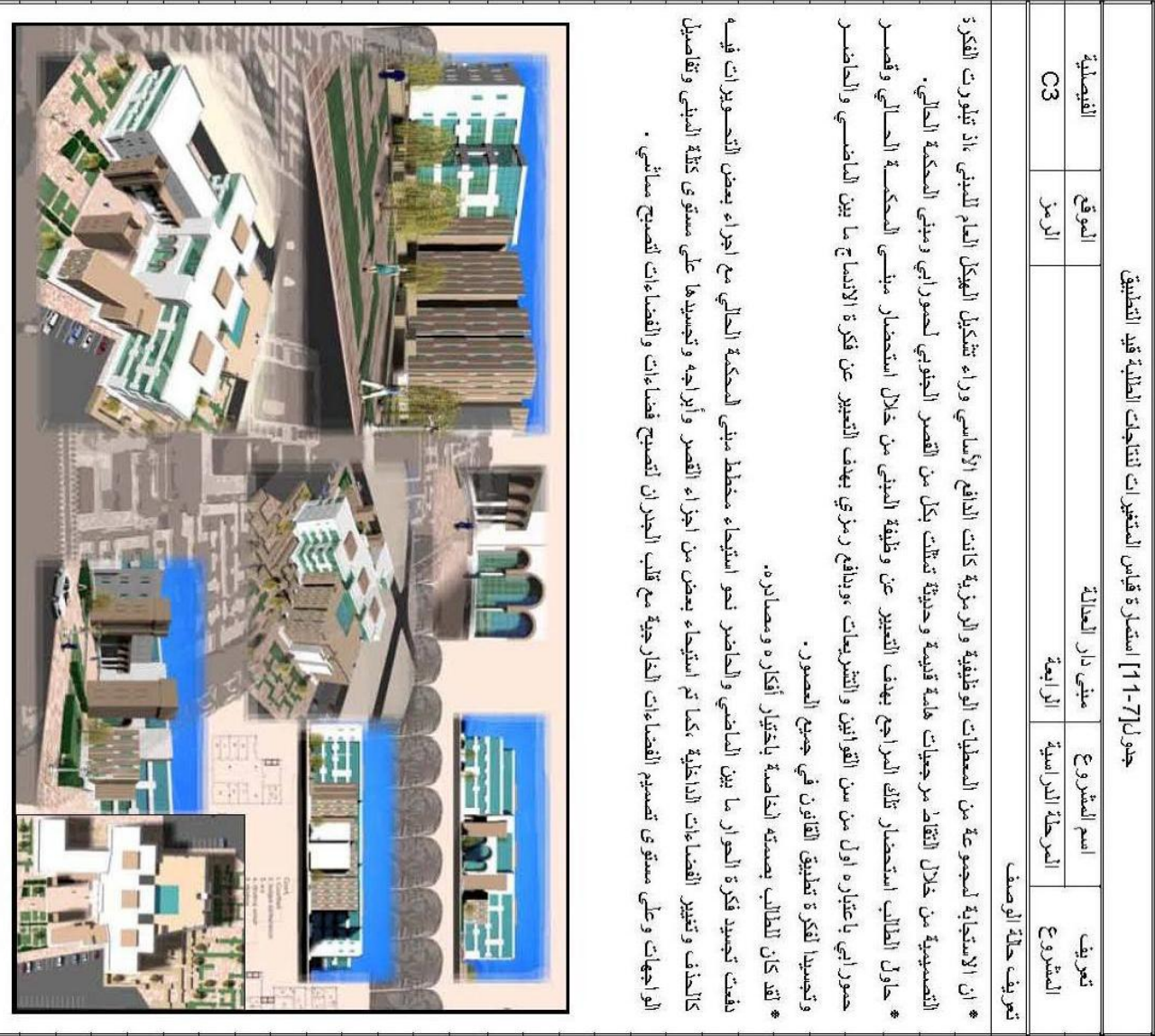


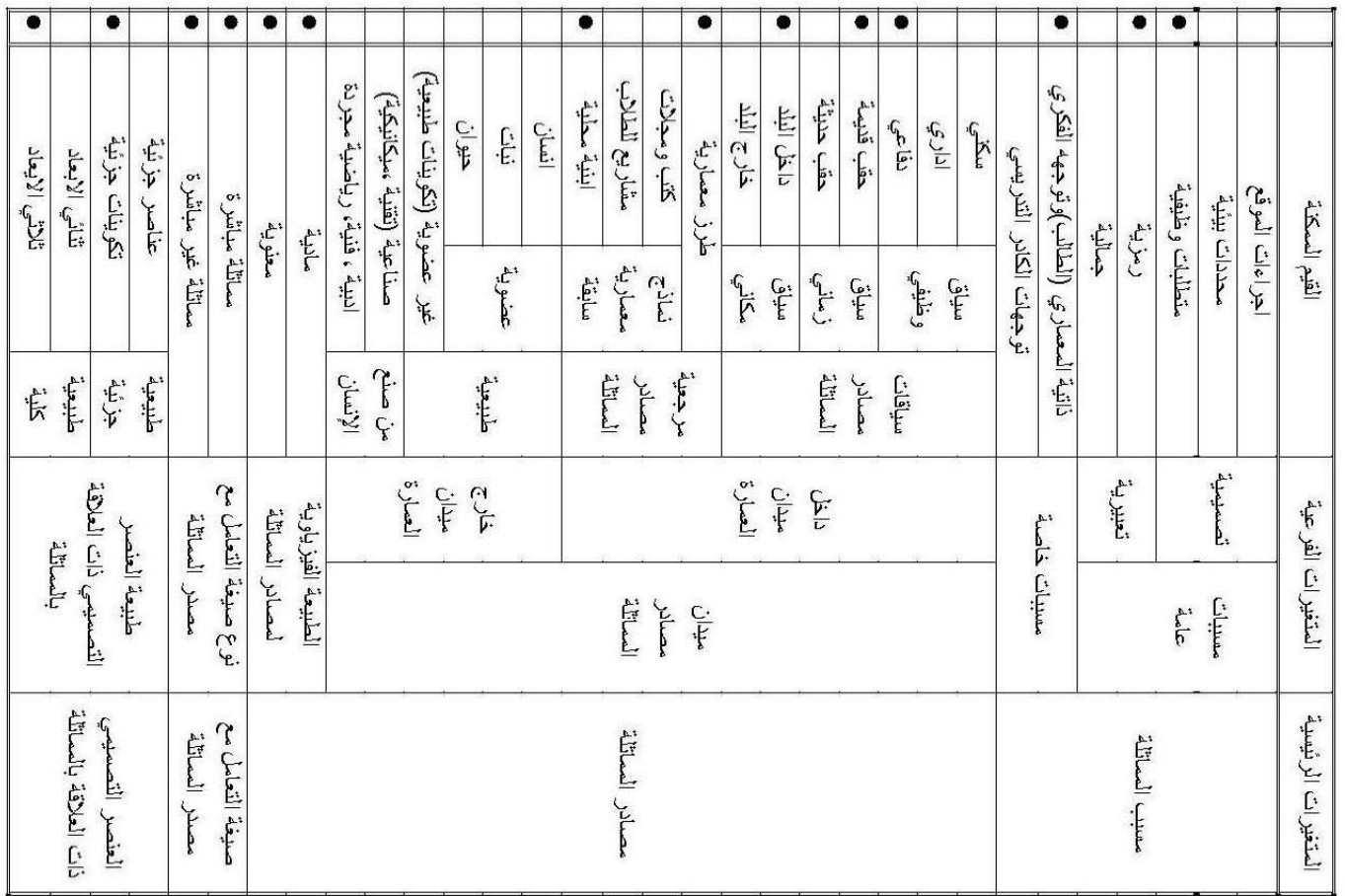
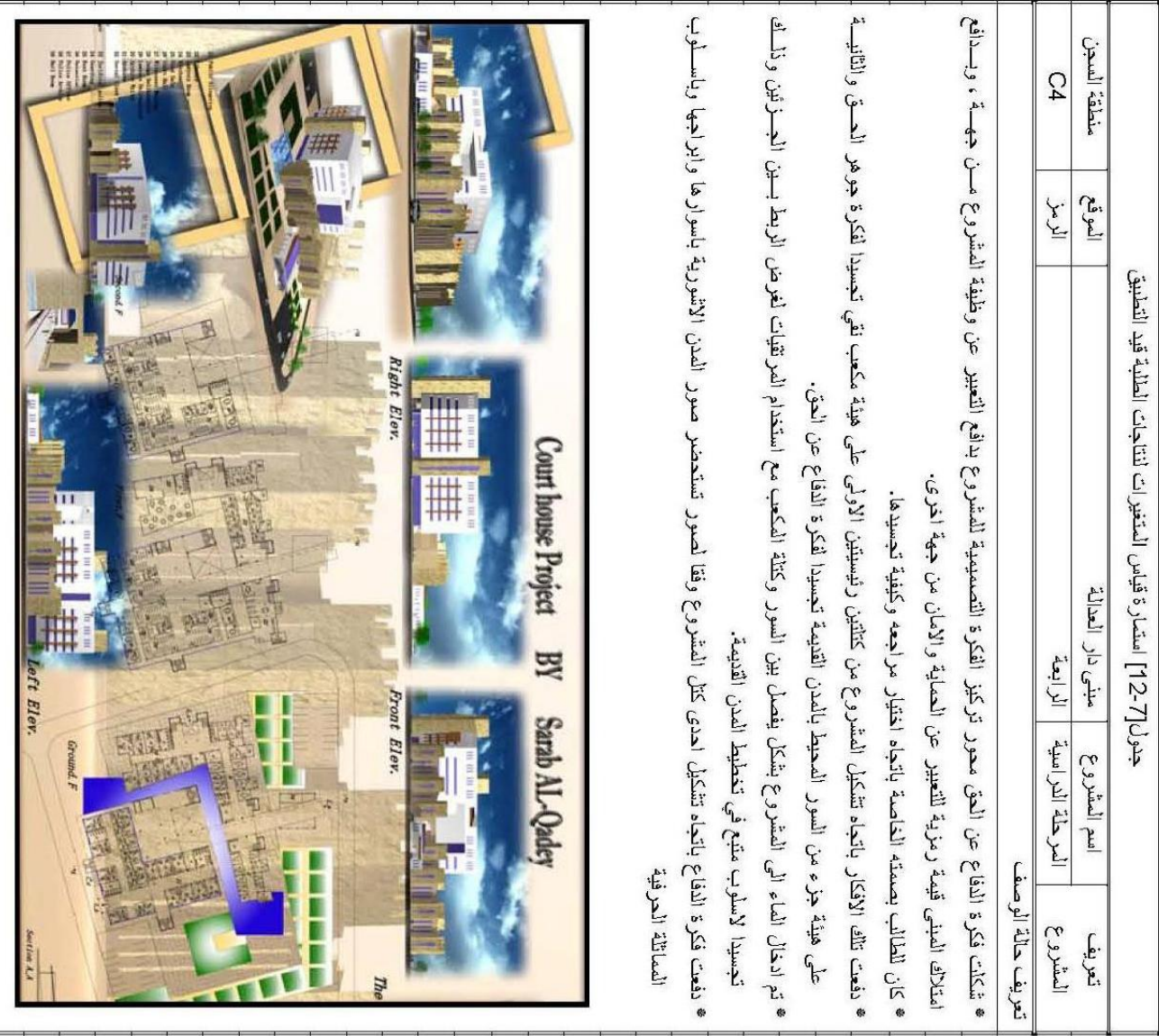


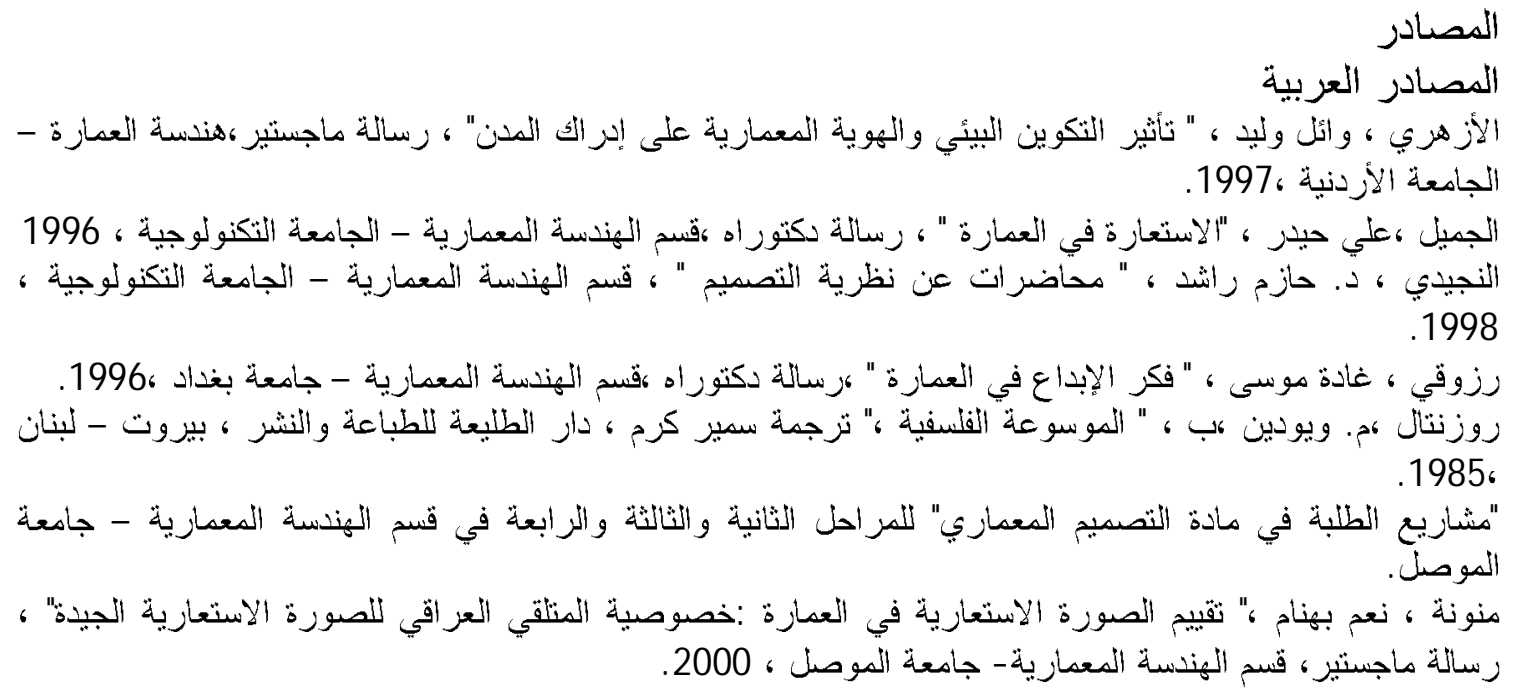

المصدئر الأجنبية

Abel, Chris, " Architecture and Identity" , U.K., Architectural press. Oxford, 1997.

Atto, Wayne, " Theory, Criticism, and History of Architecture" in James c. Snyder and Anthony J. Catanese, " Introduction to Architecture" , U.S.A, Mc Graw- Hill Book company , 1979.

Broadbent, Geoffrey, " Design in Architecture- Architecture and the Human Sciences", London, John Wiley \& Sons, 1978.

Cross, Nigel, " Developments in Design Methodology ", London, John Wiley \& Sons Ltd., 1984.

Dowing , F.," The Role of Place and Event Imagery in the Act of Design" ,The Journal of Architectural and Planning Research, a: 1 Spring, USA, Locke Science Publishing Company , Inc, 1992.

Gelernter, Mark, " Sources of Architectural form" , U.S.A, New York, Manchester University press, 1995.

Jencks, Charles, " The Language of Post- modern Architecture",16 ${ }^{\mathrm{TH}}$ edition, London, Academy Editions, 1991.

Jencks, Charles, " Architecture Today ", London, Academy Editions, 1993.

Lang, Jon," Greating Architectural Theory - The Role of the Behavioral Sciences in Environmental Design", New York, Van Nostrand Reinhold company, 1987.

Laseau , Paul," Graphic Thinking for Architects and Designers" , New York , Van Nostrand Reinhold company, 1980.

McGinty, Tim, " Concepts in Architecture ", in James C. Snyder and Anthony J. Catanese, "Introduction to Architecture", U.S.A, Mc Graw- Hill Book company, 1979.

$$
\text { تم اجر اء البحث في كلية الهندسة - جامعة الموصل }
$$

